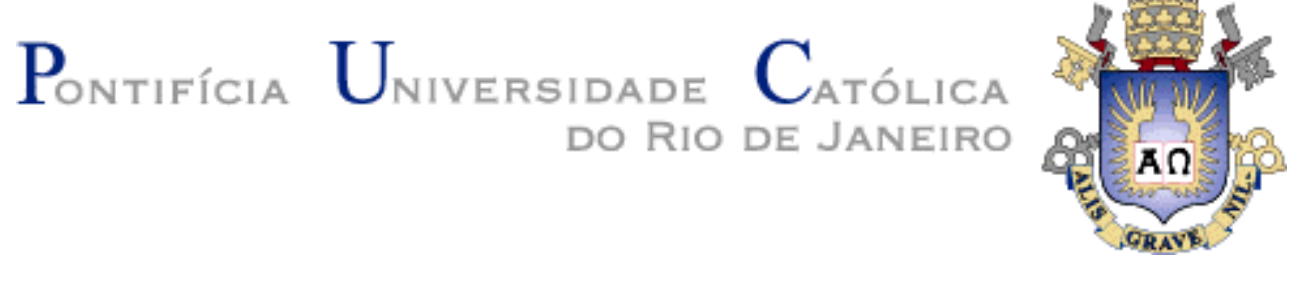

Fischer Jônatas Ferreira

Uma análise da eficácia de assertivas executáveis como observadora de falhas em software

Dissertação de Mestrado

Dissertação apresentada como requisito parcial para obtenção do grau de Mestre pelo Programa de Pósgraduação de Informática da PUC-Rio.

Orientador: Prof. Arndt von Staa

Rio de Janeiro

Abril de 2015 
Fischer Jônatas Ferreira

\section{Uma análise da eficácia de assertivas executáveis como observadora de falhas em software}

Dissertação apresentada como requisito parcial para obtenção do grau de Mestre pelo Programa de PósGraduação em Informática do Centro Técnico Científico da PUC-Rio. Aprovada pela Comissão Examinadora abaixo assinada.

Prof. Arndt von Staa

Orientador

Departamento de Informática - PUC-Rio

Prof. Alberto Barbosa Raposo

Departamento de Informática - PUC-Rio

Prof. Hélio Côrtes Vieira Lopes

Departamento de Informática - PUC-Rio

Profa. Simone Diniz Junqueira Barbosa

Departamento de Informática - PUC-Rio

Prof. José Eugenio Leal

Coordenador (a) Setorial do Centro Técnico Científico - PUC-Rio 
Todos os direitos reservados. É proibida a reprodução total ou parcial do trabalho sem autorização da universidade, do autor e do orientador.

Fischer Jônatas Ferreira

Graduou-se em Tecnologia em Análise e Desenvolvimento de Sistema pela Universidade Federal do Rio Grande em Dezembro de 2011. Especializou-se em Análise de Sistema pela Universidade Católica de Petrópolis em outubro de 2013.

Ficha Catalográfica

Ferreira, Fischer Jônatas

Uma análise da eficácia de assertivas executáveis como observadora de falhas em software / Fischer Jônatas Ferreira; orientador: Arndt von Staa - Rio de Janeiro PUC, Departamento de Informática, 2015.

v., $117 \mathrm{f}, ;$ il. ; $29,7 \mathrm{~cm}$

1. Dissertação (mestrado) - Pontifícia Universidade Católica do Rio de Janeiro, Departamento de Informática.

Inclui referências bibliográficas.

1. Informática - Teses. 2. Instrumentação de software 3 . Teste de software 4 . Software auto verificante 5 . Métodos Formais Leves. I. Staa, Arndt von. II. Pontifícia Universidade Católica do Rio de Janeiro. III. Departamento de Informática. IV. Título. 


\section{Agradecimentos}

Agradeço a DEUS, por tudo ter providenciado com relação a este curso em todos os momentos com intervenções indispensáveis.

Agradeço a minha mãe, Ângela Maria da Silva Ferreira, por todo carinho atenção e cuidado e junto com meu pai Manoel Messias Ferreira ter forjado meu caráter e ter contribuído com tudo que sou. Sem seus cuidados, dedicação e amor incondicional certamente eu não teria persistido e chegado até o término desse curso. Muito obrigado!

Agradeço minha esposa Michele Faria de Oliveira pelo incentivo, por todas as horas sacrificadas do nosso convívio que estive ausente em dedicação a este curso, pelo apoio incentivo e motivação que me prestou em toda minha vida acadêmica. Ainda pelo seu companheirismo principalmente na fase final desse curso.

Agradeço de forma especial ao professor Arndt von Staa por todas as orientações, dedicação e a contribuição significativa e extremamente necessária que me conduziu neste trabalho bem como todo o curso.

Agradeço a Senhora Regina Maria Zanon da Silva pelo apoio dedicação, por todas as horas em que precisei esteve prontamente a ajudar.

Agradeço a professora Maria Carlota Barreto Raimundo por todo apoio nesta dissertação. Por toda atenção a mim dada e por ter contribuído significante com este trabalho.

Agradeço aos professores Edward Hermann Haeusler e Simone Diniz Junqueira Barbosa pela ajuda compreensão e por todas as oportunidades a mim dadas.

Agradeço aos meus amigos e colegas de curso por terem trilhado este caminho junto a mim e dividido momentos de alegria, tensão e conquistas.

Finalmente, gostaria de agradecer à PUC-Rio que me deu a oportunidade de realizar o Mestrado em Informática, por toda a estrutura que me propiciou. 


\section{Resumo}

Ferreira, Fischer Jônatas; Staa, Arndt von. Uma análise da eficácia de assertivas executáveis como observadora de falhas em software. Rio de Janeiro, 2015. 117p. Dissertação de Mestrado - Departamento de Informática, Pontifícia Universidade Católica do Rio de Janeiro.

A confiabilidade absoluta do software é considerada inatingível, pois mesmo quando confeccionado seguindo regras rígidas de qualidade, o software não está livre da ocorrência de falhas durante a sua vida útil. $O$ nível de confiabilidade do software está relacionado, entre outros, à quantidade de defeitos remanescentes que serão exercitados durante seu uso. Contendo menos defeitos remanescentes, espera-se que o software falhe menos frequentemente, embora muitos desses defeitos sejam exercitados nenhuma vez durante a vida útil do software. Mas desenvolvedores, além de redigir programas, utilizam cada vez mais bibliotecas e serviços remotos que muitas vezes possuem qualidade duvidosa. Na tentativa de tornar o software capaz de observar erros em tempo de execução, surge a hipótese que o uso dos Métodos Formais Leves, por meio do emprego sistemático de assertivas executáveis, pode ser eficaz e economicamente viável para assegurar a confiabilidade do software, tanto em tempo de teste como em tempo de uso. O objetivo principal desta pesquisa é avaliar a eficácia de assertivas executáveis para prevenção e observação de falhas em tempo de execução. As avaliações da eficácia foram feitas por intermédio de uma análise quantitativa utilizando experimentos. Estes, utilizam, implementações de estruturas de dados instrumentadas com assertivas executáveis, submetidas a testes baseados em mutações. Os resultados mostraram que todos os mutantes não equivalentes foram identificados pelas assertivas, embora os testes não foram capazes disso. Também é apresentada uma estimativa do custo computacional relativo ao uso de assertivas executáveis. Com base na infraestrutura criada para realização dos experimentos é proposta uma política de instrumentação de programas utilizando assertivas executáveis a serem mantidas ativas tanto durante os testes como durante o uso produtivo.

\section{Palavras-chave}

Instrumentação de software; Teste de software; Software autoverificante; Métodos Formais Leves. 


\section{Abstract}

Ferreira, Fischer Jônatas; Staa, Arndt von (Advisor). An Effective Analysis of Executable Assertives as Indicators of Software Fails. Rio de Janeiro, 2015. 117p. MSc. Dissertation - Departamento de Informática, Pontifícia Universidade Católica do Rio de Janeiro.

Absolute reliability of software is considered unattainable, because even when it is build following strict quality rules, software is not free of failure occurrences during its lifetime. Software's reliability level is related, among others, to the amount of remaining defects that will be exercised during its use. If software contains less remaining defects, it is expected that failures will occur less often, although many of these defects will never be exercised during its useful life. However, libraries and remote services of dubious quality are frequently used. In an attempt to enable software to check mistakes at runtime, hypothetically Lightweight Formal Methods, by means of executable assertions, can be effective and economically viable to ensure software's reliability both at test time as well as at run-time. The main objective of this research is to evaluate the effectiveness of executable assertions for the prevention and observation of run-time failures. Effectiveness was evaluated by means of experiments. We instrumented data structures with executable assertions, and subjected them to tests based on mutations. The results have shown that all non-equivalent mutants were detected by assertions, although several of them were not detected by tests using noninstrumented versions of the programs. Furthermore, estimates of the computational cost for the use of executable assertions are presented. Based on the infrastructure created for the experiments we propose an instrumentation policy using executable assertions to be used for testing and to safeguard run-time.

\section{Keywords}

Software Instrumentation; Software Testing; Software and self-verificante; Lightweight Formal Methods. 


\section{Sumário}

1 Introdução 14

1.1. Objetivos gerais e específicos 17

1.2. Trabalho proposto 18

1.3. Organização do trabalho 19

2 Fundamentação teórica e trabalhos relacionados 20

2.1. Revisão da literatura sobre Métodos Formais Leves 20

2.2. Métodos Formais Leves 22

2.3. Assertivas 23

2.4. Diferenças e comparações na abordagem utilizada 24

3 Política de instrumentação de programas proposta 26

3.1. Modelo de verificação da eficácia das assertivas executáveis por meio de testes mutantes 26

3.2. Métricas utilizadas $\quad 29$

3.3. Assertivas executáveis 30

3.4. Modelo de criação de assertivas executáveis 31

4 Demonstrações do emprego de assertivas executáveis 35

4.1. Introdução 35

4.2. Árvore de pesquisa binária 36

4.2.1. Assertivas estruturais 36

4.2.1.1. Árvore sem elementos 36

4.2.1.2. Árvore com apenas um elemento $\quad 37$

4.2.1.3. Árvore com mais de um elemento 38

4.2.1.4. Encadeamento da árvore 39

4.2.1.5. Folhas da árvore 40

4.2.1.6. Árvore de Pesquisa Binária 41

4.2.1.7. Número de filhos de um nó 42

4.2.2. Assertivas pontuais 43

4.2.3. Possíveis anomalias para Árvore de Pesquisa Binária 44 
4.3. Árvore AVL 45

4.3.1. Assertivas estruturais 46

4.3.1.1. Balanceamento da árvore 46

4.3.1.2. Altura da árvore $\quad 47$

4.3.2. Anomalias 48

4.4. Árvore Vermelho e Preto 48

4.4.1. Assertivas estruturais 48

4.4.1.1. Cor da raiz da árvore 48

4.4.1.2. Cor dos elementos da árvore $\quad 49$

4.4.1.3. Cor das folhas $\quad 50$

4.4.1.4. Cor dos filhos de um nó vermelho 51

4.4.1.5. Quantidade de elementos pretos no caminho 52

4.4.2. Possíveis anomalias para Árvore Vermelho e Preto 55

4.5. Árvore AA 56

4.5.1. Assertivas estruturais 56

đิ 4.5.1.1. Nível do filho à esquerda de um nó 56

4.5.1.2. Nível do filho à direita de um nó $\quad 57$

4.5.2. Possíveis anomalias para Árvore AA 58

4.6. Árvore Splay $\quad 59$

4.6.1. Assertivas estruturais $\quad 59$

4.6.1.1. Elemento da raiz $\quad 59$

4.6.2. Possíveis anomalias para Árvore Splay 60

$\begin{array}{ll}\text { 4.7. Árvore B } & 60\end{array}$

$\begin{array}{ll}\text { 4.7.1. Assertivas estruturais } & 61\end{array}$

4.7.1.1. Limite superior sobre o número de filhos de um nó 61

4.7.1.2. Nós internos e folhas 62

4.7.2. Possíveis anomalias para Árvore B 63

4.8. Heap binária 63

4.8.1. Assertivas estruturais 63

4.8.1.1. Filhos maiores que os pais 63

4.8.1.2. Heap Binária completa 64

4.8.2. Possíveis anomalias para Heap Binária 65

4.9. Heap Leftist 66

4.9.1. Assertivas estruturais 66

4.9.1.1. Caminho nulo da Heap Leftist 66

$\begin{array}{ll}\text { 4.9.2. Possíveis anomalias para Heap Leftist } & 67\end{array}$ 
$\begin{array}{ll}\text { 4.10. Heap Fibonacci } & 67\end{array}$

4.10.1. Assertivas estruturais: 68

4.10.1.1. Encadeamento da Heap Fibonacci 68

4.10.2. Possíveis anomalias para Heap Fibonacci 69

4.11. Assertivas executáveis para Árvore AVL implementada em PHP 69

4.11.1. Árvore sem elemento 69

4.11.2. Árvore com apenas um elemento 70

4.11.3. Árvore com mais de um elemento $\quad 70$

4.11.4. Encadeamento da árvore 70

4.11.5. Folhas da árvore $\quad 71$

4.11.6. Árvore de Pesquisa Binária $\quad 71$

5 Teste de análise mutante $\quad 72$

5.1. Teste de análise mutante 72

5.2. MuClipse: ferramenta para teste análise mutante para Java 73

5.3. MuPhp: Protótipo de ferramenta para testes de análise mutante em PHP 79

5.4. Teste Unitário 81

6 Experimentos e resultados 84

6.1. Resultados obtidos com as estruturas de dados 84

6.2. Medidas e comparações do tempo computacional no uso das assertivas executáveis 88

6.2.1. Problema de Programação Hiperbólica (PPH) 89

6.2.2. Assertivas: $\quad 89$

6.2.2.1. Vetor ordenado: $\quad 89$

6.2.3. Ambiente do experimento 90

6.2.4. Resultados obtidos para o PPH: $\quad 91$

6.2.4.1. Resultados obtidos para o PPH com Merge Sort. 91

6.2.4.2. Resultados obtidos para o PPH com Quick Sort. 92

6.2.4.3. Resultados obtidos para PPH com Selection Sort. 94

6.2.4.4. Média de tempo de execução obtida para PPH. 95

6.2.5. Resultados obtidos para o PAGM: 95

6.2.5.1. Resultados obtidos para AGM utilizando a árvore AVL 97

6.2.5.2. Resultados obtidos para AGM utilizando a Leftist Heap 98

6.2.5.3. Resultados obtidos para AGM utilizando a Fibonacci 99

6.2.5.4. Resultados obtidos para AGM utilizando a árvore AVL. 100 
7 Considerações finais $\quad 102$

7.1. Contribuições 104

7.2. Limitações e trabalhos futuros 104

8 Referências Bibliográficas 106 


\section{Lista de Figuras}

Figura 1 - Modelo de uso de assertivas com teste de análise mutante

Figura 2 - Diagrama de Classe da instrumentação por meio das

assertivas executáveis

Figura 3 - Exemplo da estrutura de instrumentação por meio das assertivas executáveis

Figura 4 - Assertiva verificadora da árvore sem elementos

Figura 5 - Assertiva verificadora da árvore com um elemento

Figura 6 - Assertiva verificadora da árvore com mais de um elemento

Figura 7 - Assertiva verificadora do encadeamento da árvore $\quad 40$

Figura 8 - Método para geração de encadeamento duplicado 40

Figura 9 - Assertiva verificadora das folhas da árvore 41

Figura 10 - Assertiva verificadora da árvore binária 42

Figura 11 - Assertiva verificadora do número de filhos de um nó

Figura 12 - Assertivas pontuais para Árvore de Pesquisa Binária

Figura 13 - Assertiva executável verificadora do balanceamento da árvore

Figura 14 - Assertiva executável verificadora da altura da árvore

Figura 15 - Assertiva executável verificadora da cor da raiz

Figura 16 - Assertiva executável verificadora da cor dos elementos

Figura 17 - Assertiva executável verificadora da cor das folhas

Figura 18 - Assertiva executável verificadora da cor dos nós filhos

Figura 19 - Assertiva executável verificadora da quantidade de nós pretos 53

Figura 20 - Método para inicialização dos nós da árvore 54

Figura 21 - Método para controlar os nós não visitados 54

Figura 22 - Método para contar os nós pretos encontrados 54

Figura 23 - Assertiva executável verificadora do nível do filho à esquerda 57

Figura 24 - Assertiva executável verificadora do nível do filho à direita 58

Figura 25 - Assertiva executável verificadora do ajuste da Árvore Splay $\quad 60$

Figura 26 - Assertiva verificadora do limite superior 61

Figura 27 - Assertiva executável verificadora das chaves da Árvore B 62

Figura 28 - Assertiva executável verificadora da Heap Mínimo 64

Figura 29 - Assertiva executável verificadora da alocação dos nós na Heap 65

Figura 30 - Assertiva executável verificadora do caminho nulo 
Figura 31 - Assertiva executável verificadora do encadeamento

da Heap Fibonacci 68

Figura 32 - Assertiva executável verificadora da árvore sem elementos $\quad 69$

Figura 33 - Assertiva executável verificadora da árvore com um elemento $\quad 70$

Figura 34 - Assertiva executável verificadora da árvore com mais

de um elemento $\quad 70$

Figura 35 - Métodos auxiliares para criação das assertivas executáveis $\quad 70$

Figura 36 - Assertiva executável verificadora do encadeamento da árvore 71

Figura 37 - Assertiva executável verificadora das folhas da árvore binária 71

Figura 38 - Assertiva executável verificadora da propriedade da

árvore binária $\quad 71$

Figura 39 - Interface gráfica para selecionar operadores de mutação

$\begin{array}{ll}\text { MuCplise } & 79\end{array}$

Figura 40 - Demonstração de um mutante criado 79

Figura 41 - Demonstração da criação de mutantes via a ferramenta MuPHP 80

Figura 42 - Caso de testes unitários para Árvore AA, parte 1

Figura 43 - Caso de testes unitários para Árvore AA, parte 2

Figura 44 - Assertiva executável verificadora da ordenação do vetor $\quad 90$

Figura 45 - Gráfico do resultado do Merge Sort sem instrumentação 92

Figura 46 - Gráfico do resultado do Merge Sort com instrumentação 92

Figura 47 - Gráfico dos resultados do Quick Sort sem instrumentação 93

Figura 48 - Gráfico dos resultados do Quick Sort com instrumentação 93

Figura 49 - Gráfico dos resultados do Selection Sort sem instrumentação 94

Figura 50 - Gráfico dos resultados do Selecion Sort com instrumentação 95 


\section{Lista de Tabelas}

Tabela 1 - Classificação numérica dos artigos pesquisados 21

Tabela 2 - Possíveis tipos de anomalias para Árvore de Pesquisa Binária $\quad 45$

Tabela 3 - Possíveis tipos de anomalias para Árvore AVL 48

Tabela 4 - Possíveis tipos de anomalias para Árvore Vermelho e Preto 55

Tabela 5 - Possíveis tipos de anomalias para Árvore AA 58

Tabela 6 - Possíveis tipos de anomalias para Árvore Splay 60

Tabela 7 - Possível tipo de anomalia para Árvore B 63

Tabela 8 - Possíveis tipos de anomalias para Heap Binária 65

Tabela 9 - Possíveis tipos de anomalias para Heap Leftist 67

Tabela 10 - Possíveis tipos de anomalias para Heap Fibonacci 69

Tabela 11 - Operadores de mutação relativos à classe 76

Tabela 12 - Operadores de mutação relativos à classe em uso 77

Tabela 13 - Operadores de mutação relativos ao método 77

Tabela 14 - Operadores de mutação relativos ao método em uso 78

Tabela 15 - Resultados obtidos com teste mutantes e assertivas

$\begin{array}{ll}\text { executáveis } & 86\end{array}$

Tabela 16 - Número de mutantes criados para as estruturas de $\begin{array}{ll}\text { dados usadas } & 87\end{array}$

Tabela 17 - Número de mutantes criados a Árvore AVL em PHP 88

Tabela 18 - Resultados obtidos para o Merge Sort $\quad 91$

Tabela 19 - Resultados obtidos para o Quick Sort 93

Tabela 20 - Resultados obtidos para o Selection Sort 94

Tabela 21 - Média dos resultados obtidos para o PPH 95

Tabela 22 - Resultados obtidos para o PAGM com AVL 97

Tabela 23 - Resultados obtidos para o PAGM com Leftis Heap 98

Tabela 24 - Resultados obtidos para o PAGM com Fibonnaci Heap 99

Tabela 25 - Média dos resultados obtidos para o PAGM 100

Tabela 26 - Resultados obtidos para o PAGM com AVL com

instrumentação extra 101 


\section{Introdução}

Elevada confiabilidade há muito é desejada em sistemas de computação. Essa necessidade vem se tornando mais intensa, uma vez que o software está presente em inúmeras atividades humanas e de controle de sistemas. Dia a dia, aumenta a nossa dependência de sistemas informatizados (Weber, 2002). Porém, a confiabilidade absoluta é considerada inatingível (Weber, 2002), pois software, mesmo quando confeccionado seguindo regras rígidas de qualidade, não está livre da ocorrência de falhas durante a sua vida útil (Brown, Patterson, 2001). Além disso, desenvolvedores, utilizam cada vez mais bibliotecas e serviços remotos que muitas vezes possuem qualidade duvidosa. O nível de confiabilidade do software está relacionado à quantidade de defeitos remanescentes exercitados durante seu uso. Como o software pode conter defeitos remanescentes e o hardware pode falhar mesmo que muito raras vezes, é impossível prever ou impedir por completo que o software falhe. Assim, é desejado que as falhas possam ser observadas o quanto antes em tempo de execução, a fim de que potenciais danos causados possam ser mantidos sob controle, bem como as causas possam ser removidas ou tratadas (Magalhães et al., 2007).

Uma das soluções utilizadas na tentativa de tornar o software correto por construção é o uso de Métodos Formais (Calinescu, Kikuchi, 2011). Esses se baseiam em modelos e especificações formais detalhadas, e que apoiam todas as fases de desenvolvimento e manutenção de um software. Um dos maiores benefícios da utilização de métodos formais é o entendimento minucioso que se adquire dos requisitos do software, pois os desenvolvedores são forçados a uma análise pormenorizada do sistema. Isso acarreta a detecção prévia de ambiguidades, inconsistências e lacunas que poderiam posteriormente gerar falhas (Easterbrook, 1998). Por outro lado, os altos custos envolvidos no uso dos Métodos Formais e as difíceis tarefas inerentes à sua utilização fazem com que, de modo geral, sejam usados apenas em casos muito específicos (Wikipédia, 2013), onde defeitos remanescentes no sistema possam levar a danos catastróficos, tais como: perdas de vidas, danos para o meio ambiente ou enormes prejuízos. Como o uso de métodos formais ainda requer uma 
participação substantiva de humanos, erros humanos muitas vezes comprometem as provas da corretude (Yelowitz, 1976).

Infelizmente, uma especificação, mesmo quando formal, pode estar errada, ou, ainda que correta, pode não corresponder ao problema a ser resolvido. Além disso, existe a questão da discrepância entre a prova formal e a implementação realizada (Kneuper, 1997). As práticas modernas de desenvolvimento tornam o software dependente de terceiros, virtualmente impossibilitando uma prova completa (Thomas, 2002). Finalmente, as provas podem estar erradas, dando a falsa impressão que a solução está correta quando, na realidade, contém defeitos remanescentes (Yelowitz, 1976). Disto tudo, a conclusão dos desenvolvedores de software é que o custo do uso de técnicas formais só compensa nos raros casos em que as falhas remanescentes poderiam produzir catástrofes. Mesmo assim, segundo Jackson (2012) as técnicas formais não garantem que o software seja totalmente livre de falhas remanescentes.

Em busca de uma abordagem formal com custos menores são propostos os Métodos Formais Leves (Técnicas Formais Leves). Assertivas executáveis são uma das formas de implementar tais métodos. As Técnicas Formais Leves possuem uma base formal, mas são limitadas quanto ao rigor de uma ou mais das seguintes formas: linguagem, modelagem, análise ou composição (Boyatt, Sinclair, 2008; Easterbrook, 1998).

Construir software livre de falhas ou eliminá-las "a posteriori", por completo, de um sistema que já esteja em produção é utopia (Berry, 1992). As falhas dos programas acontecem por vários fatores sejam elas internas ou externas ao sistema. Segundo (Magalhães et al., 2007) não são todos os tipos de falhas que podem ser prevenidos, principalmente aquelas externas ao sistema, já que fogem da capacidade de uma medida preventiva inserida no software como, por exemplo, interrupção de transmissão de dados, quedas de energia, ou bibliotecas contendo defeitos, embora, seja possível controlar os danos gerados por esses problemas.

Com relação às falhas internas, podem ser originadas pelos seguintes fatores: Primeiramente, inconsistência nos requisitos, aproximadamente 50\% das falhas detectadas na fase de testes são oriundas de problemas no levantamento de requisitos (Blackburn et al., 2001). Erros ocasionados pela falibilidade humana: sejam no desenvolvimento, manutenção, uso do software, ou até mesmo pela interação maliciosa, que visa propositalmente a provocar danos ao sistema (Weber, 2002). Podem ser destacados, também, problemas ocasionados por configurações incorretas ou ausentes (Araújo, 2014) ou até 
mesmo erros em hardware e plataformas (Magalhães et al., 2007). Por fim, as falhas ocorridas por questões de sincronismo que podem ser observadas quando um determinado fragmento de código apresenta defeito em um dado estado computacional, e esse não apresenta o mesmo defeito quando for executado em outro momento, ainda que sejam aparentemente estados computacionais iguais.

Utilizaremos no restante do texto a seguinte terminologia (Staa, 2014):

- Artefatos são resultados tangíveis resultantes do desenvolvimento ou manutenção.

- Defeito é um fragmento de um artefato que, se utilizado, pode levar a um erro.

- Erro é um desvio entre o que é desejado ou intencionado e o que é gerado ou derivado. Erro é causado por um defeito.

- Falha é um erro observado.

- Latência do erro é o tempo decorrido entre o momento em que o erro é gerado e o momento em que é observado.

- Dano é a consequência externa ao software conhecida (prejuízo) provocada por uma falha.

- Lesão é a consequência externa ao software desconhecida provocada por um erro não observado

Um aspecto importante a ser destacado em um mecanismo de observação de falhas são os custos relativos à manutenção de software, pois, atualmente a manutenção representa $90 \%$ do custo total da vida útil de um software (Erlikh, 2000, apud Araújo, 2011). Sendo que a tarefa mais difícil na manutenção de software, segundo (Souza, 2004), é o entendimento do sistema, correspondendo mais de $50 \%$ do trabalho total nesta fase. Durante a depuração de software, e também durante o uso produtivo, uma quantidade significativa de esforço é despendida para identificar a causa raiz de uma falha (Yi et al., 2015)

Como os defeitos não podem ser retirados por completo dos sistemas, é necessário que exista um mecanismo que se possa identificar e tratá-los da melhor forma possível, removendo aqueles que provoquem maiores danos ao software (Staa, 2006). Assim, o ideal é que esse mecanismo possa evitar possíveis defeitos, ou impedir que os erros causados possam se propagar para outros módulos do programa relacionados ao fragmento de código onde foi exercitado o defeito. Contudo, quando não for possível evitá-los que possam ao menos facilitar o processo de sua identificação, proporcionando menores custos para encontrá-los no código. 
Além disso, é importante que seja pequena a latência entre o momento da geração do erro e o da sua observação, a fim de que a causa real do defeito possa ser mais facilmente descoberta (Magalhães et al., 2007). Pois, com uma latência menor a análise se limitará a um conjunto menor de código, assim, subentende-se que seja menor a interferência de outros dados e fragmentos de código não relacionados ao defeito, dessa forma evita-se que a causa exata do defeito seja maquiada.

Assim, surge a hipótese que o uso dos Métodos Formais Leves, por meio do emprego sistemático de assertivas executáveis possa ser um mecanismo eficaz e economicamente viável para assegurar a confiabilidade do software. Além de torná-lo autoverificante por viabilizar a observação, em tempo de uso produtivo, das eventuais falhas, possibilitando o controle dos potenciais danos por elas causados. Também, permite o desenvolvimento mais próximo do ideal fidedigno por construção, por possibilitar o entendimento mais minucioso dos requisitos do software antes ainda de iniciar o desenvolvimento (Woodcock, 2009; Hierons, 2009; Boyatt, 2007).

\section{1.}

\section{Objetivos gerais e específicos}

O objetivo principal desta pesquisa foi avaliar a eficácia das assertivas para observação de falhas em tempo de execução. Por intermédio de uma pesquisa quantitativa as avaliações da eficácia foram feitas por meio de testes baseados em mutações de estruturas de dados. O experimento foi realizado com intuito de encontrar subsídios que respondam aos seguintes questionamentos sobre os sistemas implementados com assertivas executáveis:

1. As assertivas podem encontrar falhas dos mutantes antes dos oráculos associados aos casos de teste?

2. Caso ocorram falhas as assertivas podem observá-las em tempo de execução?

Ainda foi descrito o uso de assertivas executáveis segundo os tópicos abaixo relacionados:

1. Como usar assertivas;

2. Quando usá-las; 
3. Como criar assertivas segundo seus diferentes tipos, para programas escritos nas linguagens Java e PHP, considerando os seguintes tipos de assertivas:

a. Assertivas pontuais (Meyer, 1992):

i. Entrada ou pré-condições: Condição que deve estar satisfeita para ativar o método.

ii. Saída ou pós-condição: Condição que deve estar satisfeita após a execução do método.

b. Assertivas estruturais: Condições envolvendo todos os atributos de diversos objetos pertencentes a diversas classes e que realizam uma estrutura de dados. Essas condições correspondem a invariantes da estrutura e devem ser sempre verdadeiras quando a estrutura não está sendo alterada (Staa, 2000).

4. Como possibilitar um mecanismo para habilitar e desabilitar o uso de assertivas executáveis em programas escritos nas linguagens Java e PHP.

Por fim, como objetivo secundário foi feita uma revisão da literatura envolvendo os diferentes tipos de abordagens de Métodos Formais Leves e suas viabilidades para utilização em nível industrial.

\section{2. \\ Trabalho proposto}

Tendo em vista a hipótese formulada parte-se para a realização do experimento para verificar se a mesma tem aplicabilidade real ou não. $O$ experimento foi realizado em dois momentos com objetivos distintos.

O primeiro voltado para verificação de quantas falhas injetadas artificialmente e de forma sistemática as assertivas foram capazes de detectar. Aliado a essa etapa foram propostas métricas capazes de estimar o aproveitamento das assertivas criadas.

No segundo momento do experimento a preocupação foi relativa ao tempo computacional gasto pelo uso das assertivas executáveis. Há necessidade de aferir o seu custo computacional porque elas podem ser mantidas ativas no sistema, estando esse nas fases de desenvolvimento ou de produção. Assim pôde ser demonstrado quantitativamente se as assertivas foram capazes de detectar falhas de forma economicamente viável para o uso. 
Para a elaboração dos experimentos se fizeram necessários alguns prérequisitos descritos no decorrer do trabalho. Sendo esses requisitos:

1. Revisão da literatura sobre Métodos Formais Leves;

2. Criação de um modelo de uso de assertivas executáveis;

3. Criação de um modelo de utilização de teste de análise mutante para verificação da eficácia das assertivas executáveis;

4. Emprego da ferramenta MuClipse (Smith, 2007) destinada à análise de testes mutantes para linguagem Java;

5. Implementação de um protótipo chamado MuPHP que possibilita análise de testes mutantes para a linguagem PHP;

6. Criação de assertivas para diversas estruturas de dados;

7. Implementação, execução da infraestrutura do experimento e análise dos dados obtidos.

\section{3 .}

\section{Organização do trabalho}

Além do capítulo de introdução, este documento apresenta mais seis capítulos que estão organizados da seguinte forma. O Capítulo 2 apresenta Fundamentação teórica e trabalhos relacionados. O Capítulo 3 descreve uma Política de instrumentação de programas proposta. O Capítulo 4 apresenta a ferramenta de testes análise mutante utilizada no experimento, e o protótipo para teste análise mutante para PHP. O Capítulo 5 apresenta os detalhes relativos da infraestrutura do experimento e demonstrações do emprego de assertivas executáveis. O Capítulo 6 relata os resultados alcançados com experimento bem como os dados obtidos. Finalmente o Capítulo 7 apresenta as considerações finais a respeito do trabalho, destacando suas contribuições e desdobramentos em trabalhos futuros. 


\section{Fundamentação teórica e trabalhos relacionados}

Este capítulo apresenta a fundamentação teórica utilizada para criação da hipótese formulada. Ele contempla uma visão geral sobre os Métodos Formais Leves (Seção 2.1), aplicação dos Métodos Formais Leves na forma de assertivas executáveis (Seção 2.2), assertivas (Seção 2.3) e Diferenças e comparações na abordagem utilizada (Seção 2.4).

\section{1.}

\section{Revisão da literatura sobre Métodos Formais Leves}

Foi realizada uma revisão da bibliografia, a pesquisa foi voltada apenas para artigos disponíveis na web, por meio do parâmetro de consulta "Lightweight Formal Method". Foram utilizados os seguintes motores de busca web para auxiliar a pesquisa dos artigos acadêmicos.

1. ACM

2. CiteSeerX

3. leeexplore

4. Sciencedirect

5. Scopus

6. Springer link

Foram encontrados 102 artigos, os quais, tinham relevância e relação com o tema em questão, a lista desses artigos se encontra no Apêndice 1 desse trabalho. A fim de selecionar um número menor de artigos, foi realizada a seguinte estratégia:

1. Leitura dos abstracts destes artigos;

2. Por meio da leitura dos abstracts, foram feitas avaliações dos artigos, segundo uma indicação preliminar de relevância. Assim, os artigos receberam as seguintes indicações numéricas. Quando apresentavam:

a) Nenhuma relação com tema " 0 "

b) Pouca relação com o tema " 1 "

c) O assunto apenas sobre Métodos Formais "2"

d) O assunto apenas sobre Métodos Formais e possuíam exemplos de aplicação e avaliação dos Métodos Formais "3"

e) O assunto sobre Métodos Formais Leves "4" 
f) O assunto sobre Métodos Formais Leves que possuíam exemplos de aplicação e avaliação dos Métodos Formais Leves "5"

3. Foi realizada uma breve descrição dos artigos por meio dos seus resumos.

4. Foram identificados os artigos que continham exemplos com código.

5. Foram identificadas as datas de publicação dos artigos.

Com estes dados anteriormente citados preenchidos, foi feita a ordenação dos artigos pela classificação preliminar de relevância e suas datas de publicação. Os 103 artigos encontrados inicialmente receberam as seguintes indicações descritas na tabela abaixo.

Tabela 1 - Classificação numérica dos artigos pesquisados

\begin{tabular}{|c|c|}
\hline Número de artigos & Classificação \\
\hline 39 & 5 \\
\hline 17 & 4 \\
\hline 9 & 3 \\
\hline 12 & 2 \\
\hline 13 & 1 \\
\hline 13 & 0 \\
\hline
\end{tabular}

Como pode ser observado com a tabela acima 39 artigos receberam a classificação de número 5. Destes 39 artigos, por meio da ordenação feita, citada anteriormente, foram selecionados para a pesquisa apenas os cinco primeiros artigos, pois esses artigos apresentam exemplos práticos do uso de métodos formais leves. Seguem abaixo os títulos desses artigos escolhidos para a pesquisa. Encontra-se nos apêndice deste trabalho a lista dos artigos pesquisados com sua indicação preliminar de relevância dada.

1. Yang, Guowei, Sarfraz Khurshid, and Miryung Kim. "Specification-based test repair using a lightweight formal method." FM 2012: Formal Methods. Springer Berlin Heidelberg, 2012. 455-470.

2. Shao, Danhua, Sarfraz Khurshid, and Dewayne E. Perry. "An incremental approach to scope-bounded checking using a lightweight formal method." FM 2009: Formal Methods. Springer Berlin Heidelberg, 2009. 757-772.

3. Larsen, P. G; Fitzgerald, J. S; Riddle, S; Learning by Doing: Practical Course $s$ in Lightweight Formal Methods using VDM++, 2007. 
4. Paige, Richard F., and Jonathan S. Ostroff. Specification-driven design with Eiffel and agents for teaching lightweight formal methods. Springer Berlin Heidelberg, 2004.

5. Feather, Martin S. "Rapid application of lightweight formal methods for consistency analyses." Software Engineering, IEEE Transactions on 24.11 (1998): 949-959.

\section{2.}

\section{Métodos Formais Leves}

Com o objetivo de fornecer um grau de formalização nas especificações dos sistemas que não seja no nível dos tradicionais Métodos Formais, surgem os Métodos Formais Leves também chamados de Técnicas Formais. Eles possibilitam o benefício da corretude em fragmentos de códigos essenciais e módulos vitais do sistema.

Essa metodologia está se tornando uma solução viável em custoeficiência. Como foi observado por (Staa, 2013), "as técnicas formais leves têm se mostrado eficazes e economicamente viáveis como instrumentos de verificação de especificações e de apoio à criação de software autoverificante". E ainda segundo (Akhtar, Missen, 2014), "as especificações formais leves são flexíveis, menos rigorosas e mais práticas do que especificações formais".

A característica fundamental deste método é a possibilidade de realizar a tradução dos requisitos do sistema em uma linguagem em nível maior de abstração. Assim, eles induzem os desenvolvedores a terem compreensão mais aprofundada dos requisitos do sistema, melhorando a clareza e precisão das especificações dos requisitos (Feather, 1998). E ainda, a possibilidade de verificar fragmentos de código, a fim de que seja garantido um estado previamente determinado em pontos do algoritmo. Com isso, esse controle proporciona a criação de um mecanismo que viabiliza a observação de falhas em tempo de execução. Os Métodos Formais Leves são capazes de viabilizar a observação de falhas em tempo de execução, além de reduzirem a incidência de defeitos remanescentes. Como pode ser observado em um projeto para Naves Espaciais, onde foi usado retirar inconsistências em banco de dados (Feather, 1998) e na reparação em testes automatizados baseando-se na especificação do sistema (Yang et al, 2012).

Segundo (Feather, 1998) Métodos Formais Leves ocupam um lugar diferente no que diz respeito às técnicas de análise. Eles têm objetivos mais modestos, e empregam as ferramentas que necessitam de menos trabalho preparatório para aplicá-los. Pois, como foi observado por (Cheon, Leavens, 
2002) a depuração e os testes consomem uma fração significante do custo do desenvolvimento e manutenção de software.

Outra característica que merece destaque é a redução do retrabalho inútil sem aumentar em demasia o trabalho de incluir uma técnica formal leve para instrumentar um código. Pois, segundo Easterbrook (1998) os Métodos Formais Leves podem oferecer uma maneira rentável de melhoria da qualidade das especificações de software. Além do mais, o uso bem sucedido dos Métodos Formais Leves em ambiente de desenvolvimento gera resultados mais simples em tempo hábil (Feather, 1998). Existem vários exemplos bem sucedidos na literatura que demonstram os resultados obtidos com a aplicação de métodos formais na indústria, tais como: projeto de roteamento de mensagens e sistema de alerta de congestionamento de veículos (Larsen, 2006); software para Nave Espacial da NASA (Feather, 1998); ferramenta para reparação de testes (Yang, 2012); Sistema robótico multi-agente para o transporte de estoque de armazéns (Akhtar, Missen, 2014).

Outro fator de suma importância é o suporte que a especificação fornece para fase de manutenção do software. Pois, os contratos especificados conforme os requisitos do sistema também servem como uma boa documentação para projetos detalhados (Cheon, Leavens, 2002).

\section{3. \\ Assertivas}

Assertivas também chamadas de Asserções (Pezzè, Young, 2008) segundo (Duncan, Hölzle, 1998), são expressões booleanas que devem ser satisfeitas caso o fragmento de código a que são associadas esteja operando corretamente. Elas não fazem parte da implementação de um algoritmo, mas descrevem restrições sobre os valores que são manipulados dentro desses fragmentos de códigos. Ainda Boyatt (2008) as define como métodos que têm uma base formal, mas é limitada em seu alcance por um ou mais das seguintes características: é parcial na linguagem, modelagem, análise ou na composição. Segundo Plösch (2002) as técnicas baseadas em assertivas executáveis têm efeitos positivos na qualidade de software em geral.

Existem vários trabalhos na literatura que descrevem a utilização de assertivas executáveis, por meio de especificações chamadas de contrato como exemplo a linguagem Eiffel (MEYER, 1998) que estabelecem especificações, precisas e verificáveis das interfaces para componentes de software. Por meio 
de pré-condições, pós-condições e invariantes previamente elaboradas em um nível elevado de abstração, segundo os requisitos do software. Essa técnica é conhecida por Design by Contract a qual é definida como um Método Formal Leve (Paige, Ostroff, 2004). Ainda, podem ser observadas outras técnicas que utilizam Métodos Formais Leves tais como: Model Driven Development, Sistemas Self-checking, a linguagem Eiffel (MEYER, 1998) e Técnicas Alloy (Jackson, 2012).

A popularização do Design by Contract contribui para o surgimento de várias ferramentas que seguem suas especificações de interface para os componentes de software. Esta técnica também é utilizada para aplicações escritas em Java, utilizando assertivas executáveis como podem ser observadas nas ferramentas IContract (Kramer, 2001), Jcontractor (Karaorman, Hölzle and, Bruno, 1999) Jcontract (Parasoft, 2002), Jass (Bartetzko, 2001), Handshake (Duncan, Hölzle, 1998) e JML (Cheon, Leavens, 2002).

O conhecimento mais apurado dos requisitos do sistema impulsionado por meio da construção de assertivas acarreta o desenvolvimento de sistemas mais corretos. O detalhamento maior dos requisitos possibilitará um número maior de falhas observadas. Pois, serão as assertivas as observadoras de possíveis inconsistências de estados.

\section{4. Diferenças e comparações na abordagem utilizada}

A principal diferença na abordagem utilizada no trabalho proposto, comparada com trabalhos anteriores que também avaliam a eficácia de assertivas, se dá pelo fato do experimento ser feito sobre defeitos conhecidos e gerenciáveis. Os defeitos são conhecidos por serem criados por meio de mutantes gerados por operadores de mutação pré-determinados, possibilitando assim o conhecimento prévio dos defeitos injetados. Também podem ser gerenciáveis por meio da funcionalidade oferecida pela ferramenta utilizada que possibilita a identificação do estado dos mutantes (vivos ou mortos) após serem testados. Ainda a observação dos desvios sintáticos que cada mutante apresentou comparado com o programa original.

Neste experimento pode ser observado que do número total de mutantes, quantos foram mortos pelas assertivas executáveis e quantos não foram. Assim, uma estimativa da eficácia das assertivas pôde ser criada, pois o número de defeitos inseridos no código é conhecido. 
Ainda neste trabalho foi levado em consideração o tempo computacional gasto pelo uso de assertivas executáveis por dois sistemas instrumentados por elas. Para isso foi comparado o tempo computacional de dois sistemas em dois momentos, o primeiro sem o uso de assertivas e segundo com o uso delas. Assim pôde ser feita a estimativa do percentual de tempo computacional adicionado em virtude do uso de assertivas executáveis. 
3

\section{Política de instrumentação de programas proposta}

Este capítulo apresenta o modelo para verificação da eficácia das assertivas executáveis que preconiza o uso de testes de análise mutante o qual foi utilizado para a realização do experimento.

\section{1. \\ Modelo de verificação da eficácia das assertivas executáveis por meio de testes mutantes}

O experimento descrito neste trabalho foi realizado tendo por base um pequeno modelo que preconiza a utilização de assertivas executáveis com testes de analise mutante, desde a fase da implementação dessas, até a análise de sua eficácia, como pode ser observado no modelo demonstrado na Figura 1.

O modelo é constituído dos seguintes passos:

1. O programa poderá ser desenvolvido com assertivas executáveis, ou essas são acrescentadas ao programa que já tenha sido implementado;

2. Devem ser criados os casos de testes unitários para o programa que se deseja instrumentar.

3. É necessário que sejam executados os testes para o programa original juntamente com as assertivas executáveis. Neste passo necessita-se da avaliação do testador para verificar a saída gerada por meio da execução dos casos de testes, analisando o relatório desses. Caso todos os testes passem, então se deve seguir para o próximo passo do modelo, o qual é a geração dos mutantes. Se os testes não passarem, o programa original deverá ser corrigido e também as assertivas executáveis devem ser modificadas, de modo que essas observem as falhas que antes não haviam sido observadas por elas. Esse passo deve ser realizado enquanto existir algum teste que falhe.

4. No passo da geração dos mutantes devem ser escolhidos os operadores de mutação (Ma, 2005).

5. Devem ser executados os testes mutantes com as assertivas executáveis criadas. Novamente $\mathrm{o}$ testador deve verificar se os 
mutantes foram mortos. Caso tenha algum vivo, deve ser analisada qual mutação o código original sofreu e assim verificar se semanticamente o código do mutante é equivalente ao programa original.

6. Segundo a avaliação do testador se isso não ocorrer devem ser atualizados os casos de testes unitários e as assertivas executáveis, para cobrirem aqueles que permanecem vivos. Caso o mutante seja equivalente ao programa original, então se deve considerar o mutante como morto.

7. Com a quantidade de mutantes mortos e a dos que permanece vivos, o testador pode verificar se esses foram mortos por assertivas executáveis. Assim pode ser feita a verificação da eficácia destas, pois por meio dos log gerados são verificadas se as assertivas foram capazes de matar os mutantes antes do programa retornar para o controle do teste. Desse modo, as assertivas exercitadas são consideras eficientes.

8. Finalmente o fluxo do modelo termina quando restarem vivos somente os mutantes que o testador tenha julgado como equivalentes. 


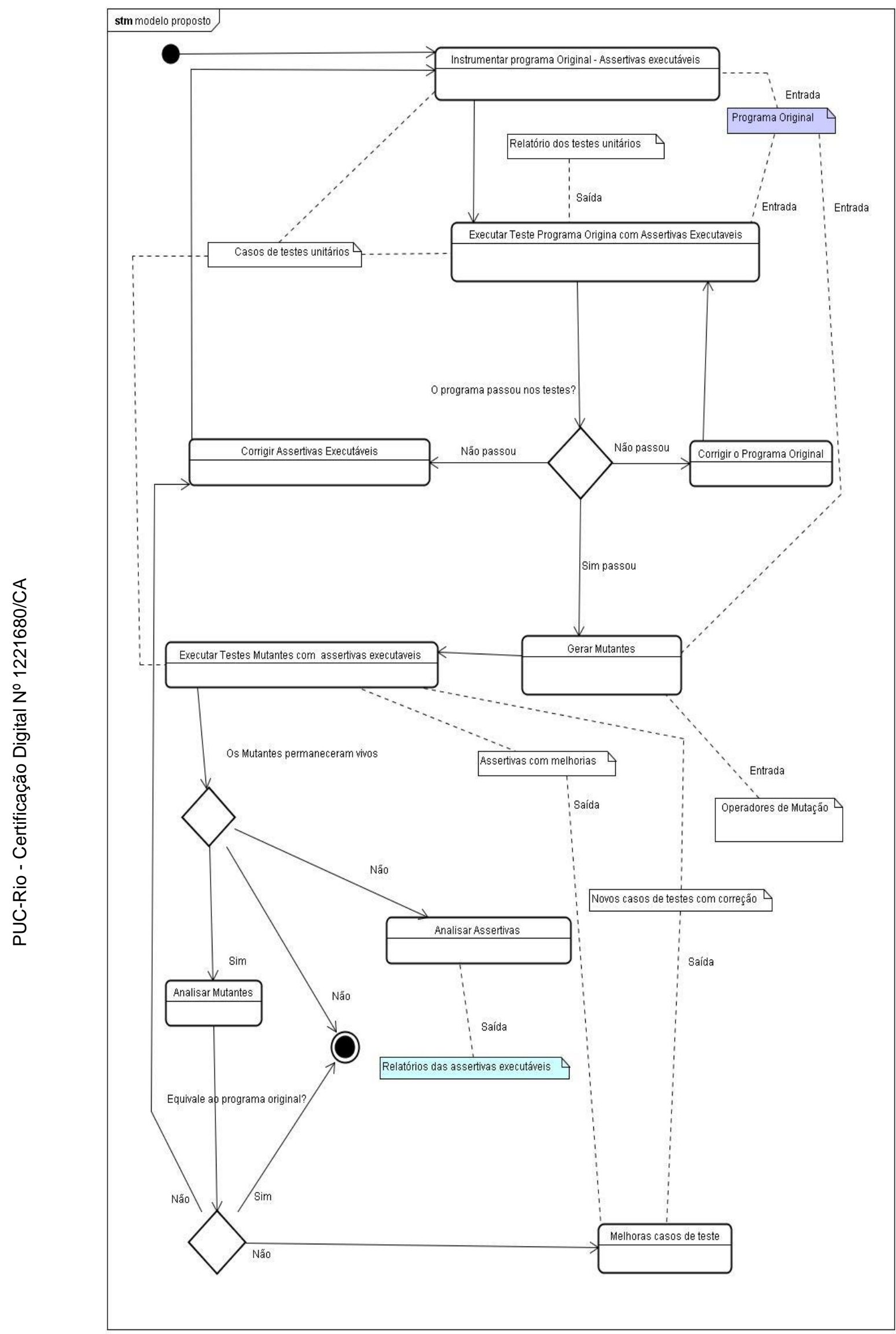

Figura 1 - Modelo de uso de assertivas com teste de análise mutante 


\section{2. \\ Métricas utilizadas}

Por meio da observação dos relatórios obtidos pode-se analisar a eficácia do uso das assertivas. Segundo (Delamaro, et al., 2007) um escore de mutação pode ser calculado com uma análise do número de mutantes que permaneceu vivo e morto, sendo que esse escore de mutação deve variar entre 0 e 1. Quanto maior for o valor do escore de mutação, mais adequado será o conjunto de casos de teste para testar o programa, o mesmo é calculado por essa forma:

$$
E M(P, T)=\frac{D M(P, T)}{M(P)-E Q(P)}
$$

Sendo:

- $\quad \mathbf{E M}(\mathbf{P}, \mathbf{T})$ : Escore de mutação de um programa $P$ em relação ao um caso teste $\mathrm{T}$;

- $\mathbf{D M}(\mathbf{P}, \mathbf{T})$ : número de mutantes mortos pelo conjunto de casos de testes $\mathrm{T}$;

- $\quad \mathbf{M}(\mathbf{P})$ : número total de mutantes gerados a partir de programa $\mathrm{P}$;

- $\quad \mathbf{E Q}(\mathbf{P})$ : número de mutantes considerados equivalentes a $\mathrm{P}$;

Para determinar a eficácia das assertivas, pode ser calculado o escore de mutação com relação às assertivas executáveis com base no que foi demonstrado no exemplo anterior. Assim, a variável DM, a que representa o número de mutantes mortos pela suíte de teste, deve ser alterado para representar o número de mutantes mortos por meio das assertivas executáveis, como segue abaixo:

$$
E M(P, A)=\frac{D M(P, A)}{M(P)-E Q(P)}
$$

Sendo:

- $\quad \mathbf{E M}(\mathbf{P}, \mathbf{A})$ : escore de mutação de um programa $P$ em relação a assertivas $A$;

- $\quad \mathbf{D M}(\mathbf{P}, \mathbf{A})$ : número de mutantes mortos pelas assertivas executáveis;

- $\mathbf{M}(\mathbf{P})$ : número total de mutantes gerados a partir de programa $\mathrm{P}$;

- $\quad \mathbf{E Q}(\mathbf{P})$ : número de mutantes considerados equivalentes a $\mathrm{P}$; 
O escore de mutação também deve variar entre 0 e 1 . Quanto maior for o valor do escore de mutação mais eficaz será o conjunto de assertivas executáveis para prevenção e observação de falhas no programa.

Com os dois escores de mutação descritos acima, pode ser feita uma estimativa da eficiência das assertivas executáveis, comparadas com a eficiência dos casos de testes em relação a um grupo de mutantes. Basta analisar qual escore de mutação tem o maior valor, como segue abaixo.

$$
\begin{aligned}
& E M(P, T) \\
& E M(P, A)
\end{aligned}
$$

Sendo:

- $\quad \mathbf{E M}(\mathbf{P}, \mathbf{T})$ : Escore de mutação de um programa $P$ em relação ao um caso teste $\mathrm{T}$;

- $\operatorname{EM}(\mathbf{P}, \mathbf{A})$ : Escore de mutação de um programa $P$ em relação a assertivas $A$;

Por fim, é importante ressaltar que por meio da saída do programa, o testador poderá observar se algum mutante criado teve uma execução interrompida pelo fato de ter entrado em algum estado errôneo, gerando uma exceção que interrompeu o processamento. É de se esperar que a assertiva observe tais erros antes do programa retornar para o controle do teste. Caso isso não ocorra, o controle do teste deverá observar a falha causada pelo mutante. Portanto, nesse caso as assertivas introduzidas não foram eficazes para observar o funcionamento incorreto provocado pelo mutante.

\section{3.}

\section{Assertivas executáveis}

A proposta de assertivas utilizada neste trabalho é oferecer uma instrumentação para código, que possibilite observar e detectar inconsistências no estado computacional do sistema e prevenir falhas de forma automática. Onde os desenvolvedores poderão rastrear as causas dos defeitos onde foram completa e corretamente localizados por meio da observação de log. Assim, as assertivas verificam a integridade de fragmento de códigos em tempo de execução. Elas serão utilizadas como observadoras dos programas em execução. As assertivas poderão ser dos seguintes tipos: pré-condição, pós- 
condição e estruturais. Esses tipos são baseados na especificação de design do Design by Contract (Karaorman, Hölzle and Bruno, 1999).

Quando a expressão lógica de uma assertiva não for válida, isto indicará a ocorrência de algum estado incorreto naquele instante. Então, será disparada uma exceção gerando informações do estado do processamento que será incluída nas informações que serão armazenadas no log. Assim, fragmentos do código podem ser instrumentados, oferecendo um suporte para observação de falhas. Essa instrumentação não faz parte da implementação das funções do sistema, então a qualquer momento as assertivas poderão ser desativadas.

\section{4. \\ Modelo de criação de assertivas executáveis}

Para confecção das assertivas utilizadas no experimento foram realizados os seguintes passos:

1. Estender a classe original que se deseja instrumentar a fim de que sejam herdados todos os seus métodos e atributos, os quais serão utilizados para criação das assertivas executáveis como demonstrado na Figura 2.

2. Na classe filha devem ser inseridas as assertivas executáveis, para que o conjunto de assertivas seja chamado por apenas um método, cria-se um método público que internamente invoca cada assertiva estrutural criada, como apresentado na Figura 2 por meio do diagrama de classe e ainda por meio do exemplo da estrutura do código demonstrado na Figura 3.

3. Ainda devem ser criadas as assertivas pontuais para os métodos da classe pai em que for necessário verificar seus parâmetros de entradas e suas saídas. Na Figura 3 está apresentada a forma em que as assertivas pontuais foram criadas no experimento, testando se a entrada é do tipo requerido. A saída é verificada por meio das assertivas estruturais, caso elas não observem nenhuma inconsistência espera-se que o resultado esteja correto. 


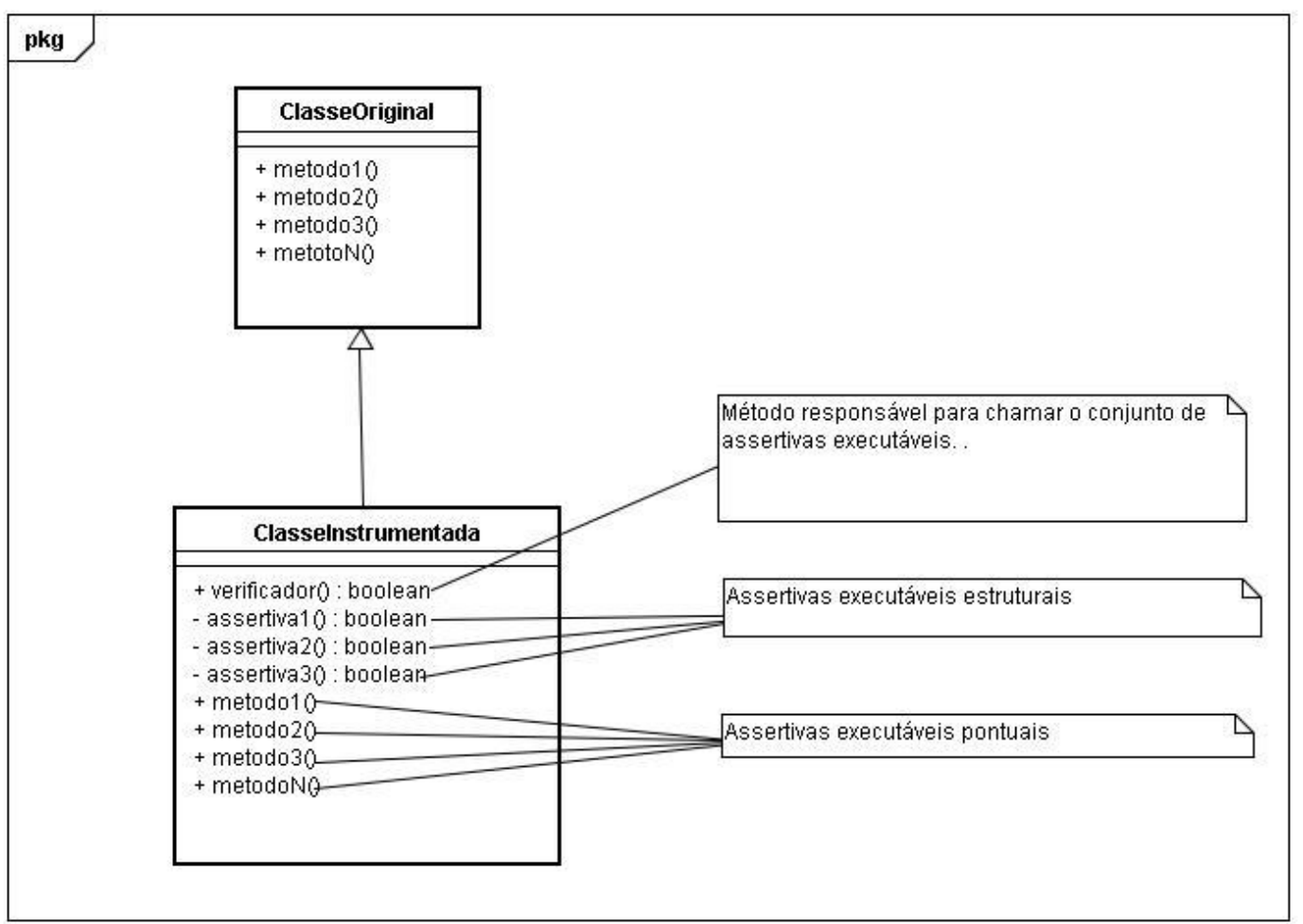

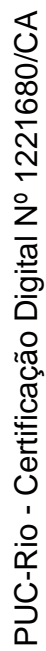

Figura 2 - Diagrama de Classe da instrumentação por meio das assertivas executáveis 


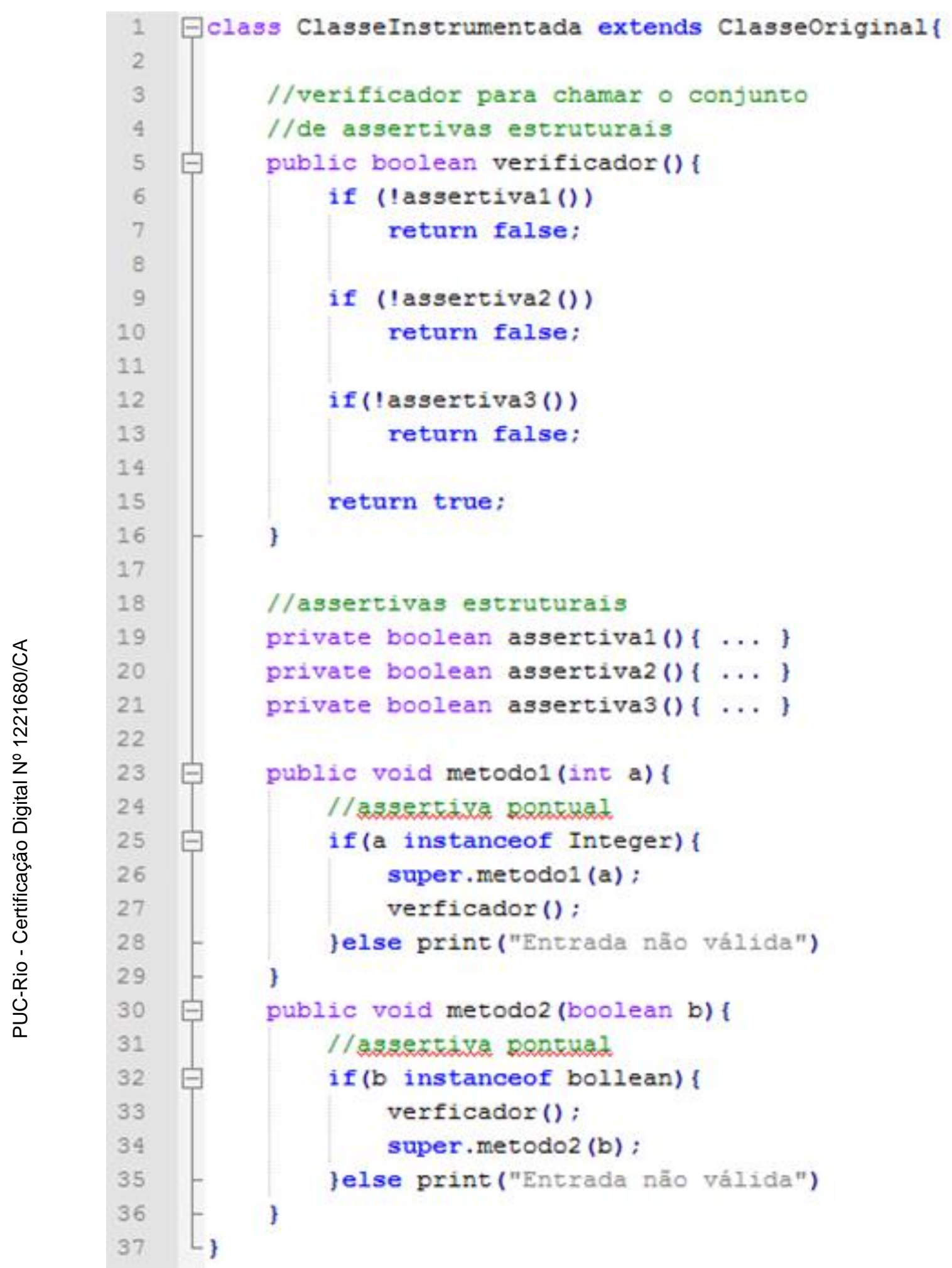

Figura 3 - Exemplo da estrutura de instrumentação por meio das assertivas executáveis

Nos exemplos de assertivas estruturais descritas neste trabalho foi usado um misto de linguagens formais e português proposto por Staa (2000). Segue um exemplo de especificação formal leve para uma lista duplamente encadeada: 


$$
\begin{gathered}
\forall \text { pElem } \in \text { lista: }:(p \text { Elem } \rightarrow \text { pAnt } !=\text { null }) \Longrightarrow \\
\text { pElem } \rightarrow \text { pAnt } \rightarrow \text { pProx }==\text { pElem }
\end{gathered}
$$

Para todos $p$ Elem pertencentes a lista vale se $p E l e m->p A n t ~ !=$ null então pElem->pAnt $->$ pProx $==$ pElem . 
4

\section{Demonstrações do emprego de assertivas executáveis}

Este capítulo tem o objetivo de demonstrar as especificações de algumas estruturas de dados utilizadas no experimento e as instrumentações realizadas com assertivas executáveis para essas estruturas. Na seção 4.1 são descritas algumas informações necessárias para entendimento geral deste capítulo e a demais seções demonstram a criação das assertivas executáveis para as estruturas de dados.

\section{1.}

\section{Introdução}

Foram utilizadas estruturas de dados como amostragem de uma população de programas reais. Serão descritas as propriedades inerentes a cada estrutura de dados e as assertivas executáveis correspondentes às propriedades demonstradas. Assim, para cada estrutura de dados serão apresentados os seguintes tópicos utilizando a nomenclatura abaixo:

1. P: Propriedade;

2. EFL: Especificação Formal Leve;

3. AEI: Assertiva estrutural implementada;

4. API: Assertiva pontual implementada;

Em cada seção dentro do capítulo correspondente à estrutura de dados são listados esses tópicos. Em alguns casos a assertiva pontual será omitida na demonstração das estruturas de dados, para que sejam focadas as propriedade inerentes de cada estrutura. Os tópicos 1, 2 e 3 dentro de cada seção correspondem a mesma especificação escrita em níveis diferentes de formalização. Algumas propriedades que são repetidas em determinadas estruturas de dados não serão descritas novamente, apenas será informado que a propriedade já foi demonstrada e também se aplica a referida estrutura de dados. Ainda, em cada seção possui uma subseção que apresenta algumas anomalias na estrutura de dados que as assertivas são capazes de observar. 


\section{2. \\ Árvore de pesquisa binária}

Uma árvore é uma estrutura de dados organizada em componentes encadeados chamados de Nós, esses elementos são capazes de armazenar informações relativas aos seus nós vizinhos diretos, além de poderem armazenar dados. Dependendo da posição em que um dado nó está alocado na árvore em relação à posição aos seus vizinhos diretos, permite a esse nó receber uma qualificação particular. Essa segue a seguinte regra: o primeiro nó da árvore é chamado de raiz, caso um dado nó tenha referência a outros nós, esse nó é chamado de pai, os nós referenciados por esses nós são chamados de filhos. Por fim os nós que não tem referências de filhos são denominados folhas.

Uma árvore de pesquisa binária possui propriedades as quais serão utilizadas para criação das assertivas executáveis, pois se a árvore em uso tiver suas propriedades intactas, considera-se que ela se mantém correta e consistente. Assim, se a estrutura da árvore se mantiver correta, também as operações internas da árvore, que são extremamente dependentes da corretude estrutural desta, terão uma base apropriada para realizar suas finalidades. Desta forma, as operações poderão apresentar resultados corretos que reflitam a realidade dos dados armazenados na árvore.

\subsubsection{Assertivas estruturais}

\subsubsection{1. Árvore sem elementos}

Para uma árvore qualquer que não possua elementos a raiz deverá ser nula, sendo a raiz o elemento de entrada para acessar a árvore, nenhum elemento da árvore poderá ser acessado, caso a raiz da árvore figure como nula. Assim, certifica-se que a inicialização da árvore esteja correta antes de seu uso. Nas implementações das árvores em que são armazenados para os nós atributos como altura e nível deverão também figurar como nulo, quando árvore não possuir elementos.

P:

Se o número de elementos de uma árvore for igual a zero então a raiz deverá ser nula. 
EFL:

$$
\begin{gathered}
\forall n \in \text { árvore: ? (totalElements }(n)==0) \\
\Rightarrow \\
(\text { root }==\text { null })
\end{gathered}
$$

AEI:

Figura 4 - Assertiva verificadora da árvore sem elementos

\subsubsection{2. Árvore com apenas um elemento}

A árvore com altura zero deve possuir apenas um elemento o qual figurará como raiz da árvore, e ainda nenhum outro elemento poderá pertencer à árvore. Portanto, a assertiva estrutural deverá assegurar que não existam os nós filhos da direita e esquerda da raiz da árvore.

P:

Se a raiz for diferente de nulo e a altura da raiz for igual a zero então os filhos da esquerda e da direita deverão ser nulos.

EFL:

$$
\begin{gathered}
?((\text { root } !=\text { null }) \& \&(\text { root } \rightarrow \text { height }==0)) \\
\Longrightarrow \\
((\text { root } \rightarrow \text { left }==\text { null }) \& \&(\text { root } \rightarrow \text { right }==\text { null }))
\end{gathered}
$$


AEI:

Figura 5 - Assertiva verificadora da árvore com um elemento

\subsubsection{3. Árvore com mais de um elemento}

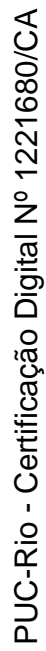

P:

Se a raiz é diferente de nulo e a altura da raiz for maior ou igual a um então o ramo da esquerda, direita ou ambos deverão ser diferentes de nulo.

\section{EFL:}

$$
\begin{gathered}
?((\text { root } !=\text { null }) \& \&(\text { root } \rightarrow \text { height } \geq 1)) \\
\Longrightarrow \\
((\text { root } \rightarrow \text { left } !=\text { null }) \|(\text { root } \rightarrow \text { right } !=\text { null }))
\end{gathered}
$$




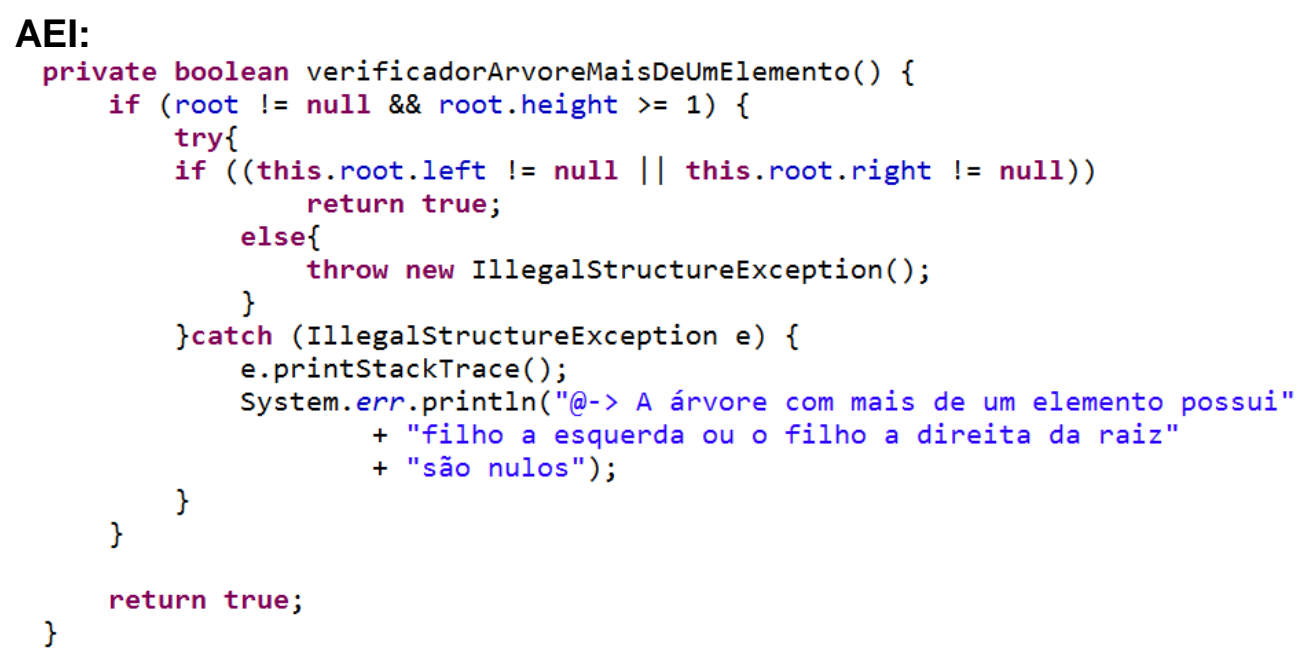

Figura 6 - Assertiva verificadora da árvore com mais de um elemento

\subsubsection{Encadeamento da árvore}

P:

Para todo elemento $p$ pertencente à árvore se o filho esquerdo de $p$ for diferente de nulo então o pai do filho esquerdo de $p$ deverá ser 0 próprio $p$. Ainda se o filho direito de $p$ for diferente de nulo então o pai do filho direito de $p$ deverá ser o próprio $p$.

EFL:

$\forall p \in$ árvore $: ?(p \rightarrow$ left $!=$ null $) \Longrightarrow(p \rightarrow$ left $\rightarrow$ father $==p)$

$\forall p \in$ árvore $: ?(p \rightarrow$ right $!=$ null $) \Rightarrow(p \rightarrow$ right $\rightarrow$ father $==p)$

AEI:

Para realizar a verificação do encadeamento da árvore é necessário fazer com que o nó filho guarde a referência para seu nó pai. Para isso, é chamado um método auxiliar nessa operação o qual pode ser observado na Figura 8. 


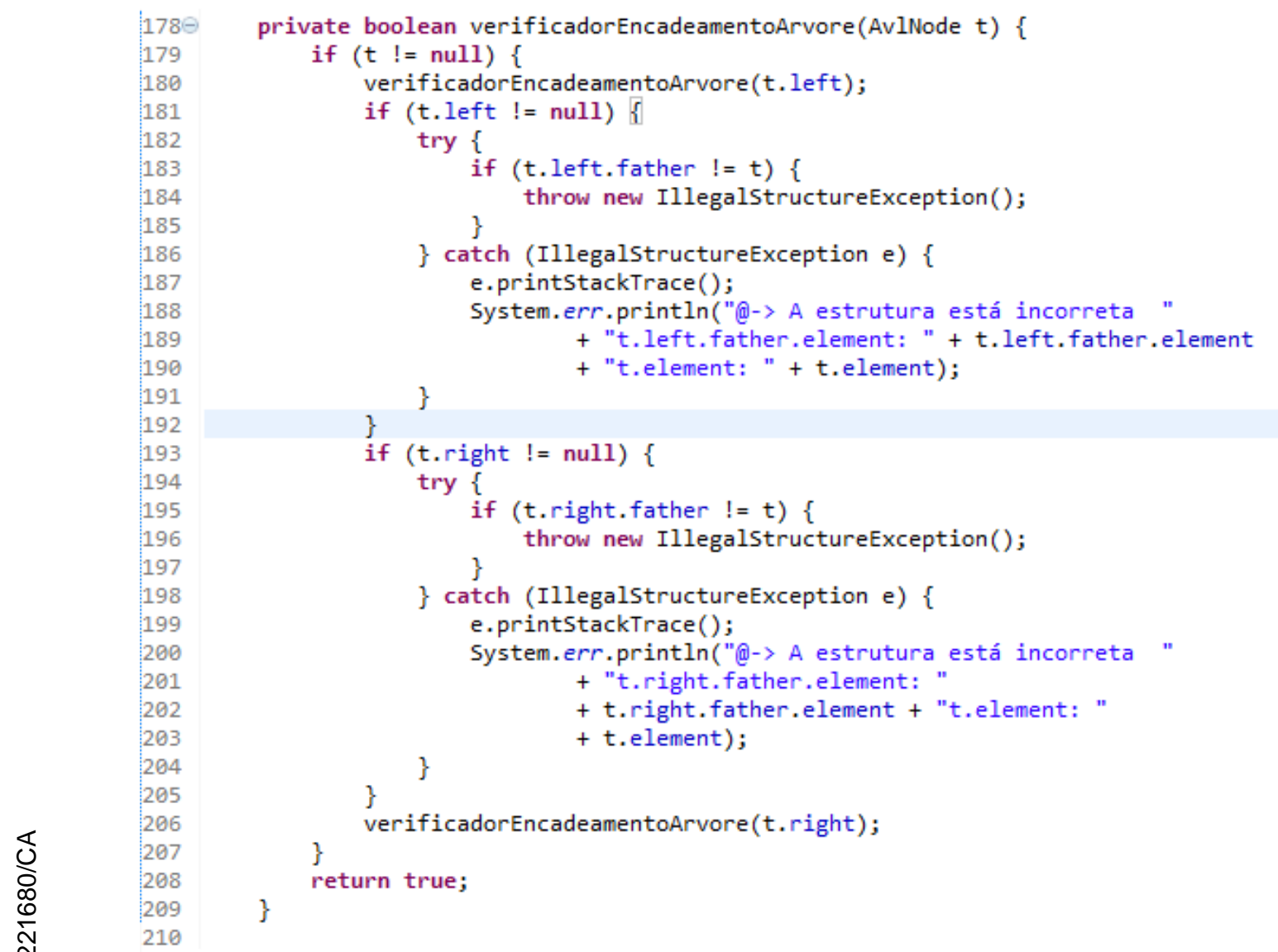

Figura 7 - Assertiva verificadora do encadeamento da árvore

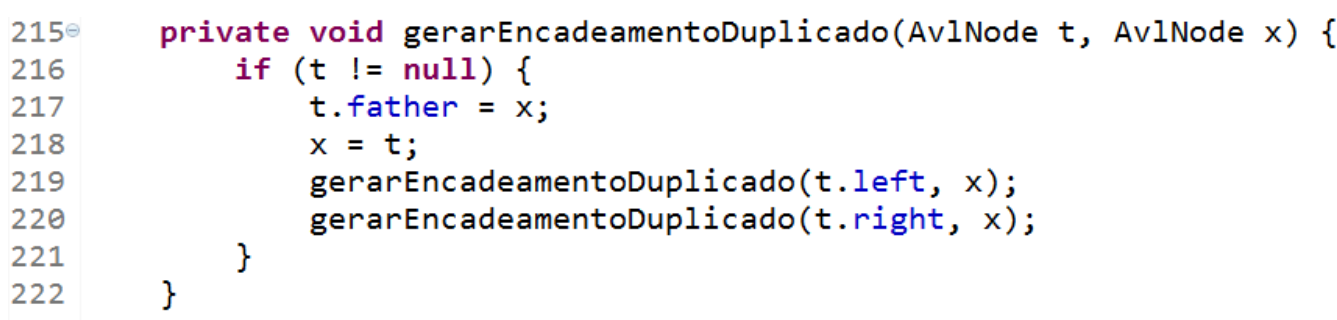

Figura 8 - Método para geração de encadeamento duplicado

\subsubsection{Folhas da árvore}

P:

Para todo elemento $p$ pertencente à árvore se a altura de $p$ for igual a zero e $p$ for diferente da raiz então o filho esquerdo de $p$ tem que ser diferente de nulo ou o filho direito de $p$ tem que ser diferente de nulo. 
EFL:

$$
\begin{gathered}
\forall p \in \text { árvore }: ?((p \rightarrow \text { height }=0) \& \&(p !=\text { root })) \\
\Rightarrow \\
((p \rightarrow \text { left } !=\text { null }) \|(p \rightarrow \text { right } !=\text { null }))
\end{gathered}
$$

AEl:

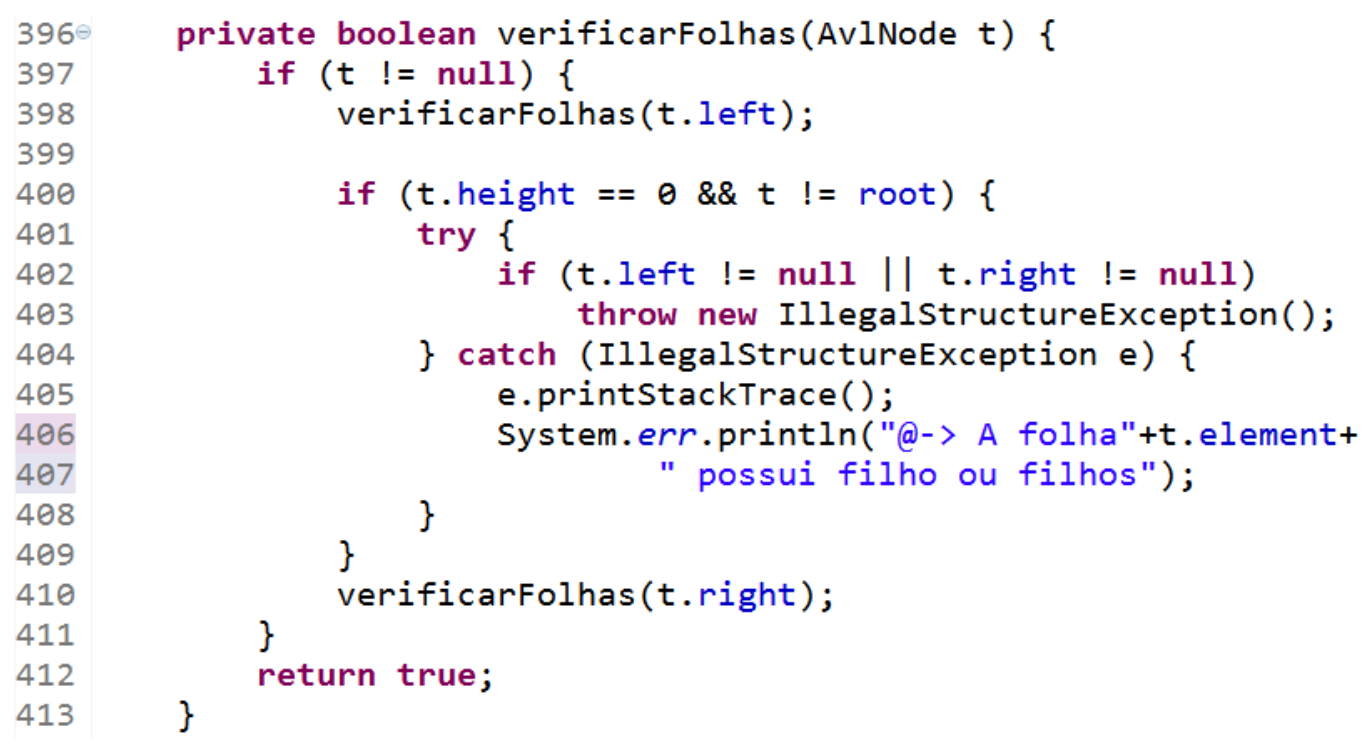

Figura 9 - Assertiva verificadora das folhas da árvore

\subsubsection{6. Árvore de Pesquisa Binária}

P:

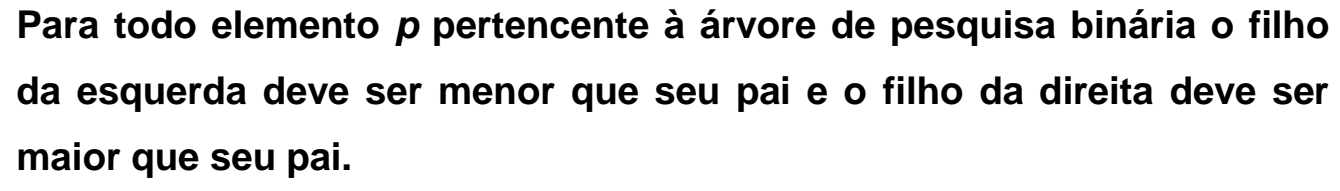


EFL:

$$
\begin{gathered}
\forall n \in \text { árvore }:(n \rightarrow \text { left } !=\text { null }) \\
\Rightarrow \\
((n \rightarrow \text { elemento })>(n \rightarrow \text { left } \rightarrow \text { elemento })) \\
\forall n \in \text { árvore }:(n \rightarrow \text { right } !=\text { null }) \\
\Longrightarrow \\
((n \rightarrow \text { elemento })<(n \rightarrow \text { right } \rightarrow \text { elemento }))
\end{gathered}
$$

AEI:

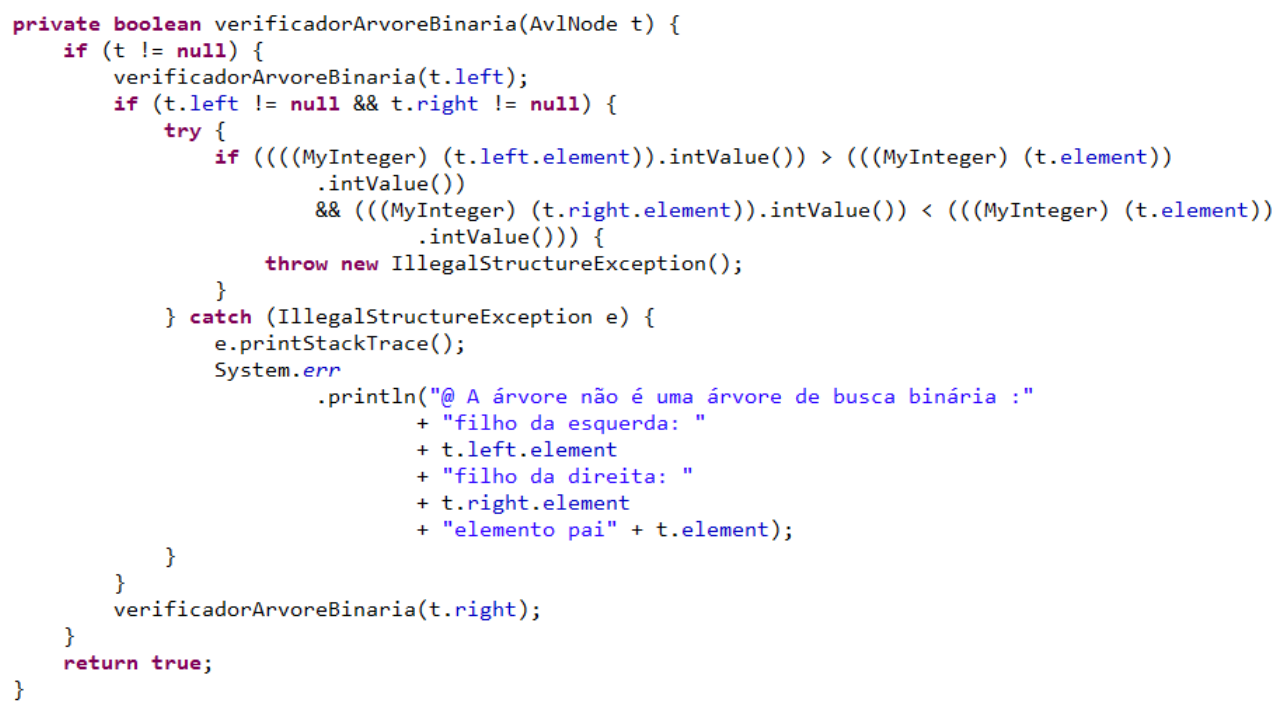

Figura 10 - Assertiva verificadora da árvore binária

\subsubsection{Número de filhos de um nó}

P:

Para todo elemento $p$ pertencente à árvore de pesquisa binária poderá possuir apenas um filho direto esquerdo e um filho direto direito. 
EFL:

$$
\begin{gathered}
\forall n \in \text { árvore }: ?(n \rightarrow \text { left } !=\text { null }) \\
\Rightarrow \\
((\operatorname{card}(n \rightarrow \text { left }) \leq 1) \& \&(\operatorname{card}(n \rightarrow \text { left }) \geq 1)) \\
\forall n \in \text { árvore }: ?(n \rightarrow \text { right } !=n u l l) \\
\Longrightarrow \\
((\operatorname{card}(n \rightarrow \text { right }) \leq 1) \& \&(\operatorname{card}(n \rightarrow \text { right }) \geq 1))
\end{gathered}
$$

\section{AEI:}

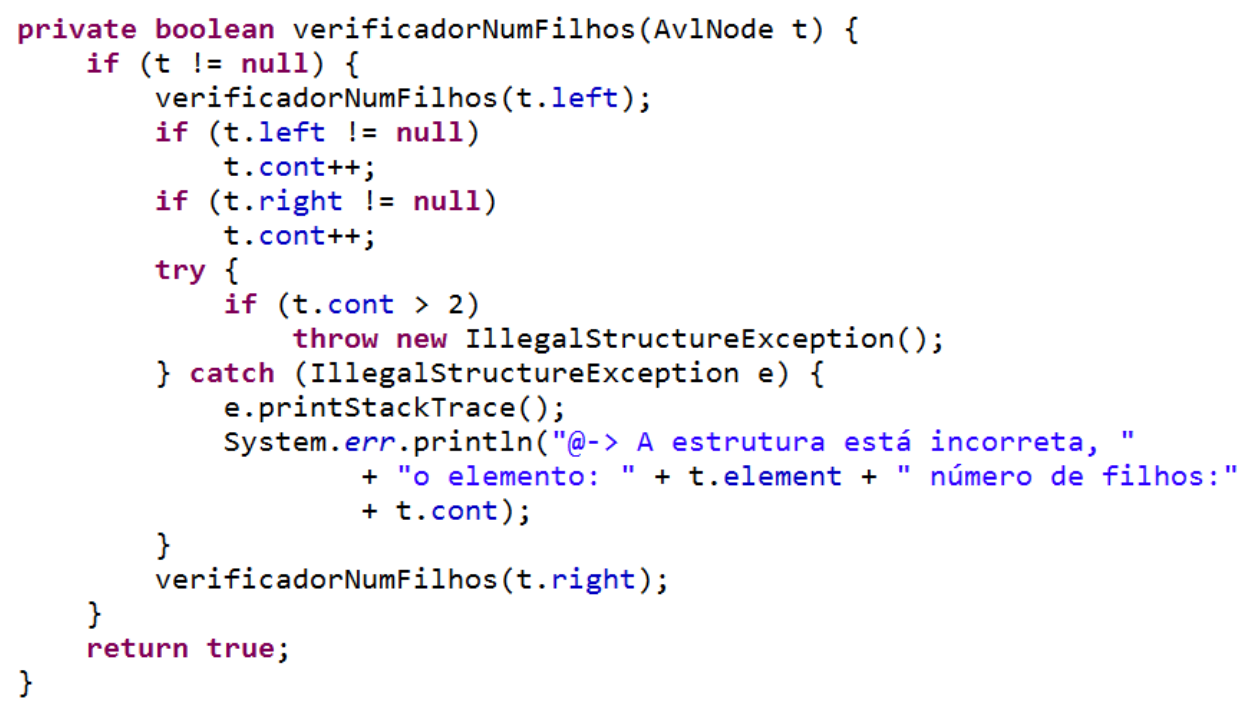

Figura 11 - Assertiva verificadora do número de filhos de um nó

\subsubsection{Assertivas pontuais}

Foram utilizadas as assertivas pontuais para possibilitar que cada método chamado tenha uma verificação de sua entrada (pré-condição), garantindo que ela seja do tipo requerido. Ainda a verificação da saída (pós-condição) é feita por meio das assertivas estruturais as quais analisam a estrutura da árvore. Caso ela se mantenha correta então a saída tende a estar correta também. Nos exemplos da Figura 12 pode ser observado que é feita uma verificação se os parâmetros de entrada dos métodos são do tipo esperado por ele. Neste exemplo deverá ser do tipo Comparable o qual é o tipo de parâmetro esperado pelos métodos demonstrados, essa verificação constitui a assertiva de entrada. Ainda as assertivas de saída verificam se a estrutura da árvore se mantém consistente, chamando o verificador estrutural. 


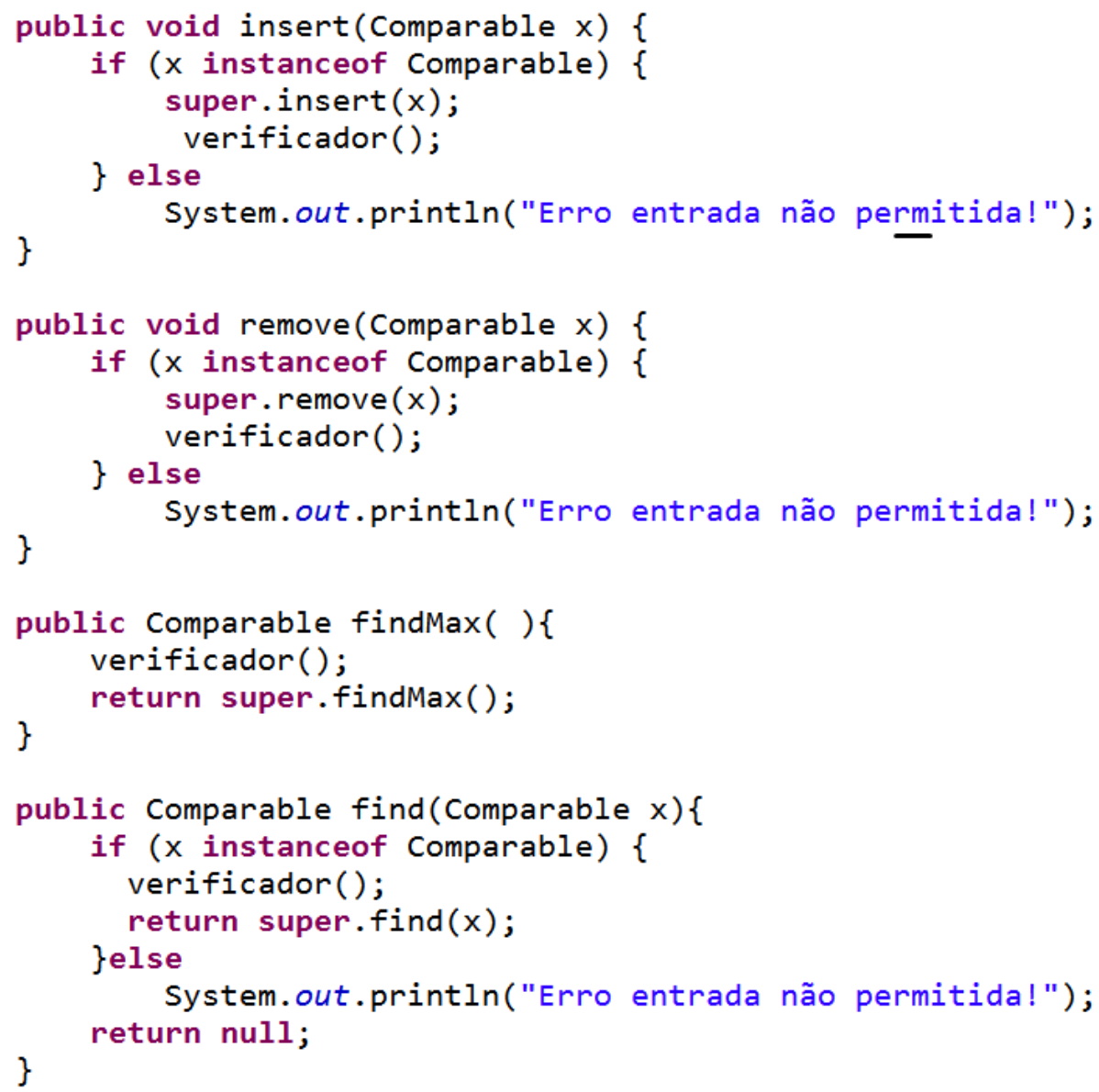

Figura 12 - Assertivas pontuais para Árvore de Pesquisa Binária

A forma em que as assertivas pontuais executáveis demonstradas na Figura 12 foram confeccionadas também se aplica as demais árvores utilizadas no experimento. Porque, mesmo que os métodos tenham implementações diferentes para as diferentes árvores demonstradas, a maneira de utilizar as assertivas pontuais foi a mesma. Portanto, elas não serão apresentadas novamente nas demais seções.

\subsubsection{Possíveis anomalias para Árvore de Pesquisa Binária}

As assertivas são capazes de observar anomalias que as estruturas poderão apresentar em uso. Abaixo é demonstrada para cada assertiva utilizada a anomalia que ela é capaz de observar. 
Tabela 2 - Possíveis tipos de anomalias para Árvore de Pesquisa Binária

\begin{tabular}{|c|c|c|}
\hline Anomalias & Descrição das anomalias & Assertivas exercitadas \\
\hline 1- Árvore vazia & $\begin{array}{l}\text { - A árvore que não teve } \\
\text { nenhum elemento } \\
\text { inserido, mas mesmo } \\
\text { assim, contém um } \\
\text { elemento. }\end{array}$ & $\begin{array}{l}\text { - 4.2.1.1- AEI (Árvore } \\
\text { sem elementos) }\end{array}$ \\
\hline $\begin{array}{l}\text { Total elements =1 } \\
\text { 2- Árvore com um } \\
\text { elemento }\end{array}$ & $\begin{array}{l}\text { - A árvore com um } \\
\text { elemento inserido, } \\
\text { porém está } \\
\text { apresentando mais de } \\
\text { um elemento. }\end{array}$ & $\begin{array}{l}\text { - 4.2.1.2 - AEI (Árvore } \\
\text { com apenas um } \\
\text { elemento) }\end{array}$ \\
\hline 3- Nós sem referência & $\begin{array}{l}\text { - A árvore não possui } \\
\text { referência para todos os } \\
\text { elementos inseridos; } \\
\text { - A raiz da árvore sem a } \\
\text { referência dos nós } \\
\text { filhos; }\end{array}$ & $\begin{array}{l}\text { - 4.2.1.3 - AEI (Árvore } \\
\text { com mais de um } \\
\text { elemento) } \\
\text { 4.2.1.4 - AEI } \\
\text { (Encadeamento da } \\
\text { árvore) }\end{array}$ \\
\hline 4- Árvore não binária & $\begin{array}{l}\text { - A árvore possui } \\
\text { elementos dispostos de } \\
\text { maneira que fere a } \\
\text { propriedade da árvore } \\
\text { binária ordenada; }\end{array}$ & $\begin{array}{l}\text { 4.2.1.6- AEI (Árvore } \\
\text { de pesquisa binária) }\end{array}$ \\
\hline $\begin{array}{l}\text { 5- Número de filhos para o } \\
\text { nó }\end{array}$ & $\begin{array}{l}\text { - A árvore possui } \\
\text { elementos dispostos de } \\
\text { maneira que fere a } \\
\text { propriedade do número } \\
\text { de filhos para cada nó; }\end{array}$ & $\begin{array}{l}\text { - 4.2.1.7- AEI (Número } \\
\text { de filhos de um) } \\
\text {-4.2.1.4- AEI } \\
\text { (Encadeamento da } \\
\text { árvore) }\end{array}$ \\
\hline
\end{tabular}

\section{3.}

Árvore AVL

Em 1962, dois matemáticos russos G. M. Adelson-Velskii e E. M. Landis criaram uma estrutura de árvore binária balanceada os quais denominaram de 
árvores AVL nome oriundo das iniciais dos seus nomes. Essa estrutura de dados foi criada para as operações de busca e de remoção possuíssem a complexidade $O(\log n)$, garantida porque árvore é balanceada automaticamente. A árvore possui um conjunto de nós ou células interligados dispostos um após o outro sendo que cada nó pode guardar a referência para no máximo dois nós sendo que um nó deve ser o filho da esquerda e outro deve ser o filho a direita. Comumente as implementações da AVL os nós também guardam informações do valor do elemento e altura (Adelson-Velskii, 1962).

A Árvore AVL apresenta todas as assertivas apresentadas para a Árvore Binária no Capítulo 4.1, pois Árvore AVL também é uma Árvore de Pesquisa Binária. Porém existem outras propriedades relativas ao balanceamento que a AVL possui, possibilitando novas assertivas que mantém a estrutura da árvore correta e consistente. Essas são apresentadas abaixo:

\subsubsection{Assertivas estruturais}

\subsubsection{Balanceamento da árvore}

P:

Para toda árvore balanceada a altura do nó à esquerda menos a altura do nó à direita deverá ser menor ou igual a uma unidade.

EFL:

$$
\begin{gathered}
\forall n \in \text { árvore }:((\mathrm{n} \rightarrow \text { left } !=\text { null }) \& \&(\mathrm{n} \rightarrow \text { right } !=\text { null })) \\
\Rightarrow \\
((n \rightarrow \text { left } \rightarrow \text { height })-(n \rightarrow \text { right } \rightarrow \text { height })) \leq 1
\end{gathered}
$$

AEI: 


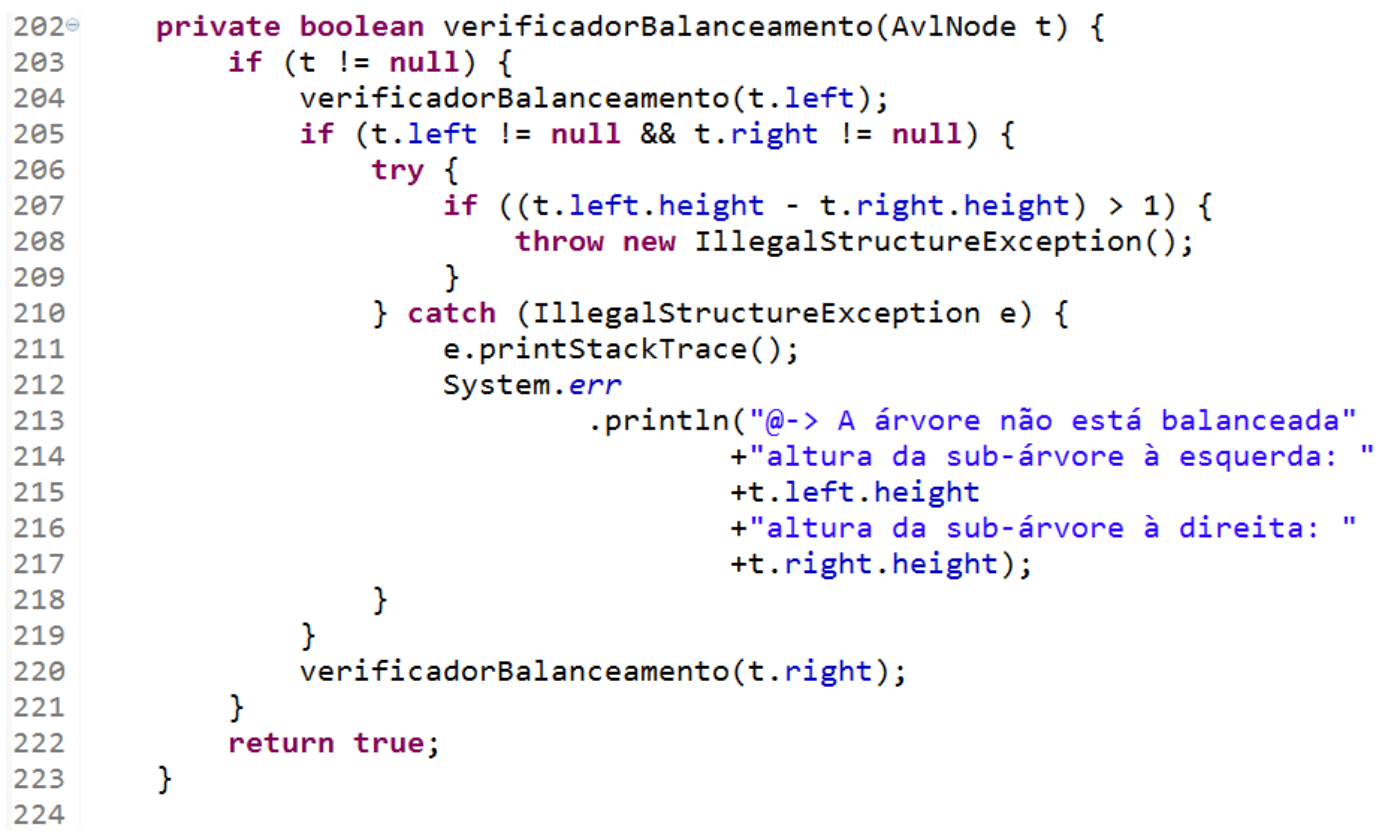

Figura 13 - Assertiva executável verificadora do balanceamento da árvore

\subsubsection{Altura da árvore}

P:

\section{Para toda árvore de pesquisa binária a altura total deve ser menor que} $1,44 \log (n+2)-1,328$

\section{EFL:}

$$
\text { heightTotal }()<1.44 \log (n+2)-1.328
$$

\section{AEI:}

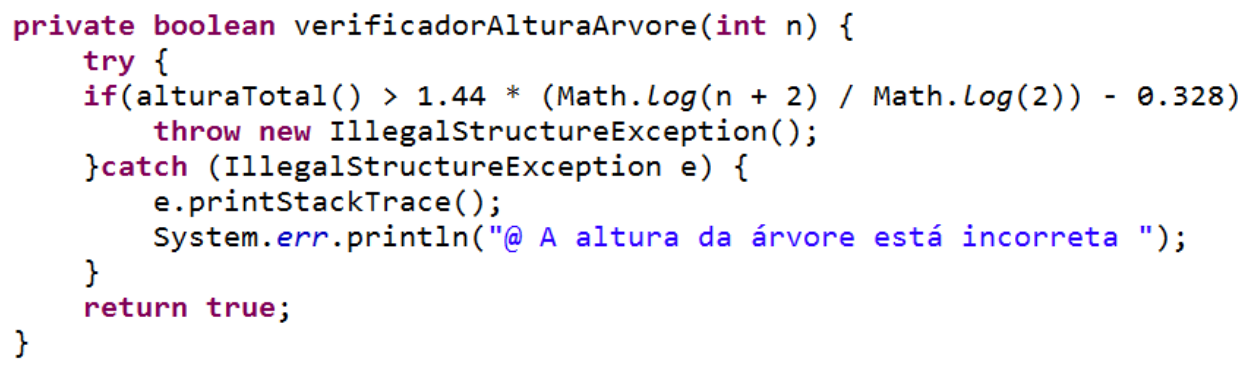

Figura 14 - Assertiva executável verificadora da altura da árvore 


\subsubsection{Anomalias}

As assertivas executáveis são capazes de observar a anomalia oriunda do balanceamento incorreto da árvore, como pode ser observado na Tabela 3. Ainda a Árvore AVL por ser uma Árvore de Pesquisa Binária é possível aplicar todas as assertivas executáveis descritas na seção 4.1 , bem como as anomalias, descritas na Tabela 2, são observadas pelo conjunto de assertivas da Árvore AVL.

Tabela 3 - Possíveis tipos de anomalias para Árvore AVL

\begin{tabular}{|c|c|c|}
\hline Anomalias & Descrição das anomalias & Assertivas exercitadas \\
\hline $\begin{array}{l}\text { 1. Altura incorreta dos } \\
\text { elementos }\end{array}$ & $\begin{array}{l}\text { - A árvore possui a altura } \\
\text { dos elementos } \\
\text { calculada de forma } \\
\text { incorreta; } \\
\text { - Elementos folhas } \\
\text { possuem a altura } \\
\text { diferente de zero; }\end{array}$ & $\begin{array}{l}\text { - 4.3.1.1- AEI (Árvore } \\
\text { balanceada) } \\
\text { - 4.2.1.5-AEI (Folhas } \\
\text { da árvore) }\end{array}$ \\
\hline
\end{tabular}

\section{4. \\ Árvore Vermelho e Preto}

A Árvore Vermelho e Preto é uma árvore de pesquisa binária que possuiu um atributo adicional que é a cor do nó, o qual pode figurar como vermelho ou preto. Por meio da forma como os nós são coloridos na árvore a propriedade do balanceamento é mantida. Assim as assertivas executáveis demonstradas nesta seção garantem a correta disposição dos elementos na árvore segundo sua cor, a fim que árvore seja balanceada corretamente.

\subsubsection{Assertivas estruturais}

\subsubsection{Cor da raiz da árvore}

P:

\section{Para todo elemento pertencente à árvore Vermelho e Preto vale se um dado elemento $\boldsymbol{n}$ for a raiz da árvore então a cor de $\boldsymbol{n}$ deverá ser preto.}




$$
\begin{gathered}
\forall n \in \text { árvoreVermelhoPreto: } ?(n==\text { root }) \\
\Rightarrow \\
(n \rightarrow \text { color }==\text { black })
\end{gathered}
$$

AEI:

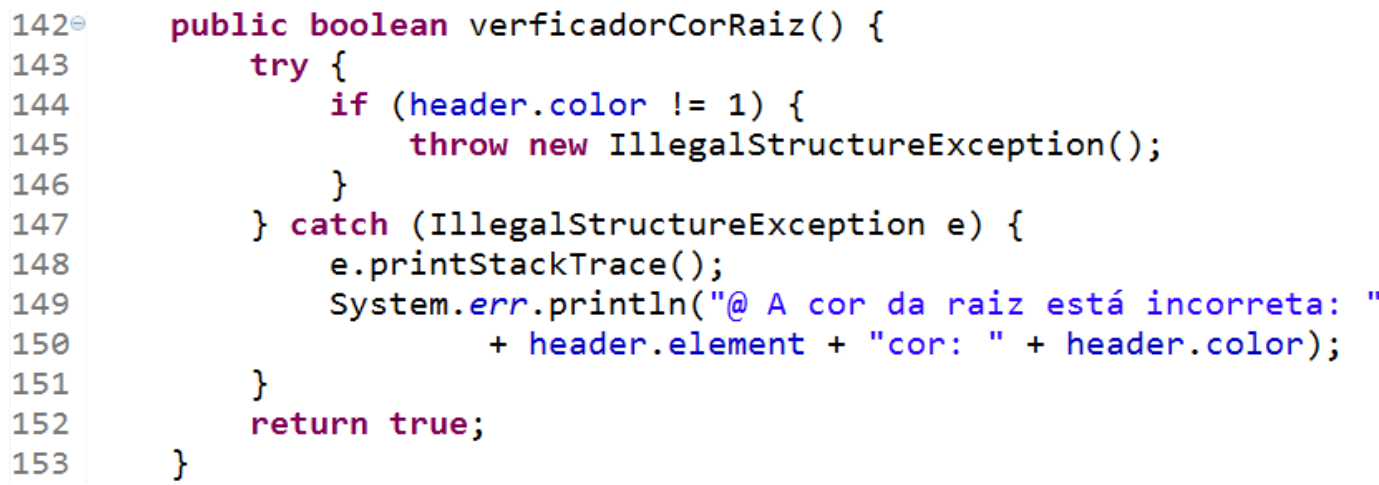

Figura 15 - Assertiva executável verificadora da cor da raiz

\subsubsection{Cor dos elementos da árvore}

P:

Para todo elemento pertencente à árvore Vermelho e Preto vale se um dado elemento $\boldsymbol{n}$ for diferente de nulo então a cor de $\boldsymbol{n}$ deverá ser igual a preto ou a cor de $\boldsymbol{n}$ deverá ser igual a vermelho.

EFL:

$$
\begin{gathered}
\forall n \in \text { árvoreVermelhoPreto: } ?(n !=\text { null }) \\
\Longrightarrow \\
((n \rightarrow \text { color }==\text { black }) \|(n \rightarrow \text { color }==\text { red }))
\end{gathered}
$$


AEI:

Figura 16 - Assertiva executável verificadora da cor dos elementos

\subsubsection{Cor das folhas}

P:

Para todo elemento pertencente à árvore Vermelho e Preto vale se um dado elemento $\boldsymbol{n}$ for uma folha então a cor de $\boldsymbol{n}$ deverá ser igual a preto.

\section{EFL:}

$$
\begin{gathered}
\forall \boldsymbol{n} \in \text { árvoreVermelhoPreto: } ?(\boldsymbol{n}==\text { leaf }) \\
\Rightarrow \\
(n \rightarrow \text { color }==\text { black })
\end{gathered}
$$




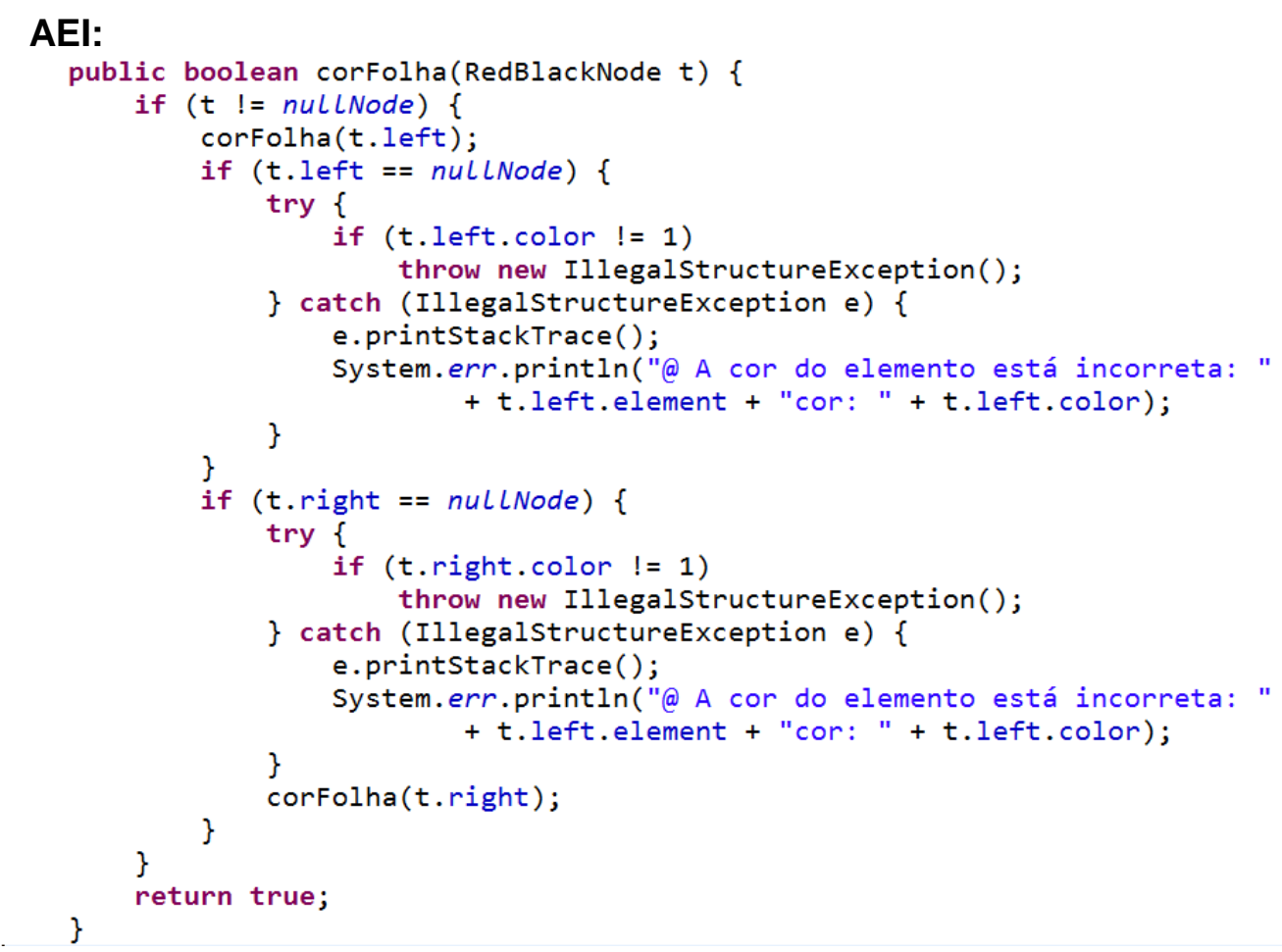

Figura 17 - Assertiva executável verificadora da cor das folhas

\subsubsection{Cor dos filhos de um nó vermelho}

P:

Para todo elemento pertencente à árvore Vermelho e Preto vale se a cor e de $\boldsymbol{n}$ for igual a vermelho então o filho esquerdo de $\boldsymbol{n}$ e o filho direito de $n$ ambos deverão ser de cor preta.

EFL:

$$
\begin{gathered}
\forall n \in \text { árvoreVermelhoPreto: } ?(n \rightarrow \text { color }==\text { red }) \\
\Rightarrow \\
((\mathrm{n} \rightarrow \text { left } \rightarrow \text { color }==\text { black }) \& \&(n \rightarrow \text { right } \rightarrow \text { color }==\text { black }))
\end{gathered}
$$




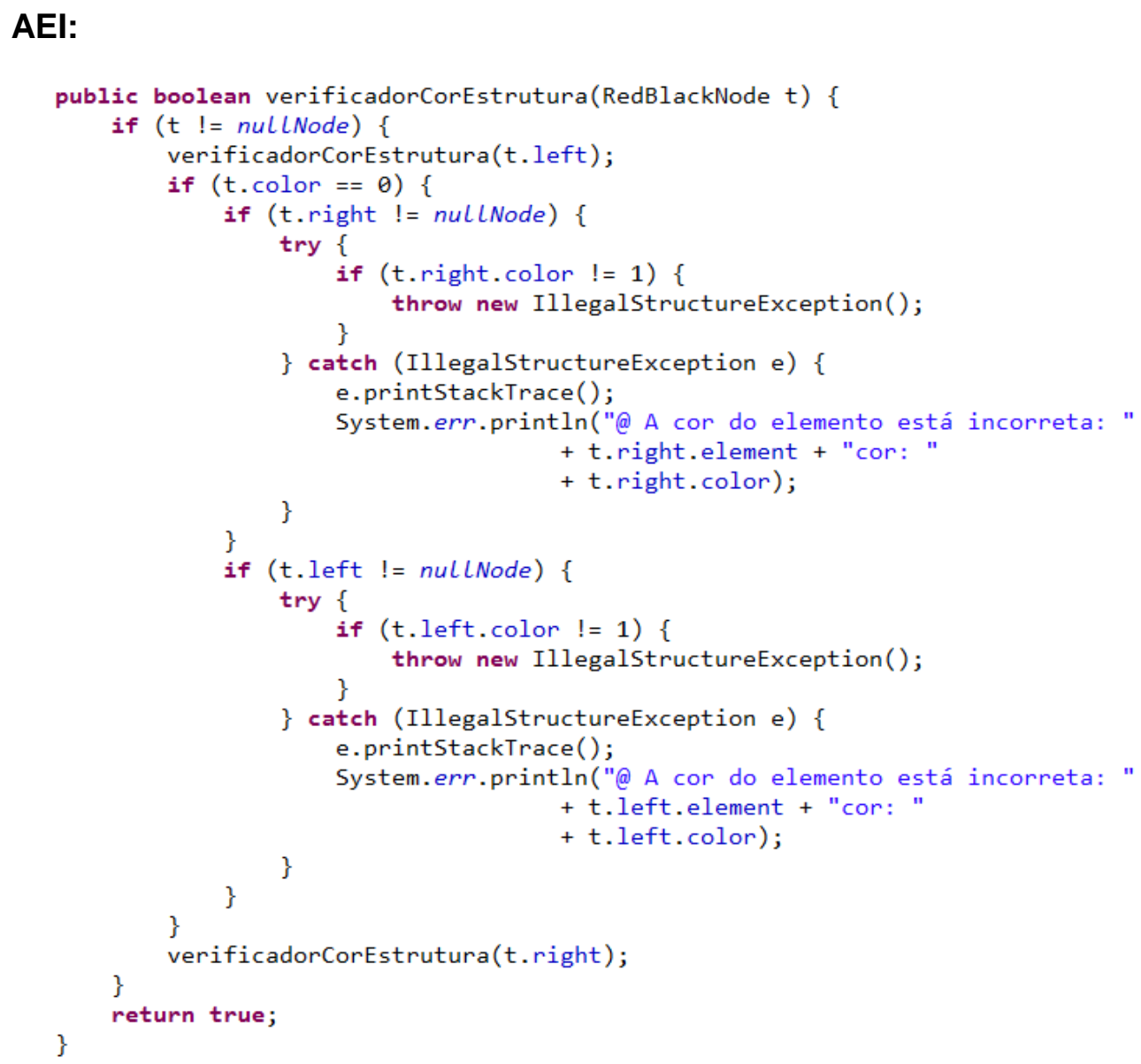

Figura 18 - Assertiva executável verificadora da cor dos nós filhos

\subsubsection{Quantidade de elementos pretos no caminho}

P:

Para cada nó, todos os caminhos desde nó até as folhas descendentes contêm o mesmo número de nós pretos.

Essa regra assegura uma propriedade crítica da árvore Vermelho e Preto que o caminho mais longo da raiz a qualquer folha não seja maior do que duas vezes o caminho mais curto da raiz a qualquer outra folha naquela árvore. Essa propriedade garante o balanceamento da Árvore Vermelho e Preto. 
EFL:

$$
\begin{gathered}
\forall r, s, t, u \in \text { árvoreVermelhoPreto }: ? \\
(((B(r, t)>0) \& \&(B(s, t)>0) \& \&(t==\text { leaf }) \& \&(u !=\text { leaf }))) \\
\Longrightarrow \\
(B(r, t)==B(s, t) \& \&(B(r, t) !=B(r, u) \& \&(B(s, t) !=B(s, u))
\end{gathered}
$$

Sendo $B(x, y)$ o número de elementos de cor preta no caminho entre os nós $x, y$.

\section{AEI:}

Para a implementação dessa assertiva foi necessário criar três métodos adicionais para que seja feita uma busca em profundidade para cada nó da árvore a fim de serem contados os nós pretos de todos os caminhos de cada nó até ao nó folha. O primeiro método "inicilazaNo" demonstrado na Figura 19 inicializa para cada nó da árvore o atributo isVisitado como false. O segundo método "chamaDFS" demonstrado na Figura 21 chama a busca em profundidade para os nós pelos quais não foi realizada a contagem dos nós pretos do caminho. O terceiro método "buscaEmProfundidade" demonstrado na Figura 22 conta efetivamente todos os nós pretos do caminho de um dado nó até a folha.

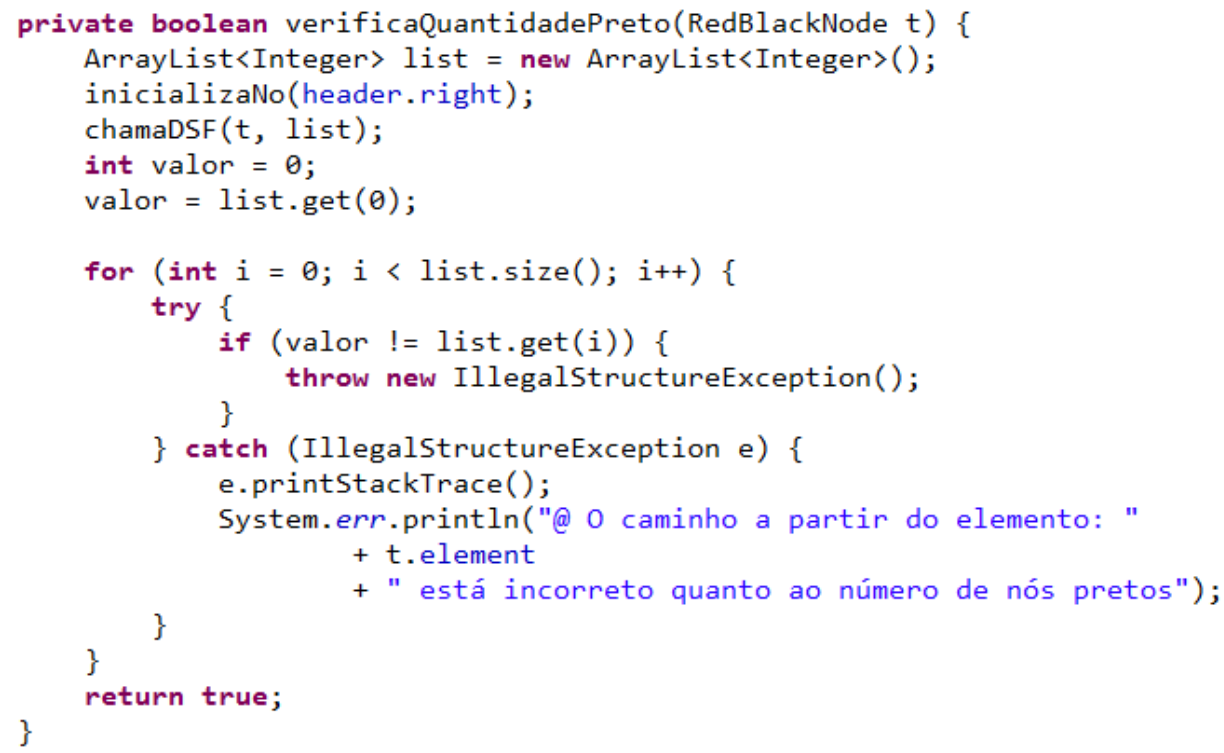

Figura 19 - Assertiva executável verificadora da quantidade de nós pretos 


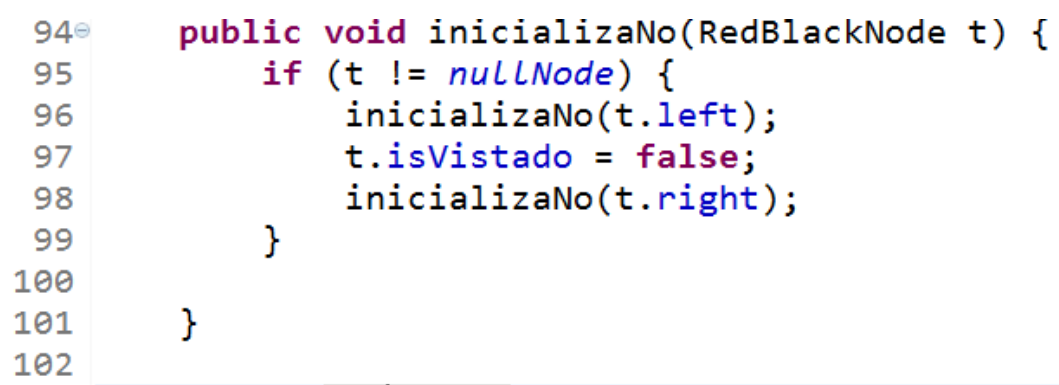

Figura 20 - Método para inicialização dos nós da árvore

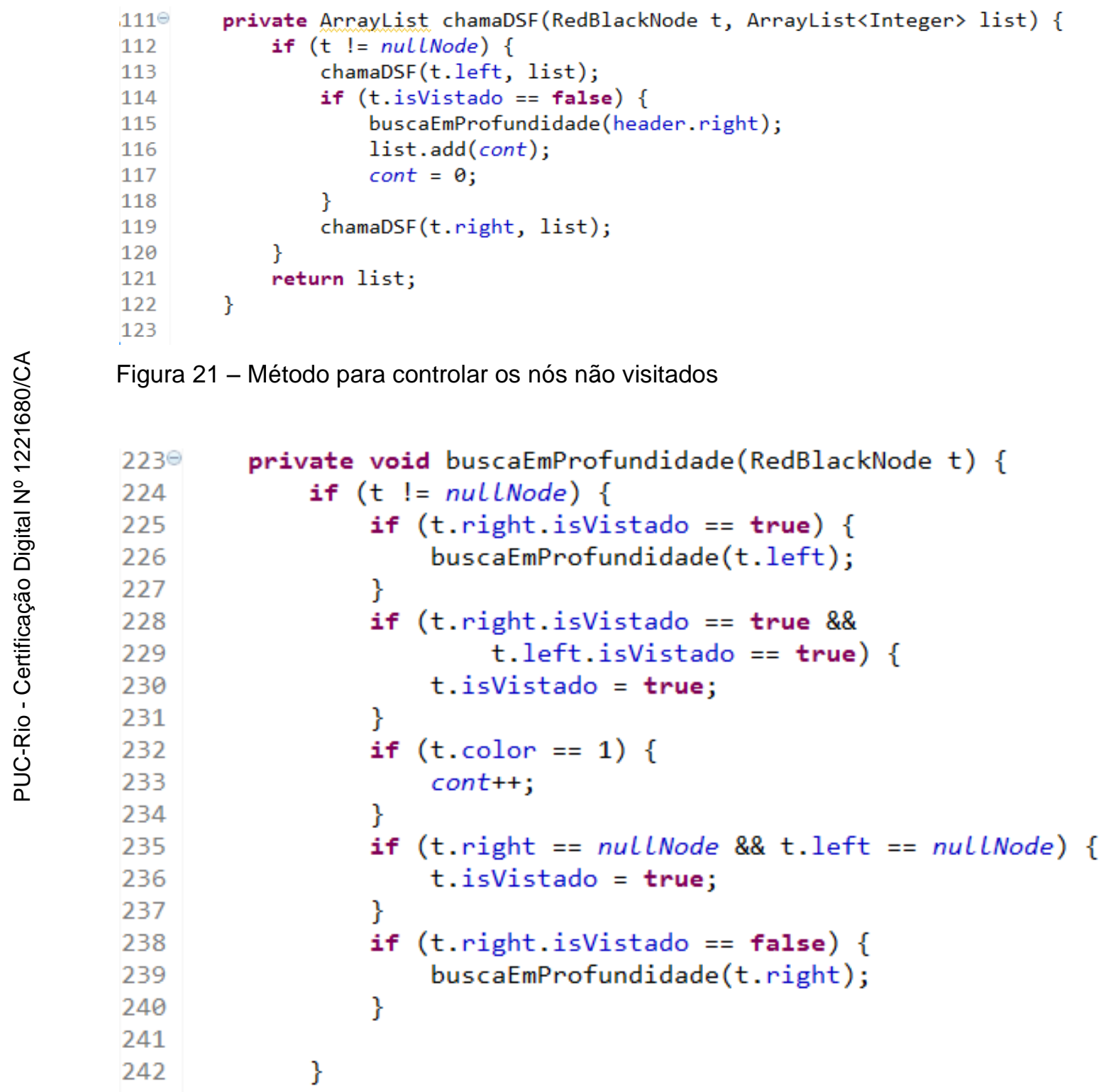

Figura 22 - Método para contar os nós pretos encontrados 


\subsubsection{Possíveis anomalias para Árvore Vermelho e Preto}

Tabela 4 - Possíveis tipos de anomalias para Árvore Vermelho e Preto

\begin{tabular}{|c|c|c|}
\hline Anomalias & Descrição das anomalias & Assertivas exercitadas \\
\hline & $\begin{array}{l}\text { - Caso a raiz da árvore } \\
\text { não tenha sido } \\
\text { inicializada com a cor } \\
\text { preta. }\end{array}$ & $\begin{array}{l}\text { - 4.4.1.1- AEI (Cor da } \\
\text { raiz da árvore) }\end{array}$ \\
\hline $\begin{array}{l}\text { 2- Nó que não seja preto } \\
\text { nem vermelho }\end{array}$ & $\begin{array}{l}\text { - Caso algum elemento } \\
\text { da árvore não tenha } \\
\text { sido inicializado com a } \\
\text { cor vermelho ou preta. } \\
\text { Neste caso a assertiva } \\
5.4 .1 .4 \text { não poderia } \\
\text { observar, pois o pai tem } \\
\text { a cor preta e não } \\
\text { vermelha. }\end{array}$ & $\begin{array}{r}\text { - 4.4.1.2-AEI (Cor dos } \\
\text { elementos da árvore) }\end{array}$ \\
\hline $\begin{array}{l}\text { 3- Filho de um nó vermelho } \\
\text { que também seja } \\
\text { vermelho }\end{array}$ & $\begin{array}{l}\text { - Caso algum filho de um } \\
\text { nó de cor vermelha } \\
\text { tenha um filho que } \\
\text { também seja de cor } \\
\text { vermelha. }\end{array}$ & $\begin{array}{l}\text { - 4.4.1.4-AEI (Cor dos } \\
\text { filhos de um nó } \\
\text { vermelho) } \\
\text { - 4.4.1.3-AEI (Cor das } \\
\text { folhas) }\end{array}$ \\
\hline $\begin{array}{l}\text { 4- Somatório de nós pretos } \\
\text { no caminho }\end{array}$ & $\begin{array}{l}\text { - A árvore possui } \\
\text { elementos dispostos de } \\
\text { maneira que fere a } \\
\text { propriedade de que } \\
\text { cada nó, todos os } \\
\text { caminhos desde um nó } \\
\text { até as folhas } \\
\text { descendentes contêm o } \\
\text { mesmo número de nós } \\
\text { pretos; }\end{array}$ & $\begin{array}{l}\text { - 4.4.1.5 -AEI } \\
\text { (Quantidade de } \\
\text { elementos pretos no } \\
\text { caminho) }\end{array}$ \\
\hline
\end{tabular}




\section{5.}

\section{Árvore AA}

O nome da Árvore de AA é oriundo das iniciais do seu inventor Arne Anderson é uma forma de árvore balanceada com uma implementação mais simples comparada a Árvore Vermelho e Preto, porém com desempenho próximo de serem similares. A facilidade de implementação é porque ela possui apenas duas formas chamadas Skew e Split para árvore manter a propriedade do balanceamento, menor que o número da Árvore Vermelho e Preto que considerada sete formas diferentes (Andersson, 1993).

A Árvore AA apresenta todas as assertivas apresentadas para a Árvore Binária no Capítulo 4.1, pois a Árvore AA também é uma Árvore de Pesquisa Binária. Porém existem outras propriedades relativas ao balanceamento que a Árvore AA possui que necessita de novas assertivas executáveis para manter a estrutura da árvore correta e consistente. Essas são apresentadas abaixo:

\subsubsection{Assertivas estruturais}

\subsubsection{Nível do filho à esquerda de um nó}

P:

Para todo elemento pertencente à Árvore AA vale se o filho esquerdo de $\boldsymbol{n}$ for diferente de nulo então, o nível do filho esquerdo de $\boldsymbol{n}$ menos uma unidade deverá ser igual ao nível de $\boldsymbol{n}$.

EFL:

$$
\begin{gathered}
\forall n \in \text { árvore } A A: ?(n \rightarrow \text { left } !=\text { null }) \\
\Longrightarrow \\
((n \rightarrow \text { left } \rightarrow \text { level }-1)==(n \rightarrow \text { level }))
\end{gathered}
$$




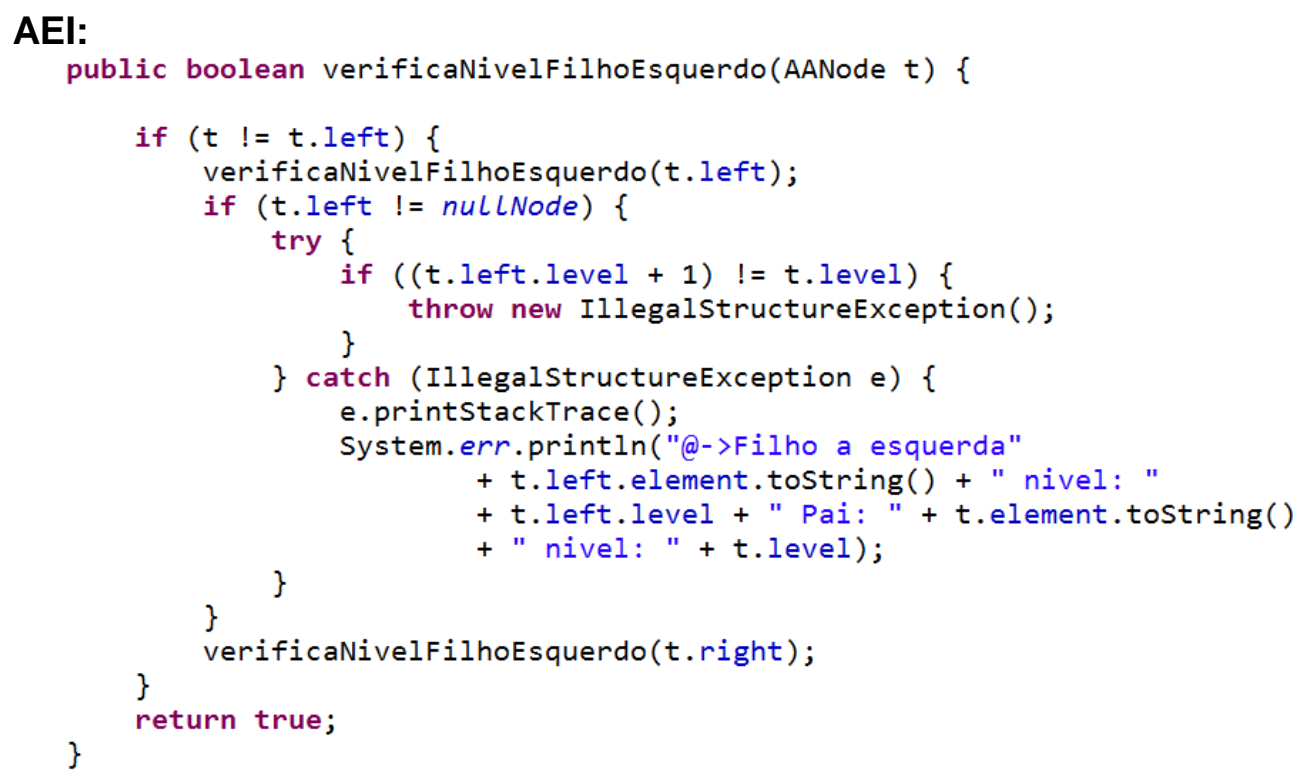

Figura 23 - Assertiva executável verificadora do nível do filho à esquerda

\subsubsection{Nível do filho à direita de um nó}

P:

Para todo elemento pertencente à Árvore AA vale se o filho direito de $\boldsymbol{n}$ for diferente de nulo então, o nível do filho direito de $\boldsymbol{n}$ menos uma unidade deverá ser igual ao nível de $\boldsymbol{n}$ ou o filho direito de $\boldsymbol{n}$ deverá ser igual ao nível de $n$.

EFL:

$$
\begin{gathered}
\forall \mathrm{n} \in \text { árvore AA: } ?(\mathrm{n} \rightarrow \text { right } !=\text { null }) \\
\Rightarrow \\
((\mathrm{n} \rightarrow \text { right } \rightarrow \text { level }-1)==(\mathrm{n} \rightarrow \text { level })) \| \\
((n \rightarrow \text { right } \rightarrow \text { level })==(n \rightarrow \text { level }))
\end{gathered}
$$




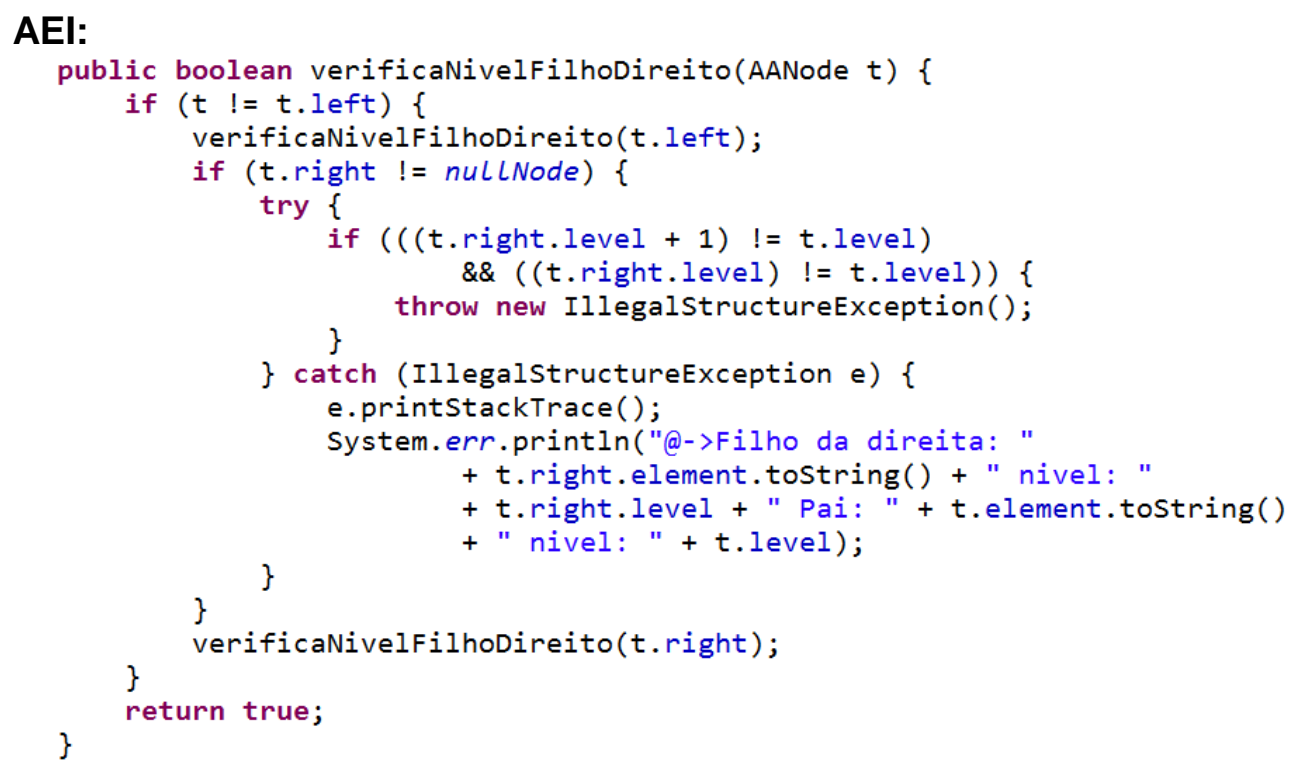

Figura 24 - Assertiva executável verificadora do nível do filho à direita

\subsubsection{Possíveis anomalias para Árvore AA}

As assertivas executáveis apresentadas são capazes de observar a anomalia oriunda do balanceamento incorreto da árvore, como pode ser observado na Tabela 5. Ainda para Árvore AA podem ser aplicadas todas as assertivas executáveis descritas na seção 4.1 , bem como as anomalias descritas na Tabela 2 são observadas pelo conjunto de assertivas da Árvore AA.

Tabela 5 - Possíveis tipos de anomalias para Árvore AA

\begin{tabular}{|c|c|c|}
\hline Anomalias & $\begin{array}{c}\text { Descrição das } \\
\text { anomalias }\end{array}$ & $\begin{array}{l}\text { Assertivas } \\
\text { exercitadas }\end{array}$ \\
\hline $\begin{array}{lll}\text { Level }=1 & \text { Level=1 } \\
\text { 1- Nível do filho à esquerda }\end{array}$ & $\begin{array}{l}\text { - A árvore possui uma } \\
\text { subárvore à esquerda } \\
\text { com um nó de mesmo } \\
\text { nível do nó pai. }\end{array}$ & $\begin{array}{l}\text { - 4.5.1.1 - AEI (Nível } \\
\text { do filho à esquerda } \\
\text { de um nó) }\end{array}$ \\
\hline 2- Nível do filho à direita & $\begin{array}{l}\text { - A árvore possui a } \\
\text { subárvore à direita um } \\
\text { nó com um nível } \\
\text { acima do nó pai. }\end{array}$ & $\begin{array}{l}\text { - 4.5.1.2 - AEI (Nível } \\
\text { do filho à direita de } \\
\text { um nó) }\end{array}$ \\
\hline
\end{tabular}




\section{6. \\ Árvore Splay}

A Árvore Splay é uma árvore binária auto-ajustável que não usa regras explícitas para forçar o balanceamento como as demais árvores apresentadas. Segundo Sleator e Tarjan (1985) as árvores balanceadas não são tão eficientes quando os nodos da árvore são acessados sequencialmente. Já a Àrvore Splay ajusta a sua estrutura à frequência de acesso aos dados. Assim ela tenta minimizar o número de operações na sua estrutura colocando os nós mais frequentemente acessados mais perto da raiz, o que faz com que eles sejam acessados mais rapidamente. Aplica-se uma operação de mover para a raiz, chamada de splaying a cada acesso, para manter essa propriedade é utilizada a assertiva executável abaixo demonstrada (seção 4.6.1).

\subsubsection{Assertivas estruturais}

\subsubsection{Elemento da raiz}

P:

Para todo elemento pertencente à Árvore Splay depois dele ser encontrado deverá figurar como raiz da árvore.

EFL:

$$
\begin{gathered}
\forall n \in \text { árvoreSplay: } ?(\text { find }(n)==\text { True }) \\
\Rightarrow \\
(\text { root }==n)
\end{gathered}
$$




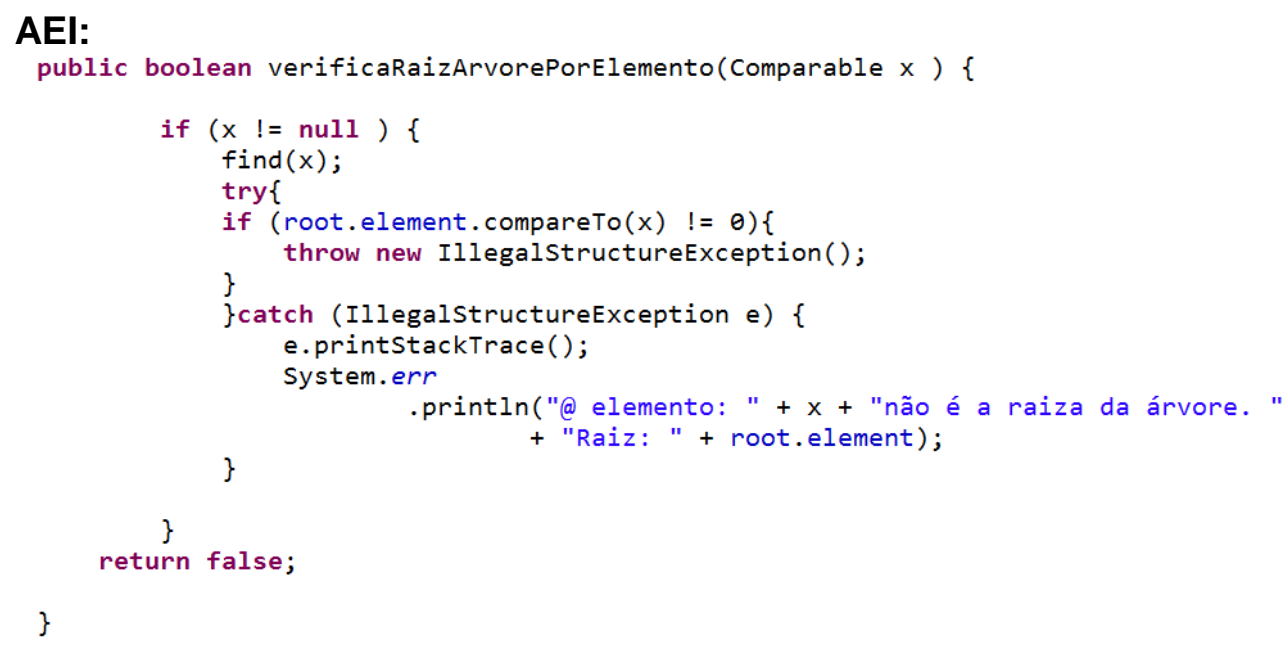

Figura 35 - Assertiva executável verificadora do ajuste da Árvore Splay

\subsubsection{Possíveis anomalias para Árvore Splay}

Tabela 6 - Possíveis tipos de anomalias para Árvore Splay

\begin{tabular}{|c|c|c|}
\hline Anomalias & $\begin{array}{c}\text { Descrição das } \\
\text { anomalias }\end{array}$ & $\begin{array}{l}\text { Assertivas } \\
\text { exercitadas }\end{array}$ \\
\hline ת & $\begin{array}{l}\text { - Caso o elemento que } \\
\text { tenha sido pesquisado } \\
\text { não ser movido para a } \\
\text { raiz da árvore; }\end{array}$ & $\begin{array}{l}\text { - 4.6.1.1- AEI } \\
\text { (Elemento da raiz) }\end{array}$ \\
\hline $\begin{array}{l}\text { 1- Elemento encontrado não } \\
\text { figura na raiz da árvore }\end{array}$ & & \\
\hline
\end{tabular}

4.7.

Árvore B

A Árvore B é uma árvore de pesquisa binária e balanceada que ao contrário das demais, árvores de pesquisa binária demonstradas neste trabalho, pode ter nós que tenham muitos filhos com número variável. Segundo Cormen (2002) o fator de ramificação de uma Árvore B pode ser muito grande, muito maior do que a Árvore Vermelho e Preto, e com a altura consideravelmente menor do que elas. As Árvores B podem ser utilizadas para trabalhar com dispositivos de armazenamento secundário como discos magnéticos bem como 
para implementar muitas operações sobre conjuntos dinâmicos em tempo $O(\lg n)$.

\subsubsection{Assertivas estruturais}

\subsubsection{Limite superior sobre o número de filhos de um nó}

P:

Para nó pertencente à Árvore B pode conter no máximo $2 t$ - 1 chaves e o nó interno no máximo $2 t$ chaves

EFL:

$\forall n \in$ árvore $B$ :

$((n \rightarrow$ Keys $\rightarrow$ lenght $<2 * t-1) \& \&(n \rightarrow$ child $\rightarrow$ lenght $<2 * t))$

AEI:

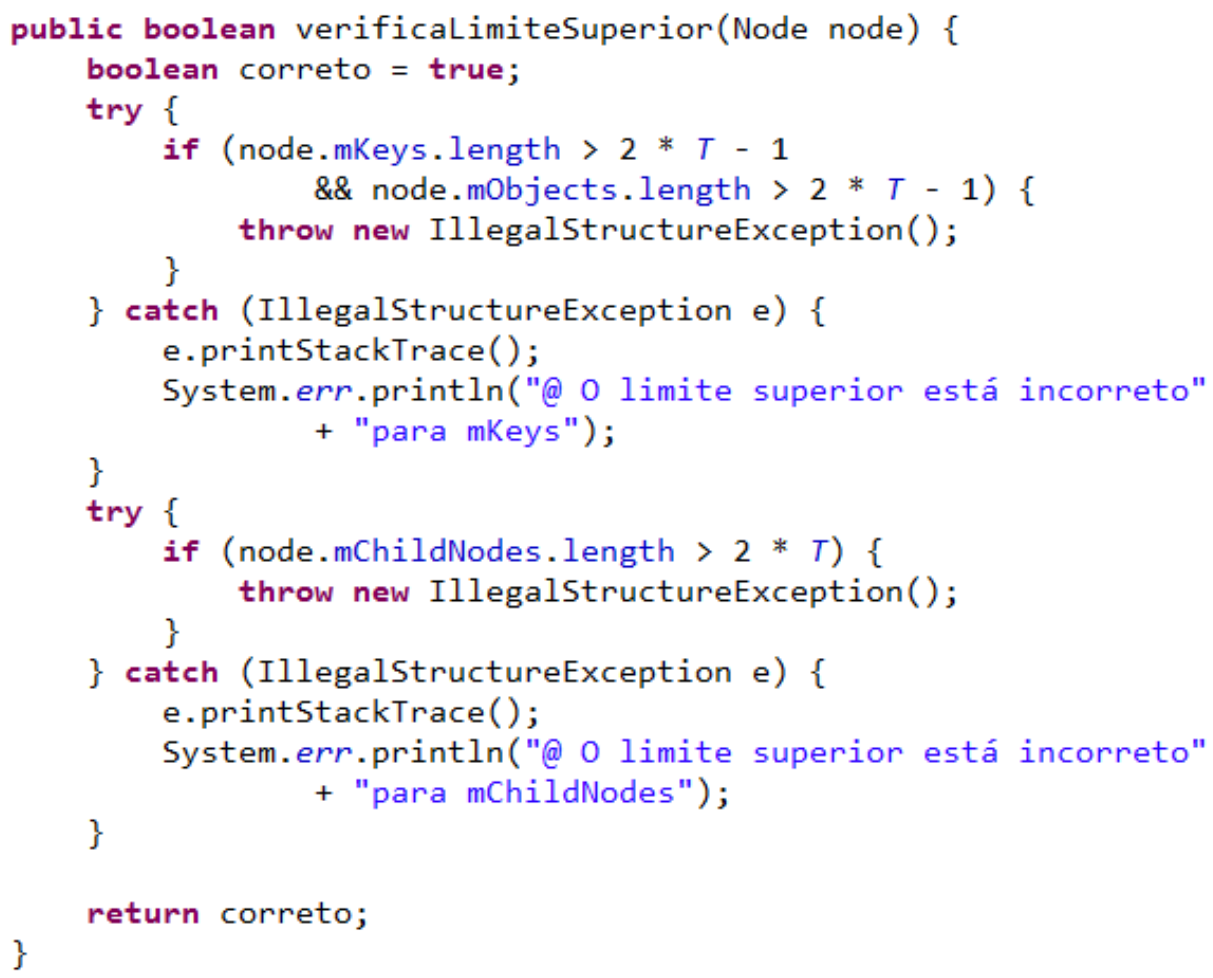

Figura 26 - Assertiva verificadora do limite superior 


\subsubsection{Nós internos e folhas}

P:

\section{Para todo elemento pertencente à árvore B se o nó é uma folha então} ele não poderá ser um nó interno.

\section{EFL:}

$\forall n \in$ árvore $B: ?(n==$ leaf $) \Rightarrow$ (node $\rightarrow$ mIsLeafNode $==$ true $)$

$\forall n \in$ árvore $B: ?(n==$ childNode $) \Rightarrow$ (node $\rightarrow$ mIsLeafNode $==$ false $)$

AEl:

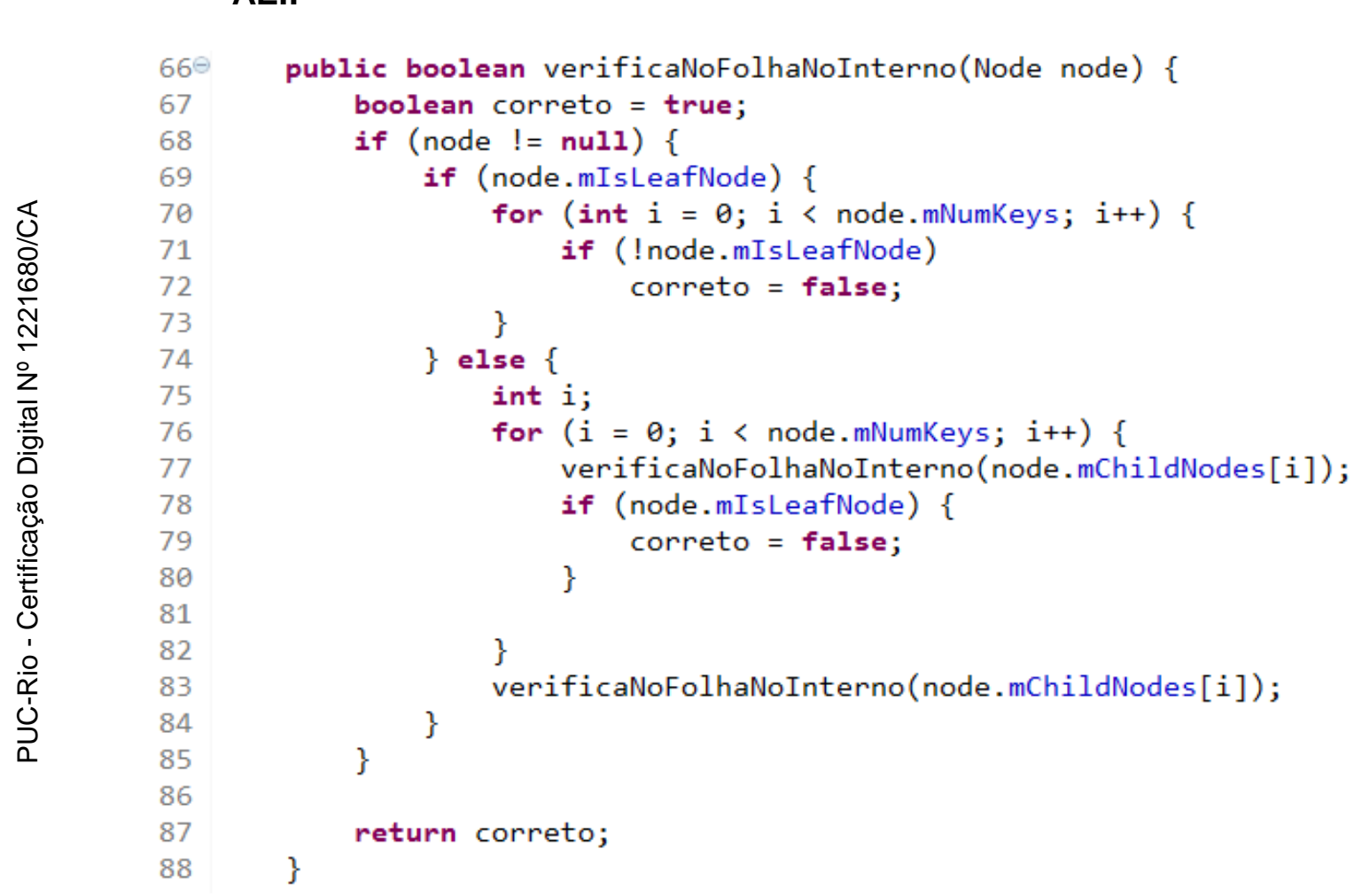

Figura 27 - Assertiva executável verificadora das chaves da Árvore B 


\subsubsection{Possíveis anomalias para Árvore B}

Tabela 7 - Possível tipo de anomalia para Árvore B

\begin{tabular}{|c|c|c|}
\hline Anomalias & $\begin{array}{c}\text { Descrição das } \\
\text { anomalias }\end{array}$ & $\begin{array}{l}\text { Assertivas } \\
\text { exercitadas }\end{array}$ \\
\hline $\begin{array}{l}\text { * } \mathrm{A} * \mathrm{~B} * \mathrm{C} * \mathrm{~A}^{*} \mathrm{~B} * \\
\text { Elemento encontrado não } \\
\text { figura na raiz da árvore }\end{array}$ & $\begin{array}{l}\text { - A capacidade que o } \\
\text { nó pode ter de filhos } \\
\text { foi estourada no filho } \\
\text { da esquerda; }\end{array}$ & $\begin{array}{l}\text { 4.7.1.1- AEI } \\
\text { (Limite superior } \\
\text { sobre o número de } \\
\text { filhos de um) }\end{array}$ \\
\hline
\end{tabular}

\section{8.}

\section{Heap binária}

Uma Heap Binária e uma estrutura de prioridades na forma de árvore binária balanceada. Inicialmente concebida por Vuillemin onde apresentou um algoritmo para a manipulação de filas de prioridade, em uma estrutura de dados que associa cada valor contido em um conjunto a uma chave (Vuillemin, 1978). A Heap Binária deve ser uma árvore que todos os níveis devem estar completos e o último nível deve armazenar os nós na ordem da esquerda para a direita.

Ainda ela poderá ser uma Heap Máximo onde o pai deverá ser sempre maior que os filhos e Heap Mínimo onde os filhos são maiores que o pai. Essas propriedades são descritas na forma de assertiva para a heap binária e deve se manter consistente em todo tempo de uso dessa estrutura.

\subsubsection{Assertivas estruturais}

\subsubsection{Filhos maiores que os pais}

P:

Para todo nó pertencente à Heap Binária os filhos de um dado nó devem ser maiores que esse nó na Heap Mínimo. 
EFL:

$$
\begin{gathered}
\forall n \in \text { heapBinária: } ?(n \rightarrow \text { children } !=\text { null }) \\
\Longrightarrow \\
(n \rightarrow \text { children } \rightarrow \text { elements })<(n \rightarrow \text { elements })
\end{gathered}
$$

AEI:

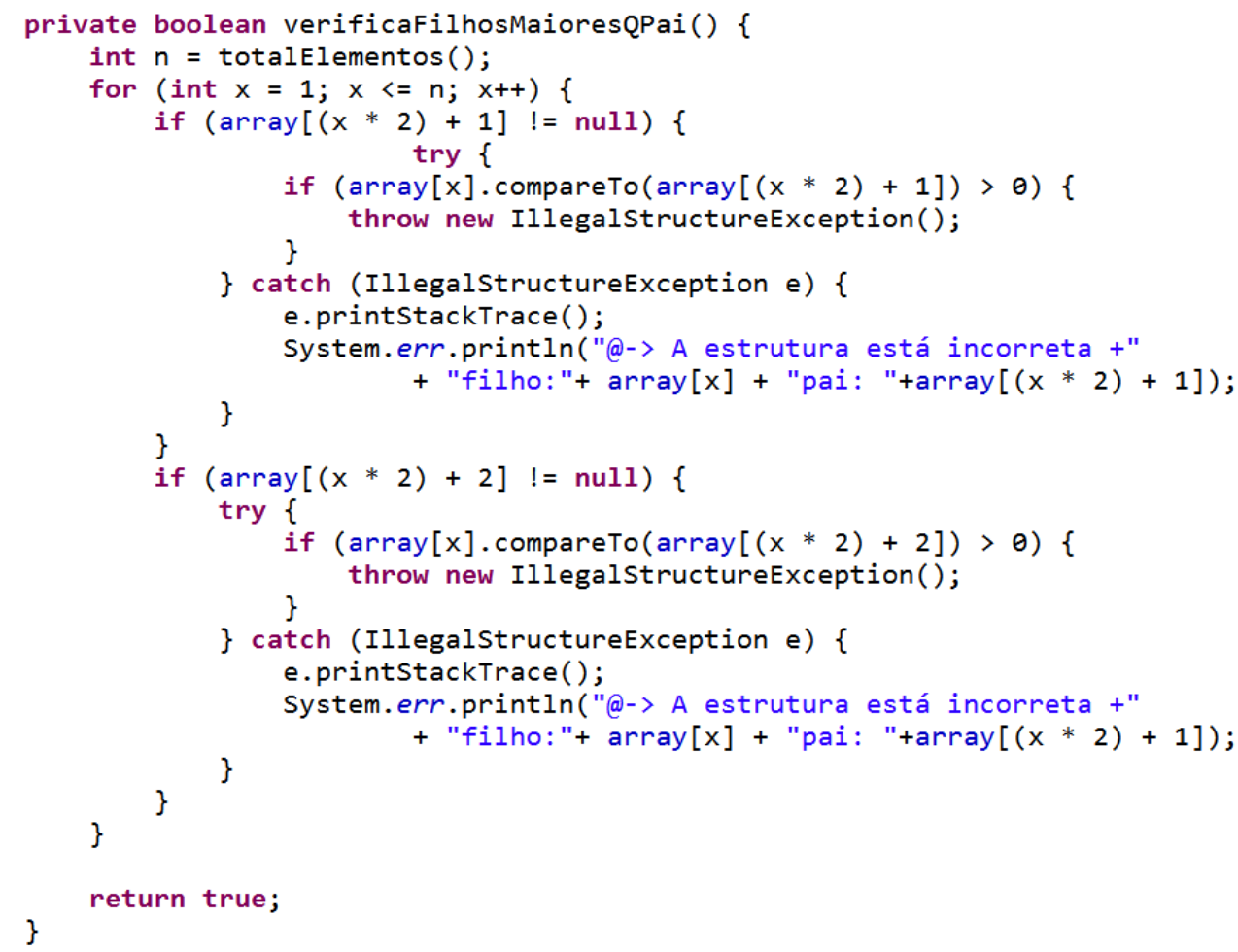

Figura 28 - Assertiva executável verificadora da Heap Mínimo

\subsubsection{Heap Binária completa}

P:

Para todo elemento pertencente à Heap Binária se o filho direito for diferente de nulo o filho esquerdo obrigatoriamente deverá ser diferente de nulo. 
EFL:

$$
\begin{gathered}
\forall n \in \text { HeapBinária: } ?(n \rightarrow \text { Right } !=\text { null }) \\
\Longrightarrow \\
(n \rightarrow \text { left } !=\text { null })
\end{gathered}
$$

AEI:

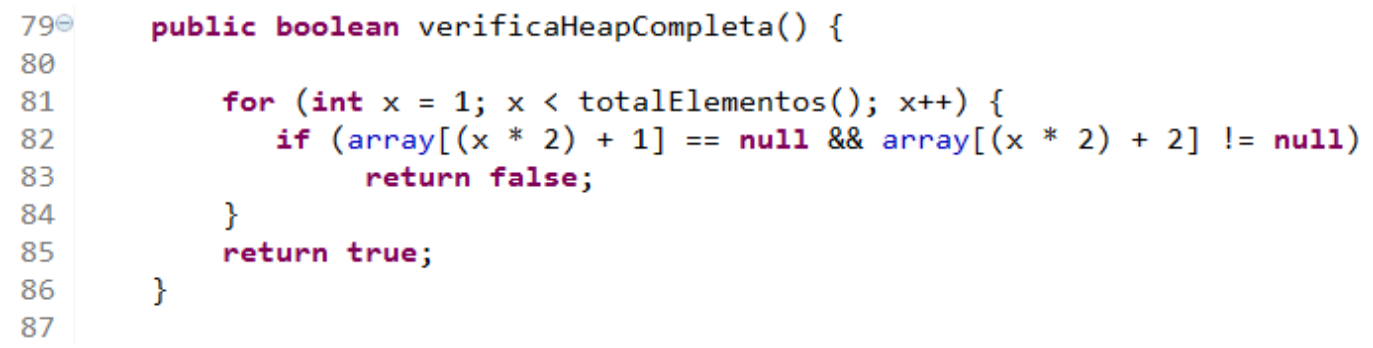

Figura 29 - Assertiva executável verificadora da alocação dos nós na Heap

\subsubsection{Possíveis anomalias para Heap Binária}

Tabela 8 - Possíveis tipos de anomalias para Heap Binária

\begin{tabular}{|c|l|c|}
\hline 1- Heap Mínimo & Descrição das anomalias & \multicolumn{1}{c|}{$\begin{array}{c}\text { Assertivas } \\
\text { exercitadas }\end{array}$} \\
\hline
\end{tabular}




\section{9.}

\section{Heap Leftist}

A Leftist Heap é uma heap binária em que, diferente das heaps mais comuns, a árvore não necessariamente é completa. Ela tem a propriedade de ser mais profunda do lado esquerdo, ou seja, ela tem subárvores esquerdas maiores do que às direitas. Para essa heap também se aplica a assertiva executável descrita na seção 5.8.1.1 Filhos maiores que os pais e não se aplica da seção 5.8.1.2, pois a leftist heap não é completa. Porém para manter sua característica que qualquer subárvore esquerda seja maior que a subárvore direita é apresentada ainda a assertiva executável do Caminho nulo.

\subsubsection{Assertivas estruturais}

\subsubsection{Caminho nulo da Heap Leftist}

P:

Caminho nulo da subárvore esquerda tem que ser maior ou igual ao caminho nulo da subárvore direita

Sendo o caminho nulo de uma árvore definido como o tamanho do menor caminho entre a raiz da árvore e um nó externo.

EFL:

$$
\forall n \in \text { leftist }
$$

$\forall s \in$ subárvore a esquerda de $n$

$\forall t \in$ subárvore a direita de $n: ?(n==$ root $)$

$($ caminhoNulo $(s)<$ caminhoNulo $(t))$ 


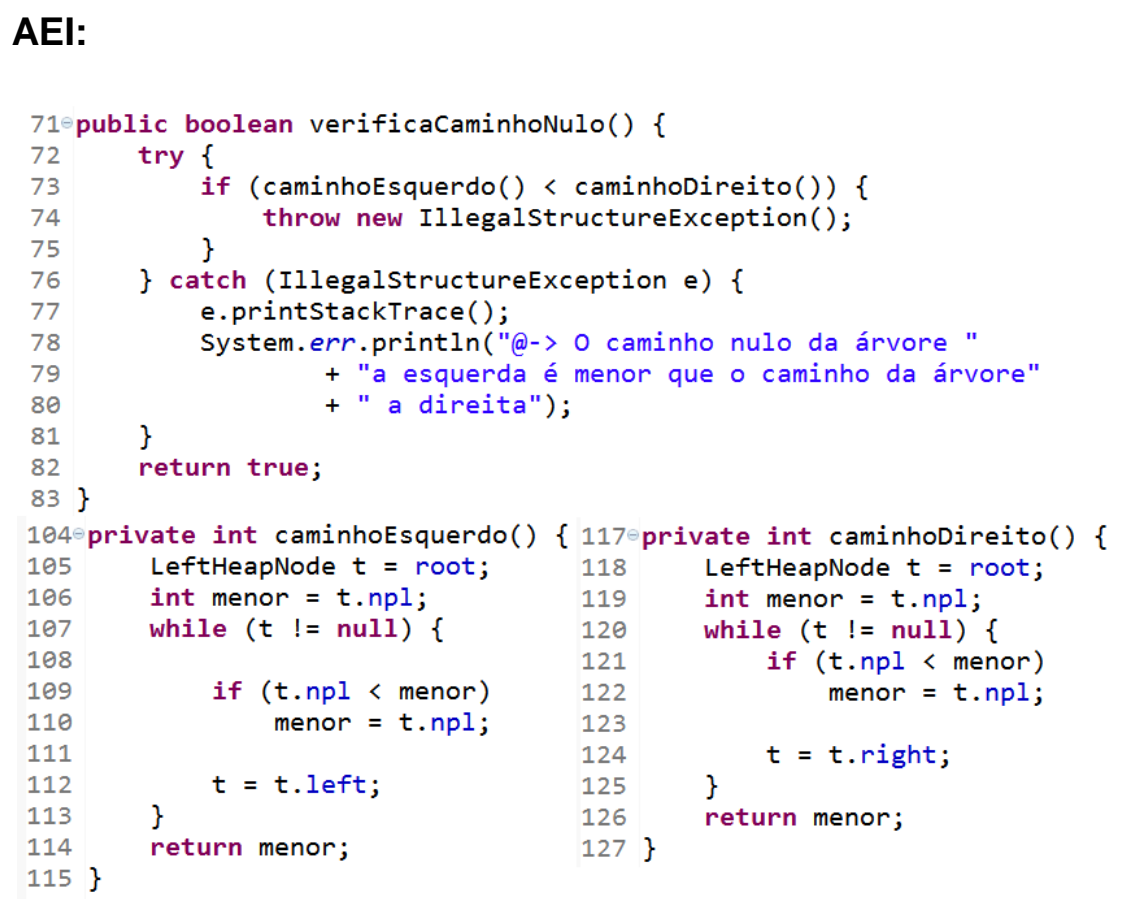

Figura 30 - Assertiva executável verificadora do caminho nulo e métodos auxiliares

\subsubsection{Possíveis anomalias para Heap Leftist}

Tabela 9 - Possíveis tipos de anomalias para Heap Leftist

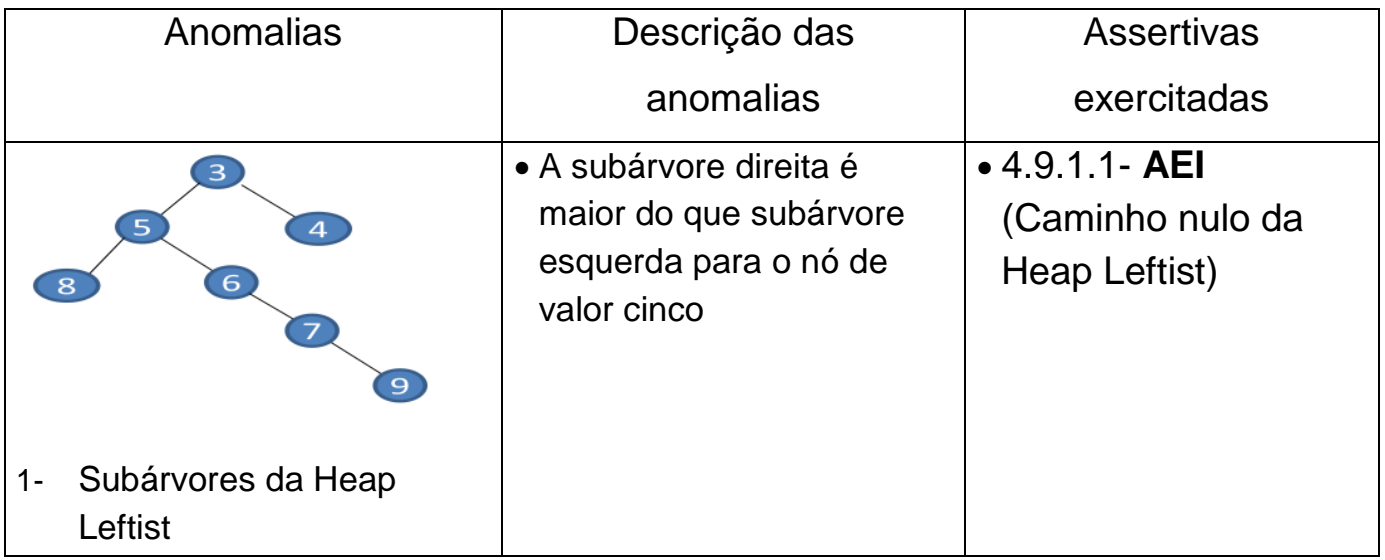

4.10.

\section{Heap Fibonacci}

A Heap Fibonacci é uma coleção de árvores que mantém a propriedade descrita para Heap Binária onde os filhos devem ser maiores que os pais. Ainda essa heap mantém seus nós organizados em um encadeamento duplo, onde o pai tem referência para seus filhos diretos e filho tem referência para seu pai. Além da assertiva para garantir que os filhos sejam maiores que os pais, a assertiva executável para garantir a propriedade do encadeamento da Heap Fibonacci é apresentada nesta seção. 


\subsubsection{Assertivas estruturais:}

\subsubsection{Encadeamento da Heap Fibonacci}

P:

Para todo elemento $p$ pertencente à Heap Fibonacci se 0 próximo elemento de $\boldsymbol{p}$ for diferente de nulo então o elemento anterior do próximo elemento de $p$ deverá ser o próprio $p$.

\section{EFL:}

$$
\begin{gathered}
\forall p \in \text { Heap Fibonacce: } ?(p \rightarrow \text { prev } !=\text { null }) \\
\Rightarrow \\
(p \rightarrow \text { next } \rightarrow \text { prev }==p)
\end{gathered}
$$

AEl:

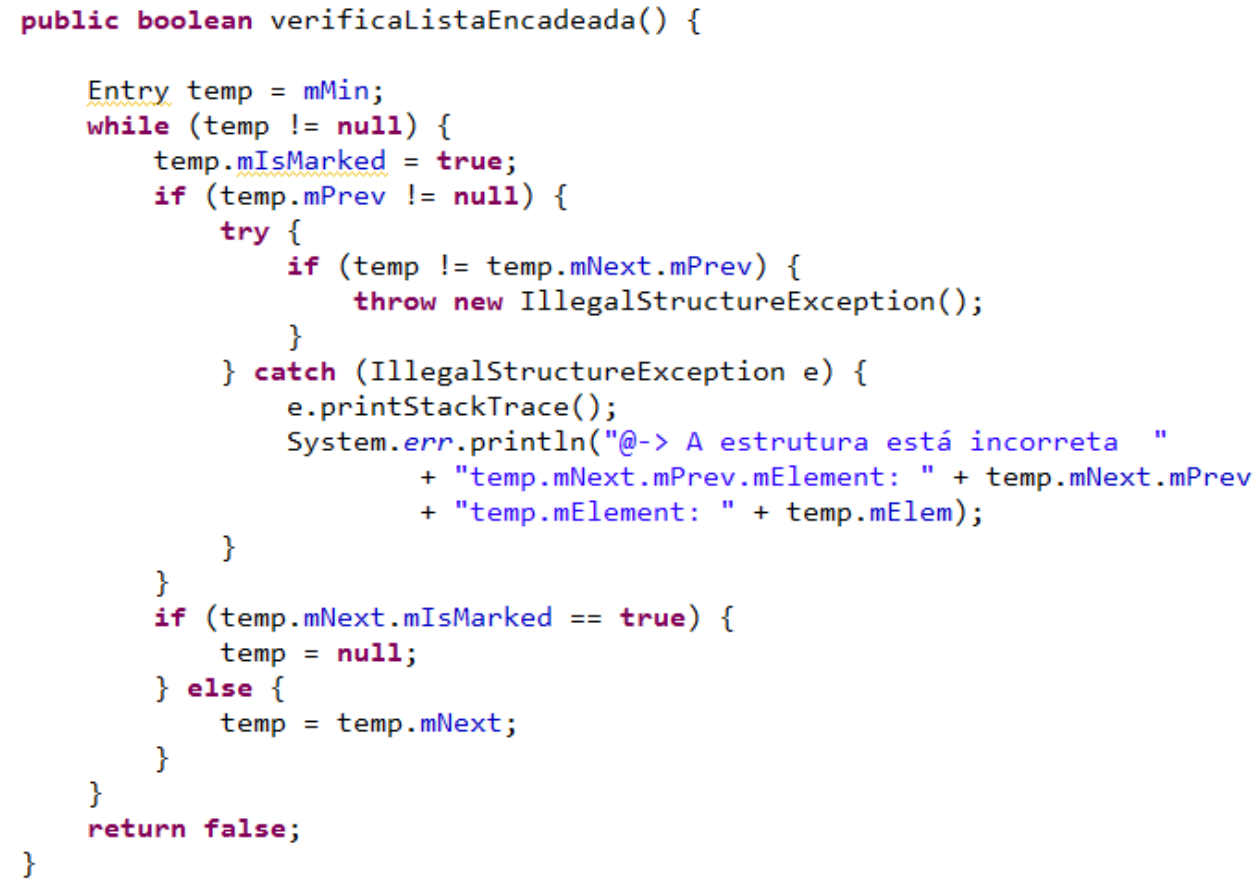

Figura 31 - Assertiva executável verificadora do encadeamento da Heap Fibonacci 


\subsubsection{Possíveis anomalias para Heap Fibonacci}

Tabela 10 - Possíveis tipos de anomalias para Heap Fibonacci

\begin{tabular}{|c|c|c|}
\hline Anomalias & Descrição das anomalias & $\begin{array}{c}\text { Assertivas } \\
\text { exercitadas }\end{array}$ \\
\hline \\
$\begin{array}{c}\text { 1-Encadeamento da Heap } \\
\text { Fibonacci }\end{array}$ & $\begin{array}{l}\bullet \text { O elemento de valor seis } \\
\text { não tem a referência do } \\
\text { seu nó pai de valor cinco }\end{array}$ & $\begin{array}{c}\text { 4.9.1.1- AEI } \\
\text { (Caminho nulo da } \\
\text { Heap Leftist) }\end{array}$ \\
\hline
\end{tabular}

\subsection{1.}

\section{Assertivas executáveis para Árvore AVL implementada em PHP}

As assertivas criadas para árvore AVL na linguagem JAVA foram traduzidas para linguagem PHP. Uso de uma segunda linguagem se dá para demonstrar que instrumentar programas com assertivas pode ser utilizado para demais linguagens não apenas em programas escritos em JAVA e ainda se as assertivas são eficazes naquela linguagem.

Foi utilizada para essa demonstração apenas a árvore AVL as demais assertivas executáveis criadas para as estruturas de dados anteriormente apresentadas em Java não foram traduzidas para PHP. Serão descritas para essa seção apenas o exemplo de implementação na linguagem PHP, pois a descrição de cada assertiva criada foi demonstrada na seção 4.2.1.

\subsection{1. Árvore sem elemento}

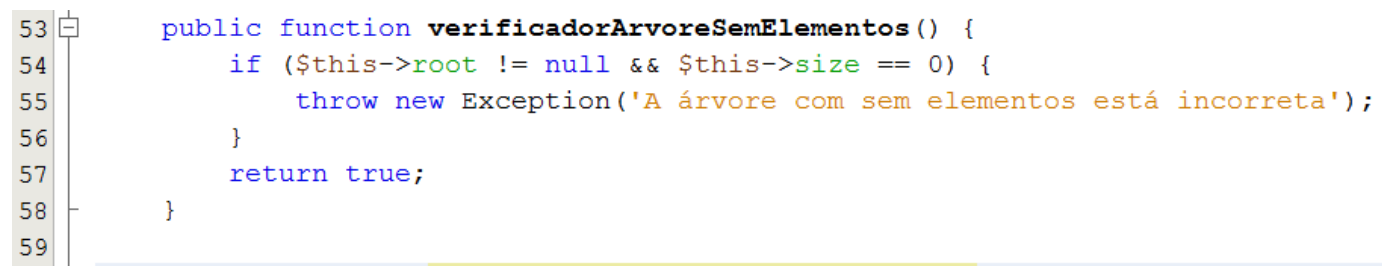

Figura 32 - Assertiva executável verificadora da árvore sem elementos 


\subsection{2. Árvore com apenas um elemento}

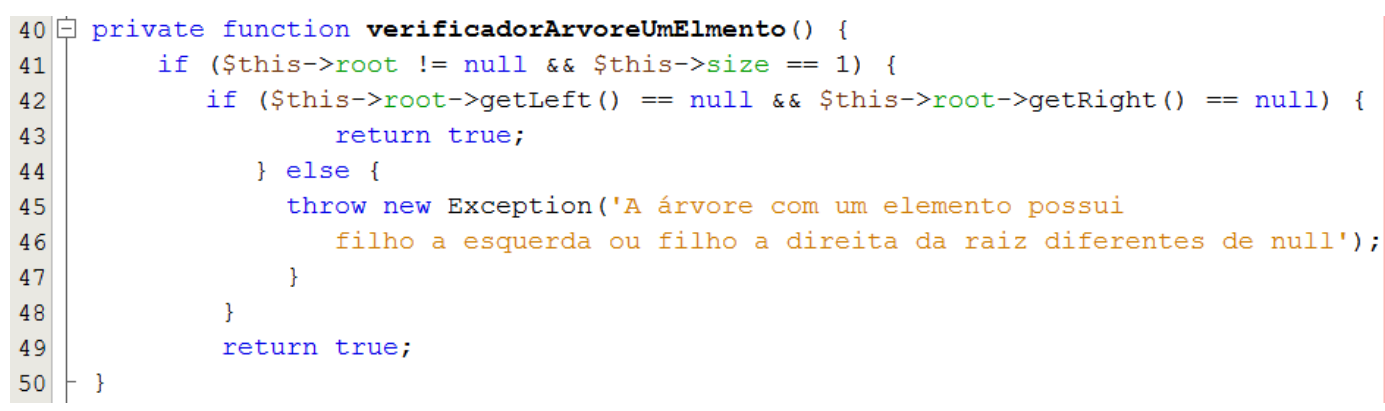

Figura 33 - Assertiva executável verificadora da árvore com um elemento

\subsection{3. Árvore com mais de um elemento}

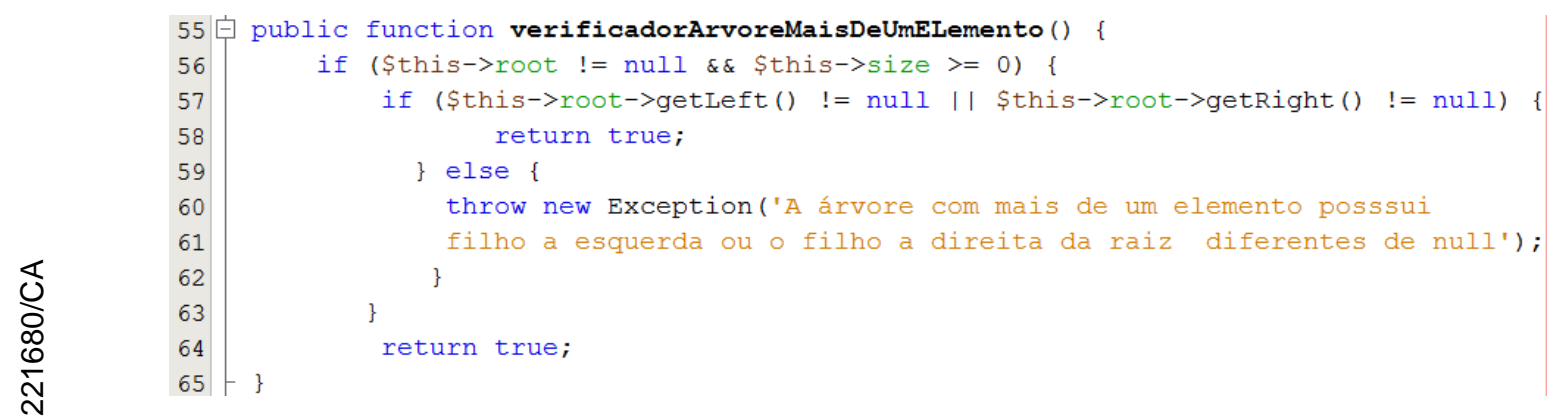

Figura 34 - Assertiva executável verificadora da árvore com mais de um elemento

\subsubsection{Encadeamento da árvore}

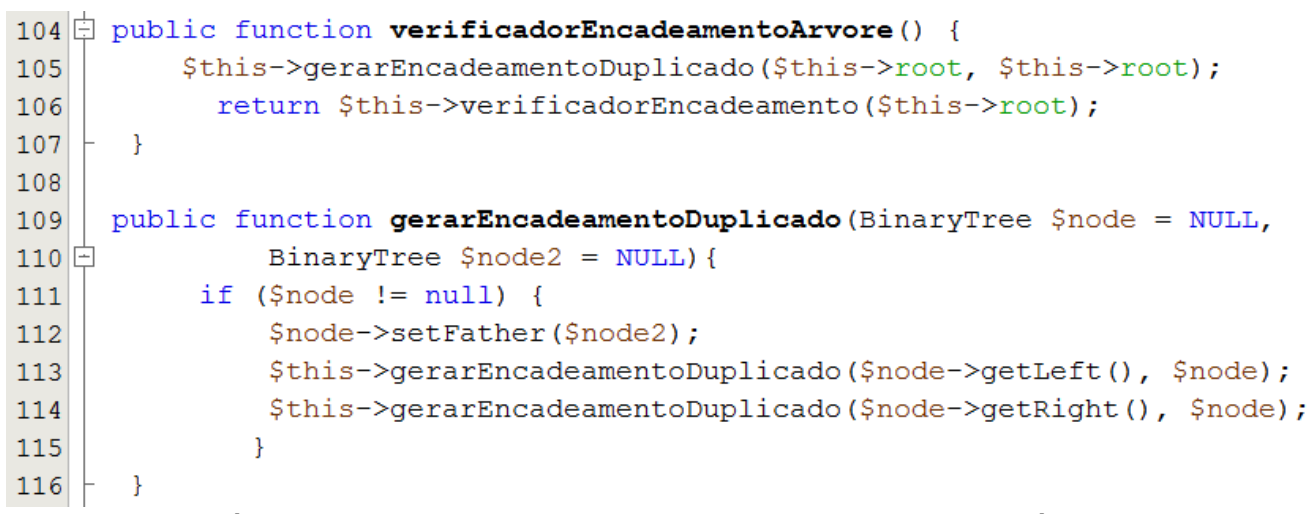

Figura 35 - Métodos auxiliares para criação das assertivas executáveis 


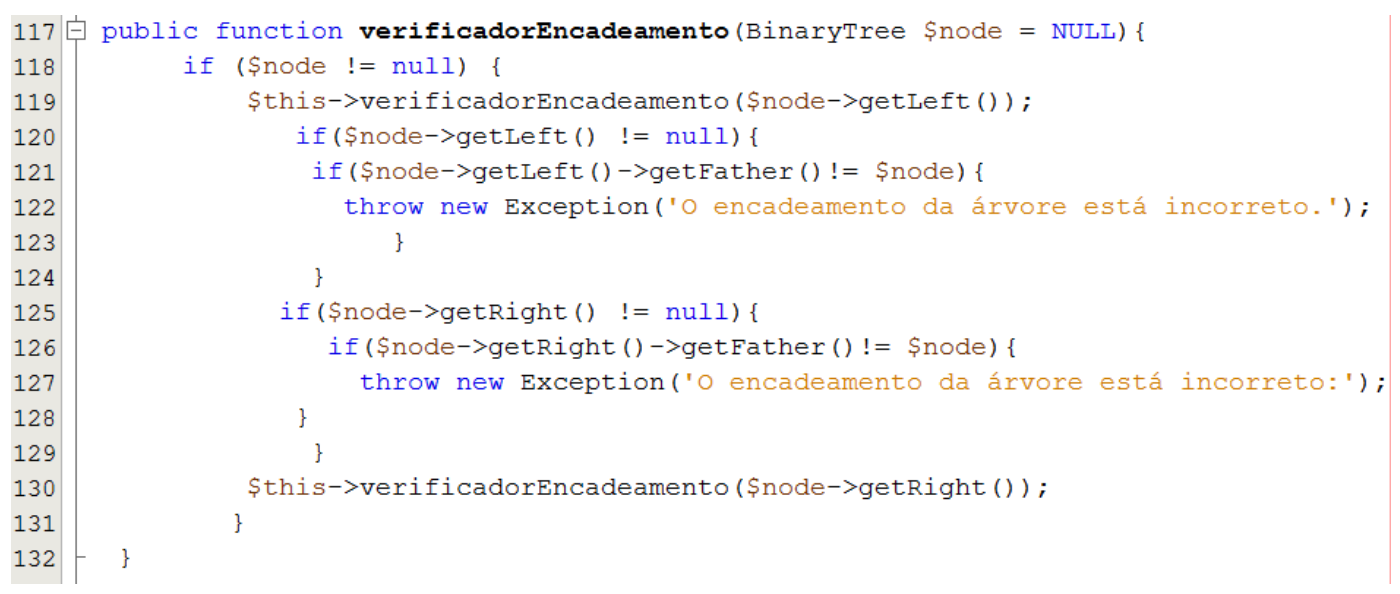

Figura 36 - Assertiva executável verificadora do encadeamento da árvore

\subsubsection{Folhas da árvore}

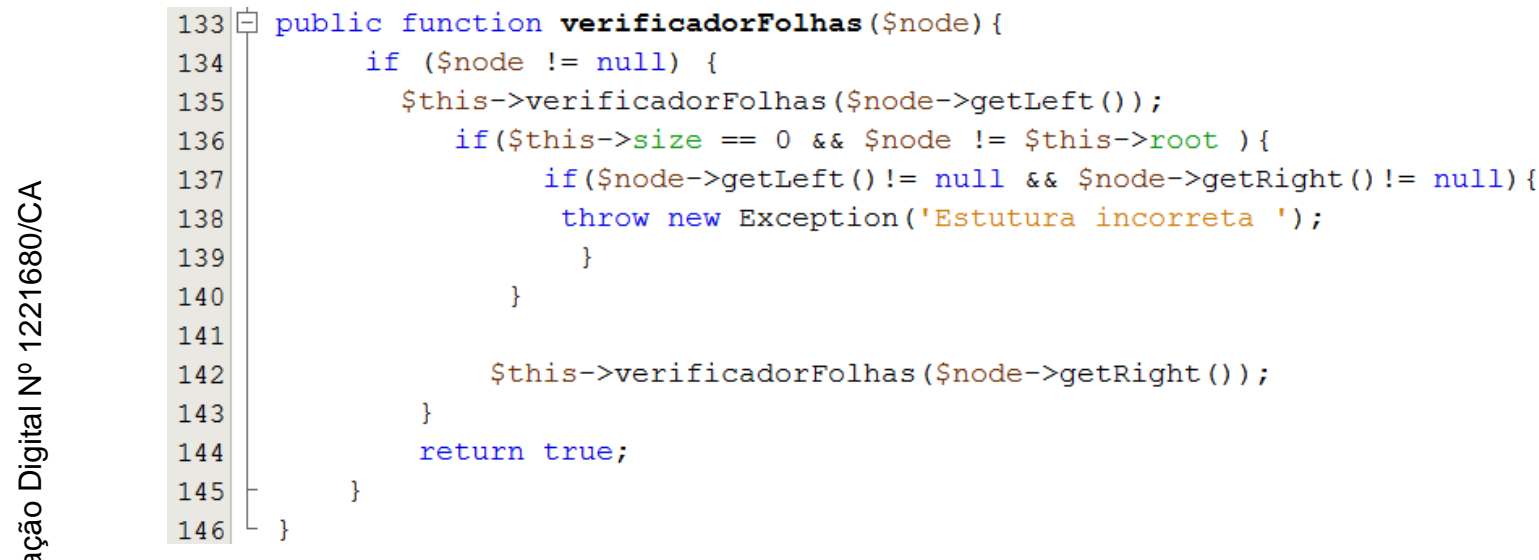

Figura 37 - Assertiva executável verificadora das folhas da árvore binária

\subsection{6. Árvore de Pesquisa Binária}

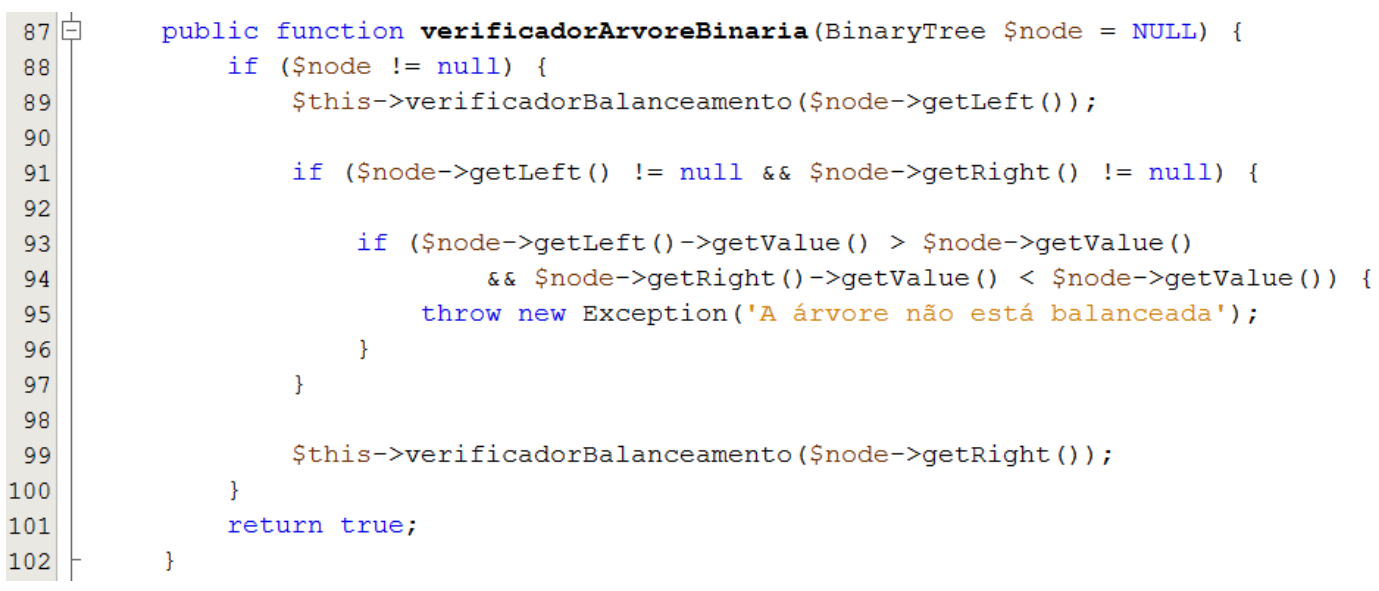

Figura 38 - Assertiva executável verificadora da propriedade da árvore binária 


\section{5}

\section{Teste de análise mutante}

Este capítulo apresenta a fundamentação teórica necessária para o entendimento das definições e terminologias com relação aos testes de análise mutante (seção 5.1). Ainda foram descritas duas ferramentas: a primeira é a principal, pois foi utilizada na maior parte do experimento (seção 5.2) já a segunda é um protótipo implementado exclusivamente para este trabalho, que possibilita a criação de mutantes na linguagem PHP (seção 5.3) por fim é apresentada uma seção reservada para descrição dos testes unitário utilizados no experimento (seção 5.4).

\section{1.}

\section{Teste de análise mutante}

Teste de mutação ou análise de mutantes é uma técnica de avaliação e melhoria da qualidade dos testes, com base na determinação da sua capacidade de detectar falhas provocadas por defeitos injetados artificialmente no código sendo testado, e que são representativas de falhas reais. Com a injeção de defeitos no programa original são criadas várias versões alteradas desse programa que constituem os mutantes. Os defeitos são injetados pela aplicação de operadores de mutação, representando defeitos típicos. Segundo Delamaro (2007) os operadores de mutação surgiram de estudos que determinavam os erros mais comuns cometidos por programadores e erros mais comuns em linguagens de programação específicas.

Quando um operador de mutação é aplicado ao programa original, e este possui a estrutura sintática que um dado operador de mutação consegue modificá-lo, então essas modificações são exercidas e um conjunto de mutantes é gerado. Assim, normalmente nas ferramentas de teste de análise mutante, o mutante criado tem o nome do operador de mutação que originou sua mudança sintática. Ainda a cada ocorrência encontrada dessa estrutura sintática no programa original é criado um novo mutante. Sendo que cada mutante tem alguma pequena modificação em relação ao programa original, então cada mutante criado é diferente dos demais mutantes para o um mesmo programa. 
Segundo a sintaxe e semântica do programa escrito, os mutantes são gerados por meio de pequenas variações do programa original e não no universo de todas as variações possíveis, essa prática é formulada como base na hipótese do programador competente que estabelece: um programa criado por um programador competente está correto ou está próximo do correto e na hipótese do efeito do acoplamento que preconiza: defeitos complexos estão ligados a defeitos simples e, por isso, a detecção de um defeito simples pode levar a descoberta de defeitos complexos (Demillo, Sayward,1978).

Para cada mutante, é aplicado o conjunto de testes original. Nos casos de testes se algum falhar, o correspondente mutante diz-se neutralizado ou morto. Neste caso, para o mesmo caso de teste o programa original e o mutante criado geram saídas diferentes. Caso os testes passem o mutante é considerado como vivo. Os mutantes que permanecem vivos poderão ser equivalentes ao programa original, ou então é um indicador de que o teste é insuficiente. Para se chegar a essa conclusão é necessária uma análise feita pelo testador, e definir se o mutante manteve vivo por ser realmente equivalente ao programa original ou se os testes não foram capazes de perceberem o defeito injetado, com isso os testes devem ser melhorados. Se os testes detectarem as falhas artificiais assume-se que detectarão falhas reais (Delamaro, et al., 2007).

Para entendimento dos termos utilizados no experimento será utilizada a seguinte terminologia:

- Mutante: o programa original modificado.

- Operador de mutação: o agente que definirá qual será o tipo de transformação que o programa original terá para ser considerado um mutante.

- Mutante morto ou neutralizado: quando a suíte de teste consegue distinguir o mutante do seu respectivo programa original, ou seja. Neste caso um ou mais testes não passaram.

- Mutante vivo: quando a suíte de teste não consegue distinguir o mutante do seu respectivo programa original, ou seja. Neste caso todos os testes passaram.

- Mutante equivalente: quando por análise de um desenvolvedor experiente o mutante é considerado equivalente ao seu respectivo programa original.

\section{2.}

\section{MuClipse: ferramenta para teste análise mutante para Java}

Por causa dos mutantes gerados serem em grande número, torna-se indispensável o uso de uma ferramenta que tenha as seguintes funções: (i) 
criação de mutantes, segundo os operadores de mutação escolhidos, (ii) execução de cada mutante segundo os casos de testes fornecidos e (iii) indicação do estado do mutante após a execução dos testes (DELAMARO, et al., 2007). Além do mais, é importante que seja demonstrada a diferença entre o mutante e o seu respectivo programa original. Isso se faz necessário para facilitar a análise do testador na hipótese da equivalência entre o programa original e o mutante. Existem algumas ferramentas para testar programas escritos em Java que apresentam essas características tais como: Jabuti (Vincenzi, et al., 2003), Jester (Moore, 2001) e MuClipse (Smith, Williams 2007).

O MuClipse comparado com as demais ferramentas pesquisadas foi utilizado para a realização do experimento por causa das seguintes qualidades:

1. Variedade de operadores de mutações;

2. Facilidade na gerência dos mutantes criados;

3. Poucas restrições para instalação;

4. Configuração rápida e descomplicada;

5. Desempenho em tempo considerável;

6. Documentação disponível;

7. Integração com JUnit;

8. Por ser um plug-in para Eclipse e assim aproveitar os benéficos desse ambiente de desenvolvimento sem ter custo maior para aprendizagem do ambiente.

As principais desvantagens encontradas com a utilização da ferramenta MuClipse foi porque ela (i) não permite a criação de mutantes para mais de uma classe ao mesmo tempo, e (ii) não permite que o programa original tenha o uso do Generics do Java. No experimento realizado alguns algoritmos das estruturas de dados eram escritos em mais de uma classe e ainda utilizavam o recurso do Generics do Java. Mas essas pendências foram sanadas para a utilização da ferramenta, pois as qualidades e principalmente pela facilidade de utilização dela compensaram as modificações feitas nas estruturas de dados.

O MuCplise é um plugin do Eclipse que fornece uma ponte entre a API Mujava existente e o Eclipse Workbench, assim MuJava é uma nova implementação das especificações do Mujava para um plugin do Eclipse (Smith, Williams 2007). Ele utiliza dois grupos de operadores de mutação para gerar os mutantes, esses são identificados como: o primeiro operador relativo à classe e o segundo operador relativo ao método. Sendo que no total são quarenta e três operadores divididos em vinte oito de classe e quinze de método. 
Os operadores de mutação para classe foram projetados por meio da observação de falhas mais comuns em Orientação a Objetos. Estes são separados em quatro grupos (Ma, Offutt, 2005):

- Encapsulamento;

- Herança;

- Polimorfismo;

- Características específicas da Orientação a Objetos em Java.

Ainda os operadores de mutação reativos ao método são baseados nos tipos primitivos do Java, separados em seis grupos de operadores (Ma, Offutt, 2005):

- Aritmético;

- Relacional;

- Condicional;

- Deslocamento;

- Lógico;

- Atribuição.

Na Tabela 11 e na Tabela 13 são demonstrados os operadores de mutação por meio de seus respectivos tipos, nomes e uma descrição de sua ação no programa original. Ainda podem ser visualizados na Tabela 12 e na Tabela 14 fragmentos de códigos extraídos das estruturas de dados utilizadas no experimento, onde são demonstradas as modificações que cada operador de mutação realizou.

Dos quarenta e três operadores de mutação disponíveis na ferramenta será demonstrado apenas aqueles em que a ferramenta MuClipse conseguiu utilizar para criar os mutantes no experimento. É necessária a demonstração destes operadores para conhecimento dos tipos de falhas inseridas nas estruturas de dados utilizadas no experimento. 
Tabela 11 - Operadores de mutação relativos à classe

\begin{tabular}{|c|c|c|c|}
\hline Tipo & Sigla & Nome & Ação \\
\hline \multirow{8}{*}{$\begin{array}{l}\text { Características } \\
\text { específicas } \\
\text { do Java }\end{array}$} & EAM & $\begin{array}{l}\text { Arithmetic Operator } \\
\text { Replacement }\end{array}$ & $\begin{array}{l}\text { É modificado o nome do método } \\
\text { "get" por outro método com } \\
\text { assinatura compatível }\end{array}$ \\
\hline & EMM & $\begin{array}{l}\text { Modifier method } \\
\text { change }\end{array}$ & $\begin{array}{l}\text { É modificado o nome do método } \\
\text { "set" por outro método com } \\
\text { assinatura compatível }\end{array}$ \\
\hline & JDC & $\begin{array}{l}\text { Java-supported } \\
\text { default constructor } \\
\text { creation }\end{array}$ & É excluído o construtor criado \\
\hline & JID & $\begin{array}{l}\text { Member variable } \\
\text { initialization deletion }\end{array}$ & $\begin{array}{l}\text { É excluída a inicialização da } \\
\text { variável de classe }\end{array}$ \\
\hline & JSI & $\begin{array}{l}\text { Static modifier } \\
\text { insertion }\end{array}$ & $\begin{array}{l}\text { É inserido o tipo "static" na } \\
\text { variável de classe }\end{array}$ \\
\hline & JSD & \begin{tabular}{|l|} 
Static modifier \\
deletion
\end{tabular} & $\begin{array}{l}\text { É excluído o tipo "static" da } \\
\text { variável de classe }\end{array}$ \\
\hline & JTD & $\begin{array}{l}\text { This keyword } \\
\text { deletion }\end{array}$ & $\begin{array}{l}\text { É excluída a palavra reservada } \\
\text { "this" da instrução }\end{array}$ \\
\hline & JTI & $\begin{array}{l}\text { This keyword } \\
\text { insertion }\end{array}$ & $\begin{array}{l}\text { É inserida a palavra reservada } \\
\text { "this" na instrução }\end{array}$ \\
\hline \multirow{3}{*}{ Polimorfismo } & OAN & $\begin{array}{l}\text { Argument number } \\
\text { change }\end{array}$ & $\begin{array}{l}\text { É modificado o número de } \\
\text { argumentos que são chamados. }\end{array}$ \\
\hline & OMR & $\begin{array}{l}\text { Overloading method } \\
\text { contents change }\end{array}$ & $\begin{array}{l}\text { Dentro de um método é } \\
\text { adicionado a chamada a outro } \\
\text { método de mesmo nome, porém } \\
\text { com número de } \\
\text { parâmetros diferentes. }\end{array}$ \\
\hline & PRV & $\begin{array}{l}\text { Reference } \\
\text { assignment with } \\
\text { other comparable } \\
\text { variable }\end{array}$ & $\begin{array}{l}\text { É substituído o tipo do valor que } \\
\text { a variável recebe por um tipo } \\
\text { descendente ao tipo da variável }\end{array}$ \\
\hline Herança & IOD & $\begin{array}{l}\text { Overriding method } \\
\text { deletion }\end{array}$ & $\begin{array}{l}\text { É excluída toda declaração da } \\
\text { classe filha, sendo executada a } \\
\text { classe pai }\end{array}$ \\
\hline
\end{tabular}


Tabela 12 - Operadores de mutação relativos à classe em uso

\begin{tabular}{|c|c|c|}
\hline Sigla & Programa Original & Mutante \\
\hline EAM & atual = atual.getProxima(); & atual = atual.getAnterior(); \\
\hline EMM & nova.setAnterior( this.ultima ); & nova.setProxima( this.ultima ); \\
\hline IOD & public String toString()\{... $\}$ & // public java.lang.String toString ()$\{\ldots\}$ \\
\hline JDC & $\begin{array}{l}\text { public SplayTree }()\{ \\
\text { root = nullNode; }\}\end{array}$ & // public JDC_1() $\{\ldots\}$ \\
\hline JID & $\begin{array}{l}\text { private static BinaryNode newNode } \\
\text { = null; }\end{array}$ & private static BinaryNode newNode; \\
\hline JSI & protected BinaryNode root; & protected static BinaryNode root; \\
\hline JSD & $\begin{array}{l}\text { private static BinaryNode newNode } \\
=\text { null; }\end{array}$ & private BinaryNode newNode = null; \\
\hline JTD & this.primeira = primeira; & primeira = primeira; \\
\hline $\mathrm{JTI}$ & this . primeira = primeira; & this. primeira = this. primeira; \\
\hline OAN & delete( mRootNode, key ); & delete(key); \\
\hline OMR & $\begin{array}{l}\text { private void printTree(AANode t })\{ \\
\text { if (t } !=\text { t.left) }\{ \\
\text { printTree( t.left }) ; \\
\text { printTree( t.right }) ; \\
\}\end{array}$ & $\begin{array}{l}\text { private void printTree(AANode t })\{ \\
\text { printTree(); }\end{array}$ \\
\hline PRV & $\begin{array}{l}\text { public void setPrimeira(Celula } \\
\text { primeira) }\{\text { this. primeira = primeira; } \\
\}\end{array}$ & $\begin{array}{l}\text { public void setPrimeira(Celula primeira ) }\{ \\
\text { this.primeira = ultima; } \\
\}\end{array}$ \\
\hline
\end{tabular}

Tabela 13 - Operadores de mutação relativos ao método 


\begin{tabular}{|c|c|c|}
\hline Sigla & Nome & Ação \\
\hline AODU & $\begin{array}{l}\text { Arithmetic Operator Deletion, } \\
\text { Unary }\end{array}$ & É excluído operador aritmético unário \\
\hline AODS & $\begin{array}{l}\text { Arithmetic Operator Deletion, } \\
\text { Shortcut }\end{array}$ & $\begin{array}{l}\text { É excluído operador aritmético de } \\
\text { atalho }\end{array}$ \\
\hline AOIS & $\begin{array}{l}\text { Arithmetic Operator Insertion, } \\
\text { Shortcut }\end{array}$ & $\begin{array}{l}\text { É excluído operador aritmético de } \\
\text { atalho }\end{array}$ \\
\hline AOIU & $\begin{array}{l}\text { (Arithmetic Operator Insertion, } \\
\text { Unary }\end{array}$ & É Inserido operador aritmético unário \\
\hline AORB & $\begin{array}{l}\text { Arithmetic Operator } \\
\text { Replacement, Binary }\end{array}$ & $\begin{array}{l}\text { É substituído o operador aritmético } \\
\text { binário }\end{array}$ \\
\hline AORS & $\begin{array}{l}\text { Arithmetic Operator } \\
\text { Replacement, Shortcut }\end{array}$ & $\begin{array}{l}\text { E substituído o operador aritmético } \\
\text { de atalho }\end{array}$ \\
\hline COD & Conditional Operator Deletion & É excluído operador condicional \\
\hline $\mathrm{COI}$ & Conditional Operator Insertion: & É inserido operador condicional. \\
\hline COR & $\begin{array}{l}\text { Conditional Operator } \\
\text { Replacement }\end{array}$ & É substituído operador condicional \\
\hline LOI & Logical Operator Insertion & É inserido operador lógico. \\
\hline ROR & $\begin{array}{l}\text { Relational Operator } \\
\text { Replacement: }\end{array}$ & É substituído operador relacional. \\
\hline SOR & Shift Operator Replacement & É substituído operador de shift. \\
\hline ASRS & $\begin{array}{l}\text { Assignment Operator } \\
\text { Replacement }\end{array}$ & É substituído operador de atribuição \\
\hline
\end{tabular}

Tabela 14 - Operadores de mutação relativos ao método em uso

\begin{tabular}{|c|c|c|}
\hline Sigla & Programa Original & Mutante \\
\hline AODU & return -1000 & return 1000; \\
\hline AODS & if (t.right.level > --t.level) & if (t.right.level > t.level) \\
\hline AOIS & if (t.left.level == t.level) & if $(++$ t.left.level == t.level) \\
\hline AOIU & array[hole]=array[hole/2] & array[hole]=array[-hole/2] \\
\hline AORB & array[hole]=array[hole/2] & array[hole]=array[hole+2] \\
\hline AORS & $\mathbf{I}++$ & i--; \\
\hline COD & $\begin{array}{l}\text { if (!(x.compareTo( t.element ) } \\
<0) \text { ) }\end{array}$ & if $(\mathrm{x} . \mathrm{compareTo}$ ( t.element $)<0)$ \\
\hline $\mathrm{COI}$ & if $(\mathrm{t}==\mathrm{null})$ & if $(!(t==$ null $))$ \\
\hline COR & $\begin{array}{l}\text { if (t.left } !=\text { null } \& \& \text { t.right } != \\
\text { null) }\end{array}$ & if (t.left != null || t.right != null) \\
\hline LOI & if (t.left.level == t.level) & if ( t.left.level == t.level) \\
\hline ROR & if $(\mathrm{t}==$ nullNode $)$ & if $(\mathrm{t} !=$ nullNode) \\
\hline SOR & $\begin{array}{l}\text { return }(1 \ll \text { theTrees.length }) \text { - } \\
1 \text {; }\end{array}$ & return ( 1 >> theTrees.length) - 1 ; \\
\hline ASRS & $\begin{array}{l}\text { currentSize }-= \\
\text { deletedQueue.currentSize }+1\end{array}$ & $\begin{array}{l}\text { currentSize }+= \\
\text { deletedQueue.currentSize + 1; }\end{array}$ \\
\hline
\end{tabular}

A Figura 39 demonstra o processo de escolha dos operadores de mutação na ferramenta MuEclipse. Ainda na Figura 40 pode ser observado um mutante 
criado (código fonte da direita) a partir do programa original (código fonte da esquerda).

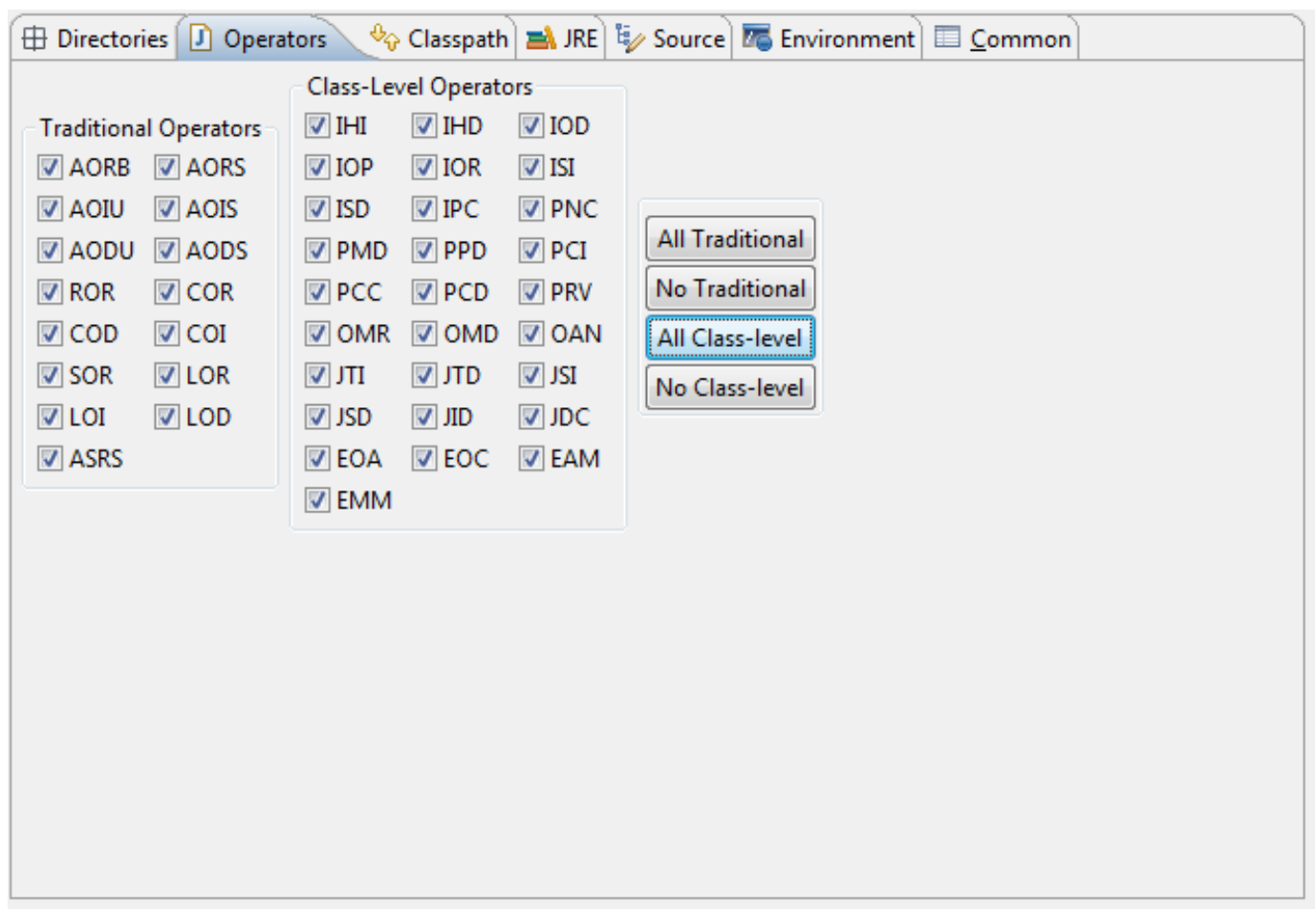

Figura 39 - Interface gráfica para selecionar operadores de mutação MuCplise

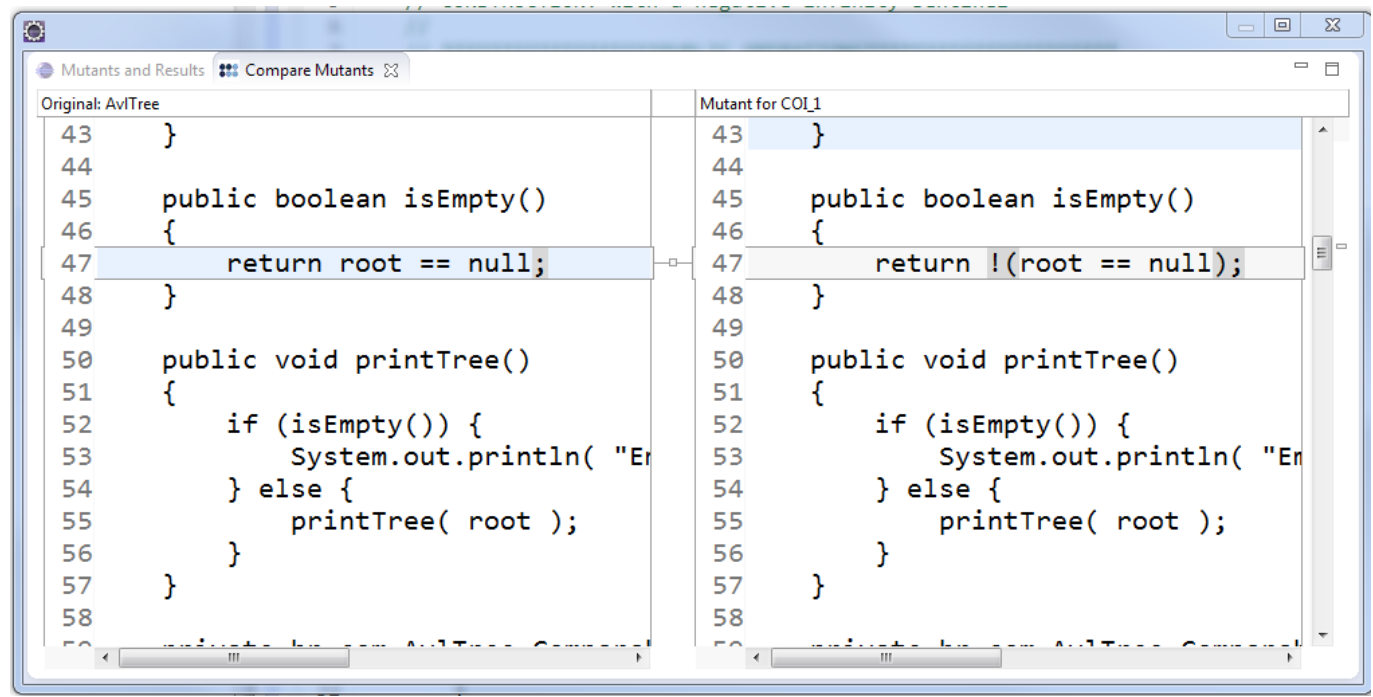

Figura 40 - Demonstração de um mutante criado

\section{3.}

MuPhp: Protótipo de ferramenta para testes de análise mutante em PHP

Foi desenvolvido neste trabalho um protótipo de ferramenta para testes de análise mutante que possibilita a criação de mutantes para a linguagem PHP. A 
razão motivadora para a criação desse protótipo se deu para que a eficácia das assertivas executáveis pudesse ser analisada em outra linguagem diferente de Java e ainda, por não ter sido encontrada na literatura uma ferramenta disponível de teste análise mutante para PHP.

O protótipo construído foi baseado nas especificações e operadores de mutação descrito para o MuJava, assim alguns operadores de mutação foi implementado a fim de ser criado mutantes a partir de um programa original escrito em PHP.

O protótipo em questão não traz nenhuma inovação para literatura com relação aos testes de análise mutante, pois ele apenas foi uma implementação de partes da especificação do MuJava. Assim não serão demonstrados detalhes da sua implementação. Porém na Figura 41 pode ser observada a interface do MuPHP referente à visualização de um mutante criado.

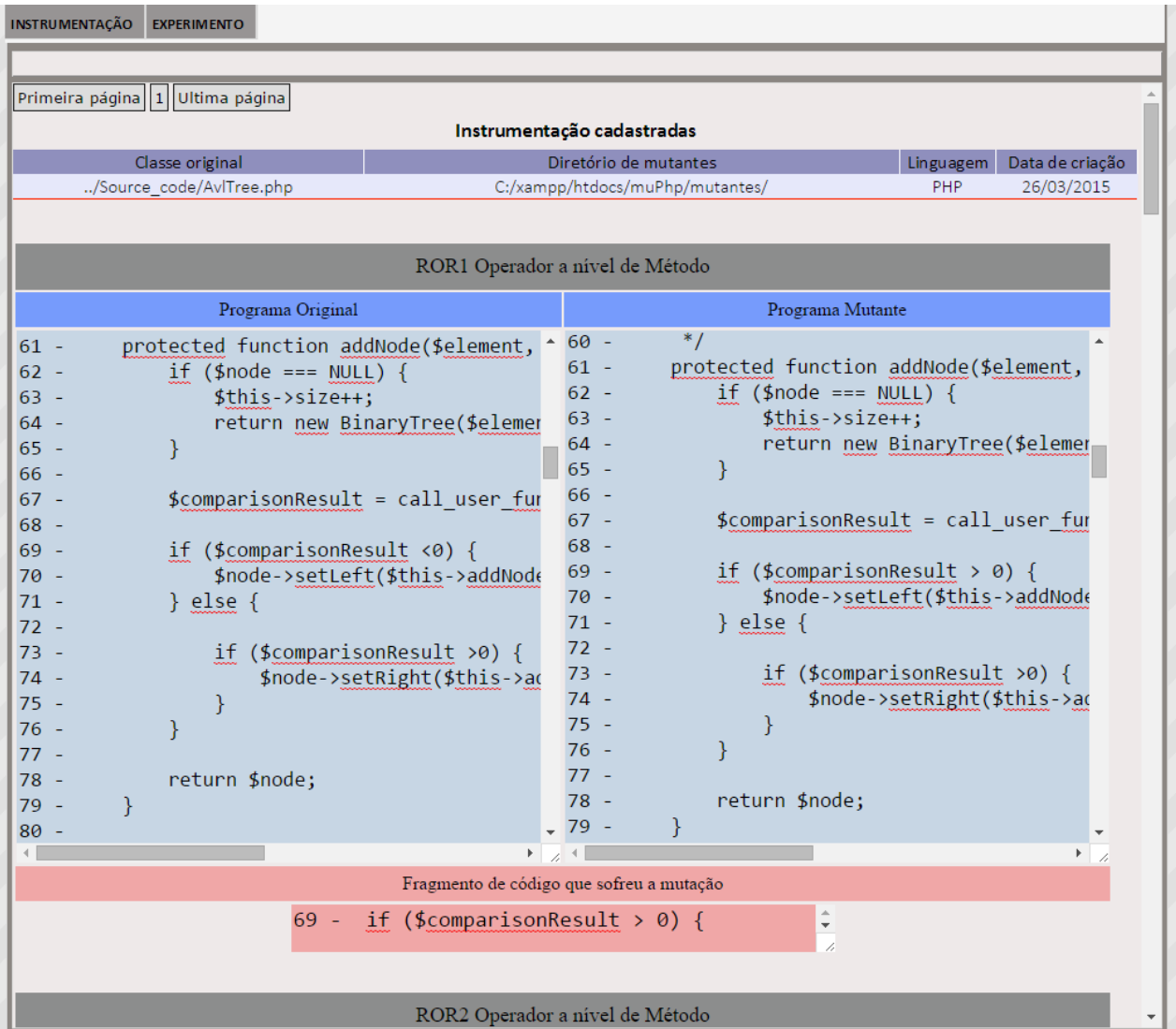

Figura 41 - Demonstração da criação de mutantes via a ferramenta MuPHP 


\section{4.}

\section{Teste Unitário}

Para a utilização das ferramentas de testes de análise mutante se faz necessário que sejam criados testes unitários no formato JUnit no caso do Java e PHPUnit para o PHP.

O teste unitário é uma modalidade de testes que se concentra na verificação de partes do código que podem ser exercitadas individualmente e que contenham regras de domínio. Por meio do fornecimento de dados suficientes para se testar apenas a lógica da unidade em questão e sabendo qual deverá ser o resultado para a unidade testada o resultado corresponde deve ser avaliado se é o resultado esperado. Essa verificação é feita pelo uso dos métodos Assert integrantes à biblioteca JUnit.

A Figura 42 e a Figura 43 demonstram os casos de testes criados para Árvore AA. Não serão demonstrados os casos de teste criados para todas as demais estruturas de dados utilizadas no experimento. 


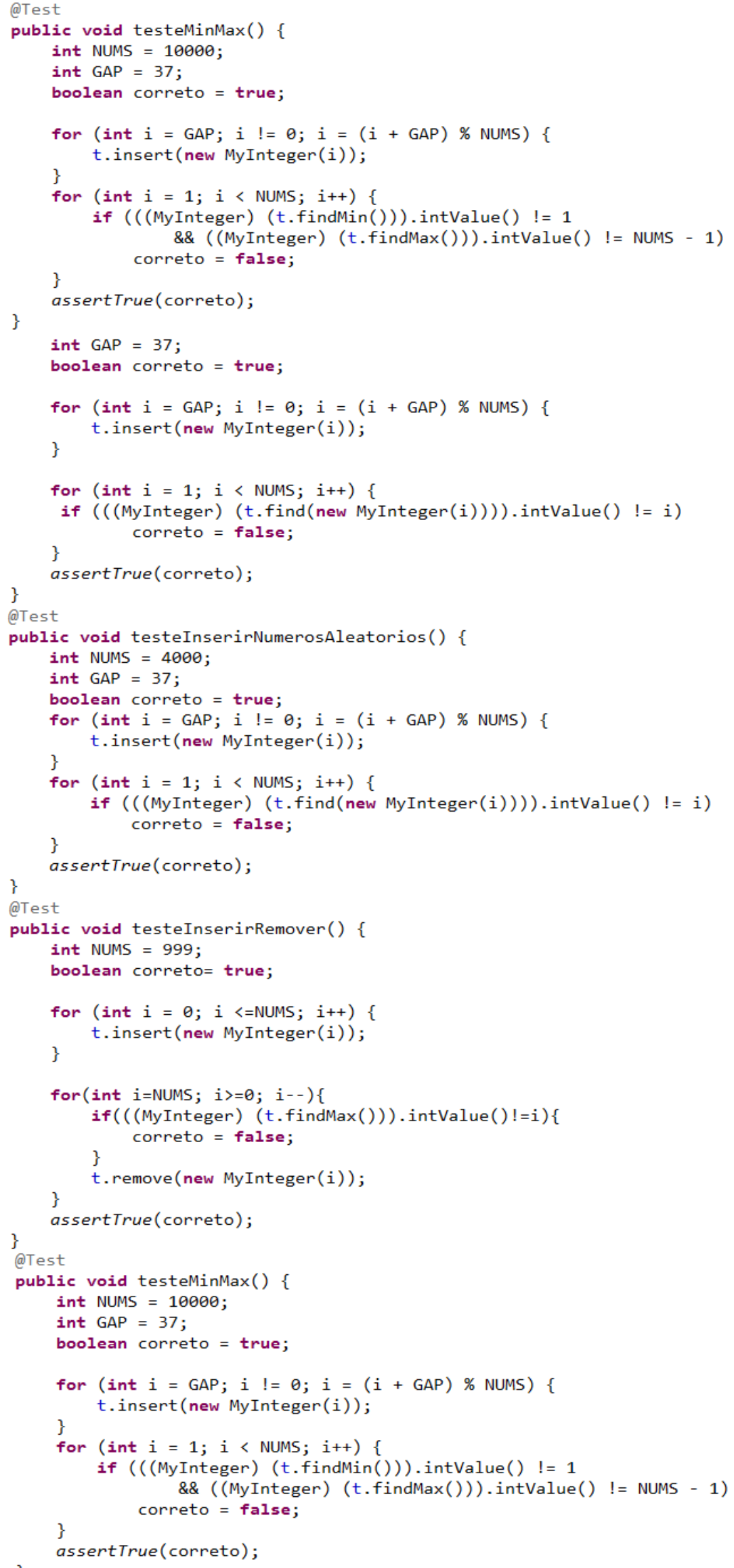

Figura 42 - Caso de testes unitários para Árvore AA, parte 1 


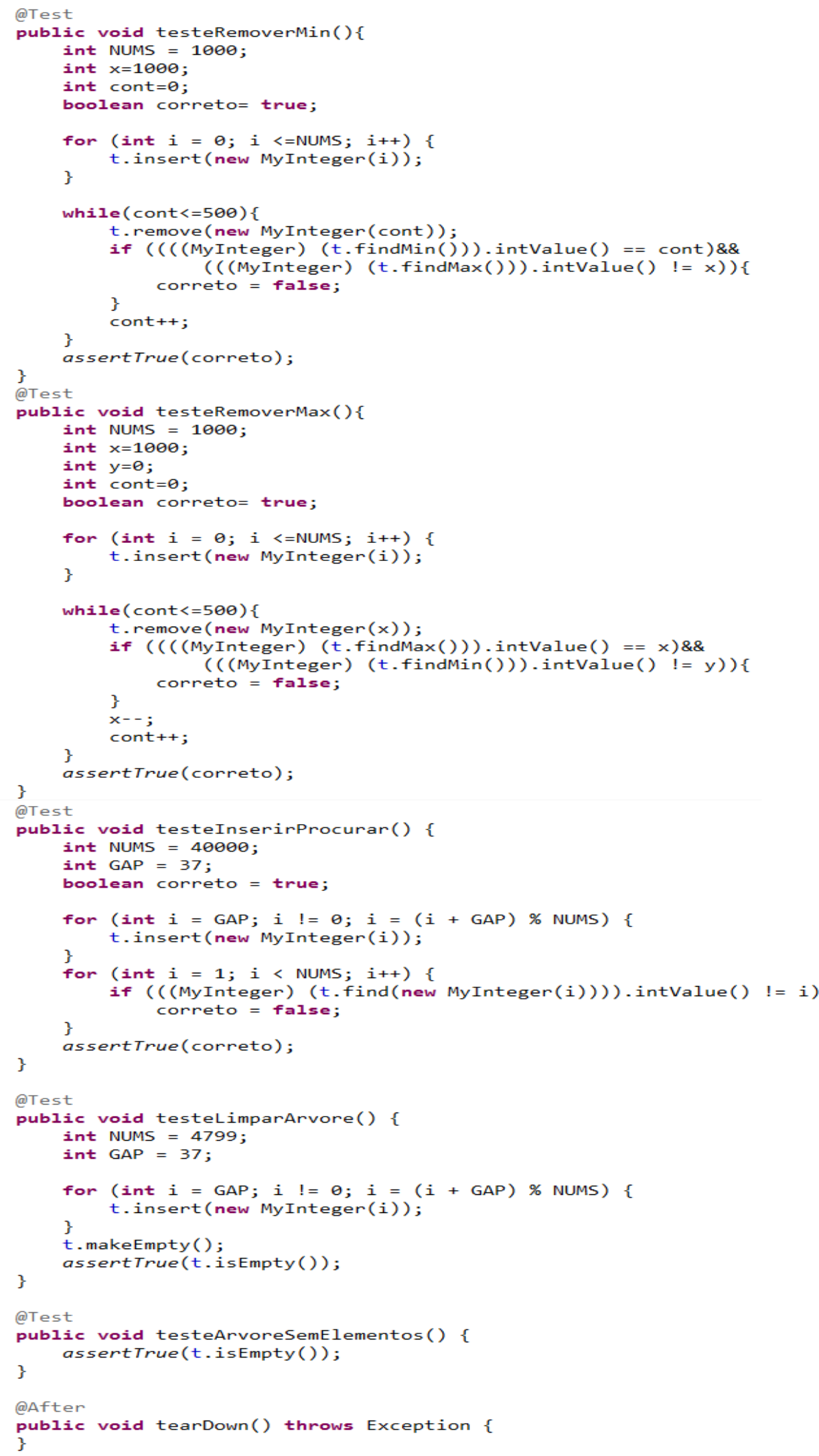

Figura 43 - Caso de testes unitários para Árvore AA, parte 2 


\section{6 \\ Experimentos e resultados}

Este capítulo tem como objetivo demonstrar de forma quantitativa os resultados obtidos com 0 experimento realizado. $\mathrm{Na}$ seção 6.1 foram demonstrados os resultados da primeira parte do experimento onde foi avaliada a eficácia das assertivas executáveis. Os resultados relativos à segunda parte do experimento estão descritos na seção 6.2 a qual teve como objetivo aferir o tempo gasto nos sistemas instrumentados com assertivas executáveis.

\section{1.}

\section{Resultados obtidos com as estruturas de dados}

As implementações das estruturas de dados utilizadas no experimento foram extraídas do livro Data Structures and Algorithm Analysis in Java (Weiss, 2012). Assim para essas implementações foram inseridas assertivas executáveis como descritas no Capítulo 3 e no Capítulo 4, uma suíte de testes unitários e a geração de mutantes segundo o Capítulo 5.

Os resultados obtidos com os testes análise mutantes para verificar a eficácia das assertivas executáveis estão apresentados na Tabela 15. Nessa tabela são descritos os tipos de mutantes criados por meio de operadores de mutação de métodos ou classe. Estão inseridos os resultados para as estruturas em Java e para a Árvore AVL escrita em PHP.

As colunas da tabela contêm as seguintes informações: A primeira coluna descreve o nome da estrutura de dados utilizada. Na segunda coluna são apresentados os mutantes de métodos e na terceira os mutantes de classe. A próxima coluna descreve o número total de mutantes criados que consiste no somatório dos tipos de mutantes de método e classe. Também consta na Tabela 16 o detalhamento dos mutantes criados segundo os operadores de mutação que puderam exercer desvios sintáticos no programa original.

Ainda na quinta coluna é informado o número de mutantes equivalentes. $O$ critério para análise dos mutantes equivalentes utilizado neste trabalho baseouse na comparação da saída que o mutante produz em relação à saída que o programa original apresenta para uma mesma instância de entrada. Quando a 
saída for a mesma em ambos os casos, considerou-se que o mutante é equivalente ao programa original.

$\mathrm{Na}$ sexta coluna, subdividida em três sub-colunas, foram descritos o número de mutantes não equivalentes mortos, vivos e o escore de mutação respectivamente para programas que não foram instrumentados com as assertivas executáveis. Da mesma forma a coluna sete da tabela descreve os resultados obtidos com programas que foram utilizados com assertivas executáveis.

Por fim a última coluna da tabela descreve a diferença entre os escores de mutação para programas instrumentados e para os não instrumentados segundo as métricas propostas neste trabalho na seção 3.2. A média obtida demonstra que as assertivas para o experimento criado puderam ser mais eficientes que os testes criados em relação ao escore de mutação numa escala de 0,3. Traduzindo em dados percentuais resultaria em 30\% a mais de eficácia das assertivas para neutralizar os mutantes em relação ao oráculo dos testes.

Ainda as assertivas tiveram o escore de mutação igual a 1,0. Isso demonstra que puderam detectar todas as modificações que os mutantes apresentaram em relação ao programa original. 
Tabela 15 - Resultados obtidos com teste mutantes e assertivas executáveis

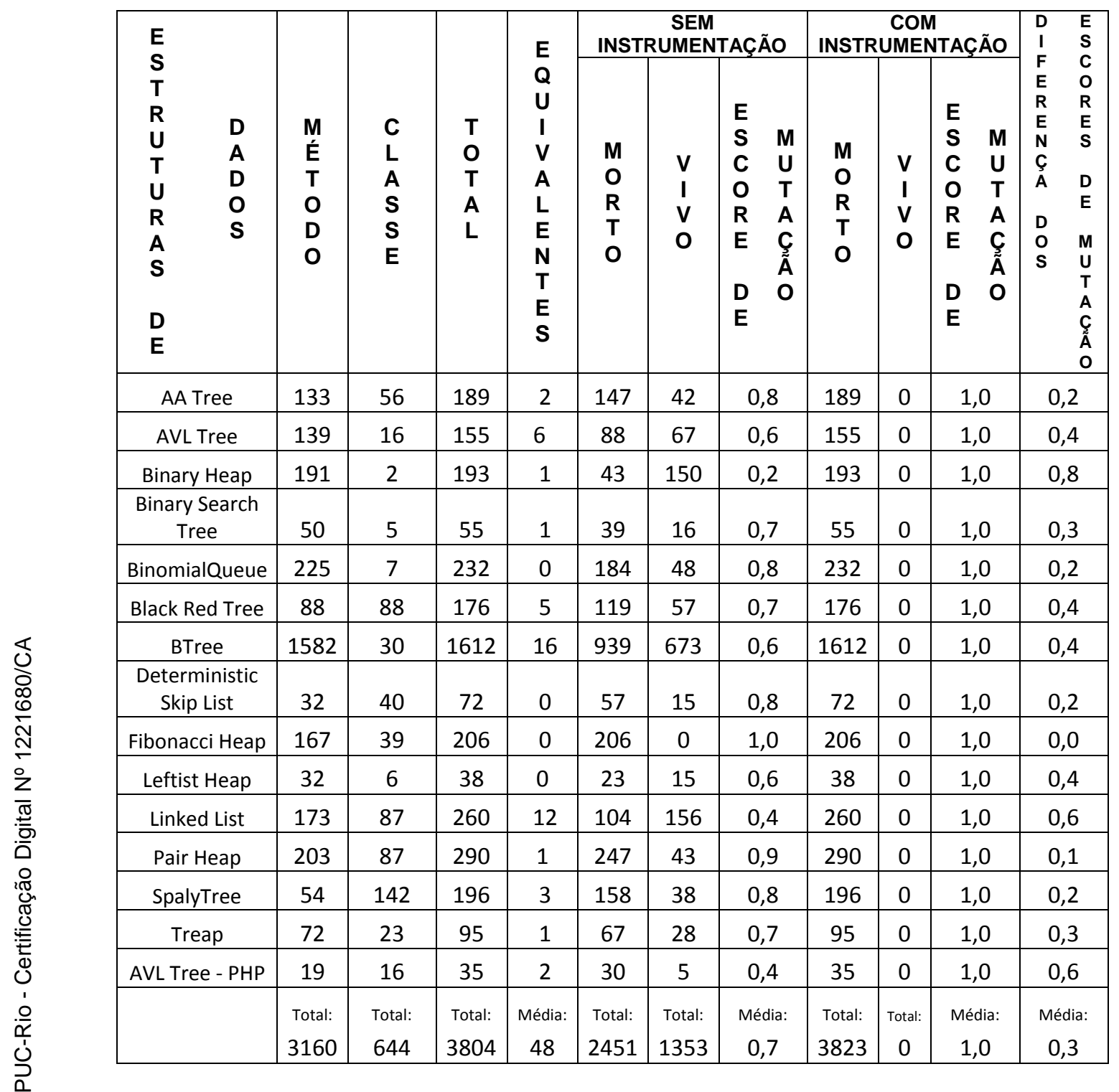


Tabela 16 - Número de mutantes criados para as estruturas de dados usadas

\begin{tabular}{|c|c|c|c|c|c|c|c|c|c|c|c|c|c|c|}
\hline & \begin{tabular}{|c|} 
Linked \\
List
\end{tabular} & \begin{tabular}{c|} 
Deterministic \\
Skip \\
List \\
\end{tabular} & \begin{tabular}{|c|} 
Binomial \\
Queue
\end{tabular} & $\begin{array}{l}\text { AA } \\
\text { Tree }\end{array}$ & \begin{tabular}{|l|} 
AVL \\
Tree
\end{tabular} & \begin{tabular}{|c|} 
Binary \\
Search \\
Tree \\
\end{tabular} & $\begin{array}{l}\text { B } \\
\text { Tree }\end{array}$ & \begin{tabular}{|l|} 
Black \\
Red \\
Tree \\
\end{tabular} & \begin{tabular}{|l|} 
Spaly \\
Tree
\end{tabular} & \begin{tabular}{|l} 
Binary \\
Heap
\end{tabular} & \begin{tabular}{|c|} 
Fibonacci \\
Heap
\end{tabular} & \begin{tabular}{|l|} 
Leftist \\
Heap
\end{tabular} & \begin{tabular}{|l|} 
Pair \\
Heap
\end{tabular} & Treap \\
\hline EAM & 7 & - & - & - & - & - & - & - & - & - & - & - & - & - \\
\hline EMM & 7 & - & - & - & - & - & - & - & - & - & - & - & - & - \\
\hline EOA & - & - & - & - & - & - & - & - & - & - & - & - & - & - \\
\hline IOD & 1 & - & - & - & - & - & - & - & - & - & - & - & - & - \\
\hline IOP & - & - & - & - & - & - & - & - & - & - & - & - & - & - \\
\hline IOR & - & - & - & - & - & - & - & - & - & - & - & - & - & - \\
\hline IHD & - & - & - & - & - & - & - & - & - & - & - & - & - & - \\
\hline $\mathrm{IHI}$ & - & - & - & - & - & - & - & - & - & - & - & - & - & - \\
\hline IPC & - & - & - & - & - & - & - & - & - & - & - & - & - & - \\
\hline ISI & - & - & - & - & - & 1 & - & 1 & - & - & - & - & - & \\
\hline JDC & - & - & 1 & 1 & 1 & 1 & 1 & - & 1 & - & - & 1 & 1 & - \\
\hline JID & - & 2 & - & 1 & 2 & - & 4 & - & 2 & - & 4 & - & 1 & 1 \\
\hline JSI & 3 & 4 & 2 & 1 & 2 & - & 6 & - & 1 & 1 & 6 & 1 & 2 & 1 \\
\hline JSD & - & - & 1 & 2 & - & - & 3 & 4 & 2 & 1 & - & - & - & - \\
\hline JTD & 3 & - & - & - & - & - & - & - & - & - & - & - & - & - \\
\hline JTI & - & - & - & - & - & - & - & - & - & - & - & - & - & - \\
\hline $\mathrm{OMD}$ & - & - & - & - & - & - & - & - & - & - & - & - & - & - \\
\hline OAN & - & - & - & - & - & - & 6 & - & - & - & - & - & - & - \\
\hline OMR & 1 & - & - & 1 & 2 & 1 & 3 & 1 & 1 & - & - & - & - & 1 \\
\hline PRV & 62 & 34 & 3 & 50 & 9 & 2 & 7 & 82 & 135 & - & 27 & 4 & 33 & 20 \\
\hline PPD & - & - & - & - & - & - & - & - & - & - & - & - & - & - \\
\hline PMD & - & - & - & - & - & - & - & - & - & - & - & - & - & - \\
\hline $\mathrm{PCl}$ & - & - & - & - & - & - & - & - & - & - & - & - & - & - \\
\hline PCD & - & - & - & - & - & - & - & - & - & - & - & - & - & - \\
\hline PCC & - & - & - & - & - & - & - & - & - & - & - & - & - & - \\
\hline AODU & - & - & - & - & - & - & 1 & - & - & - & - & - & - & - \\
\hline AODS & 6 & - & - & 2 & 1 & - & 14 & - & - & 3 & 5 & - & - & - \\
\hline AOIS & 54 & & 70 & 39 & 27 & - & 724 & 30 & - & 67 & 55 & 12 & 76 & 26 \\
\hline AOIU & 4 & - & 9 & 2 & 1 & - & 104 & 6 & - & 9 & 11 & 1 & 11 & 1 \\
\hline AORB & 20 & - & 16 & 8 & 27 & - & 308 & - & - & 28 & 4 & 4 & 32 & - \\
\hline AORS & 8 & - & 6 & 4 & 1 & - & 26 & - & - & 6 & 3 & - & 2 & - \\
\hline COD & 4 & - & - & - & - & - & 16 & - & - & - & - & - & - & - \\
\hline $\mathrm{COI}$ & 15 & 15 & 17 & 22 & 21 & 20 & 77 & 11 & 18 & 10 & 30 & 7 & 19 & 15 \\
\hline COR & 2 & 2 & 2 & 4 & - & 2 & 21 & 2 & 2 & 4 & 10 & - & - & - \\
\hline LOI & 29 & - & 45 & 13 & 11 & - & 294 & 13 & - & 30 & 18 & 3 & 28 & 7 \\
\hline LOD & - & - & - & - & - & - & - & - & - & - & - & - & - & - \\
\hline LOR & - & - & - & - & - & - & - & - & - & - & - & - & - & - \\
\hline ROR & 31 & 15 & 36 & 39 & 42 & 28 & 167 & 26 & 34 & 30 & 33 & 5 & 27 & 23 \\
\hline SOR & - & - & 4 & - & - & - & - & - & - & - & - & - & - & - \\
\hline ASRS & - & - & 20 & - & - & - & 4 & - & - & 4 & - & - & 8 & - \\
\hline total: & 260 & 72 & 232 & 189 & 155 & 55 & 1582 & 176 & 196 & 193 & 206 & 38 & 240 & 95 \\
\hline
\end{tabular}


Os operadores de mutação utilizados para criação dos mutantes para a Árvore AVL em PHP estão demonstrados na Tabela 17.

Tabela 17 - Número de mutantes criados a Árvore AVL em PHP

\begin{tabular}{|l|c|c|c|c|c|c|c|c|c|}
\hline $\begin{array}{l}\text { Operador de } \\
\text { mutação }\end{array}$ & ROR & COI & JID & OMR & PRV & AODU & AOIS & JDC & AORB \\
\hline Número de mutantes & 11 & 2 & 4 & 3 & 6 & 1 & 4 & 2 & 1 \\
\hline
\end{tabular}

\subsection{Medidas e comparações do tempo computacional no uso das assertivas executáveis}

A eficácia das assertivas executáveis quanto ao tempo computacional foram analisadas em dois sistemas utilizando algumas das estruturas de dados descritas neste trabalho. O primeiro foi o Problema de Programação Hiperbólica (PPH) e o segundo Problema da Árvore Geradora Mínima (PAGM).

Foi observado o tempo computacional no uso desses dois sistemas, em duas situações: (i) o programa no seu estado original; e (ii) instrumentado com assertivas executáveis. Assim foi possível fazer uma estimativa do acréscimo de tempo ocasionado pela execução das assertivas executáveis considerando os problemas utilizados no experimento. Como essas verificações, em última análise, são redundâncias, espera-se que o tempo computacional sofra um acréscimo.

Os dois sistemas foram utilizados com uma grande quantidade de dados lidos de instâncias que fazem parte do benchmark específico de cada problema. Para esses sistemas não foram utilizados mutantes, pois o intuito da utilização desses sistemas foi observar a média do acréscimo de tempo computacional em sistema que utilizam assertivas em tempo de uso. 


\subsubsection{Problema de Programação Hiperbólica (PPH)}

Dado um conjunto de pares ordenados $\{(\mathrm{a} 1, \mathrm{~b} 1) \ldots(\mathrm{an}, \mathrm{bn})\}$ e um par obrigatório $(\mathrm{a} 0, \mathrm{~b} 0)$ onde ai, bi $\in \mathrm{Z}_{+}, \mathrm{R}^{*} \mathrm{o}$ valor da razão máxima obtida, $\mathrm{S}^{*} \mathrm{um}$ subconjunto de $N$ tal que $R\left(S^{*}\right)=R^{*}$ e dada a fórmula:

$$
R(S)=\frac{a_{0}+\sum_{t \in S} a_{t}}{b_{0}+\sum_{t \in S} b_{t}}
$$

Lema: Seja $R^{*}$ o valor da razão máxima obtida para o $(P P H)$ e $S^{*}$ um subconjunto de $\mathrm{N}$ tal que $\mathrm{R}\left(\mathrm{S}^{*}\right)=\mathrm{R}^{*}$. Então, um par t pertence a qualquer $\mathrm{S}^{*}$ se e somente se $(a t / b t)>R^{*}$.

O sistema do PPH de maneira geral funciona desta forma: Os pares ordenados são obtidos pela leitura de um arquivo criado por um gerador de instâncias específico, que gera vários pares ordenados de números inteiros. $A$ razão é iniciada com a razão do par ordenado (a0, b0). Após todos os pares serem adicionados a uma lista, o algoritmo de ordenação coloca as razões que são criadas pela operação (ai/bi) em ordem crescente. Para cada elemento do conjunto $\mathrm{N}(\mathrm{Ai}, \mathrm{Bi})$, é testado se a razão do elemento corrente é maior que a razão atual. Em caso positivo, é adicionado o par ao conjunto S. Assim atualizase o somatório e obtém-se a nova razão. Por fim, é verificado se o Lema é válido. Se existir algum par (ai/bi) que seja menor do que a razão atual, este par será removido do conjunto $S$ e uma nova razão deverá ser calculada.

Para realização deste experimento foram escolhidos três algoritmos de ordenação de Merge Sort, Quick Sort e Selection Sort:

\subsubsection{Assertivas:}

\subsubsection{Vetor ordenado:}

P:

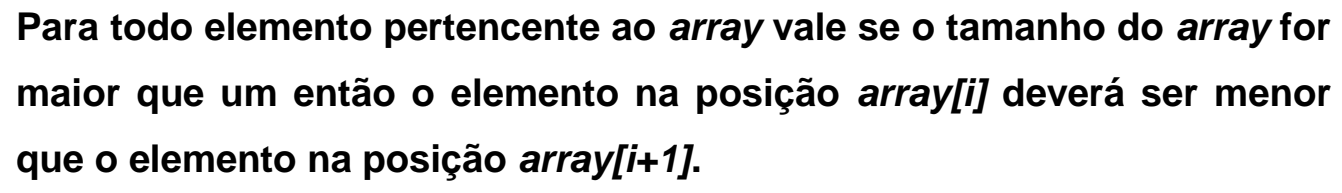


EFL:

$$
\begin{gathered}
\forall n \in \text { array: } ?(\text { array } \rightarrow \text { size }>1) \\
\Rightarrow \\
(\operatorname{array}[i]<\operatorname{array}[i+1])
\end{gathered}
$$

AEI:

Ainda o método contém uma assertiva de entrada que garante que o tamanho do vetor seja maior que um (implementado na linha 39 da Figura 44), pois quando o método é invocado o arquivo contendo os pares ordenados já terá sido lido. $O$ arquivo que contém as instâncias utilizadas não possui nenhum elemento que seja igual a zero, assim a razão final será sempre maior que zero, ou seja, sempre será maior que a razão inicial. Logo, a assertiva de saída para esse método garante que a razão final seja maior que zero (implementado na linha 58 da Figura 44). Por meio dessas assertivas o processamento principal do sistema é monitorado para que não apresente um estado inconsistente.

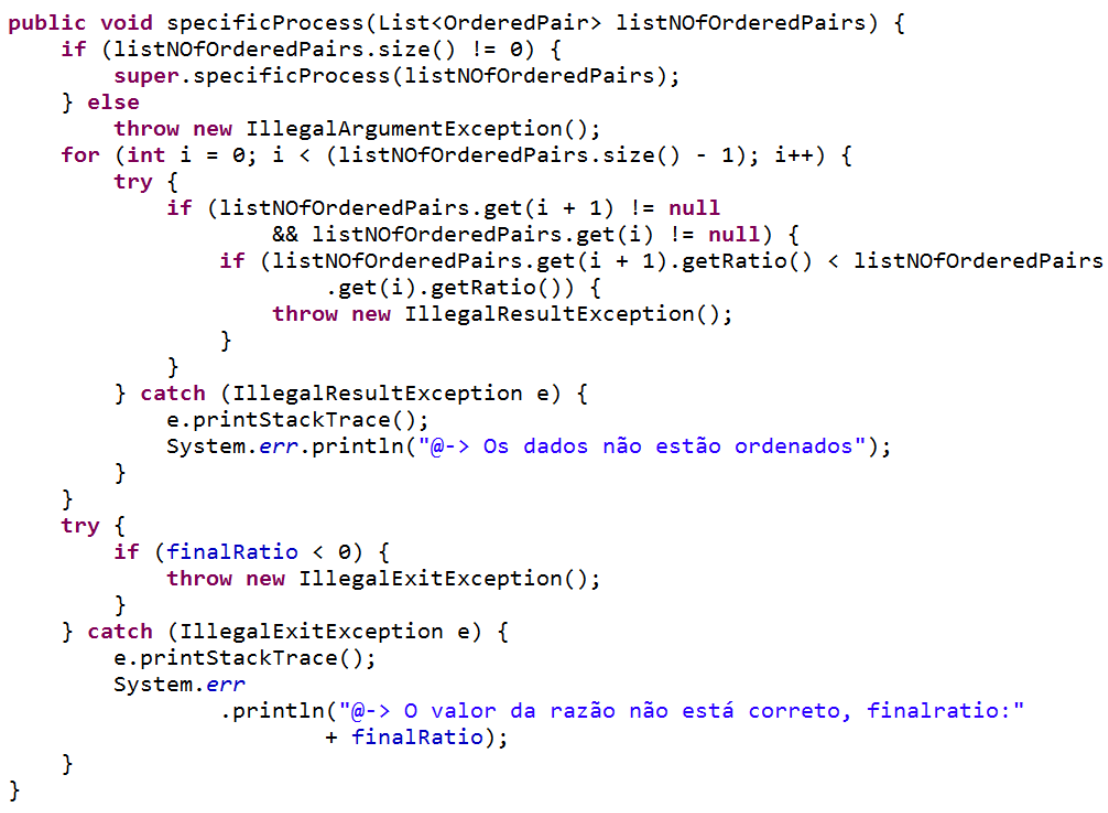

Figura 44 - Assertiva executável verificadora da ordenação do vetor

\subsubsection{Ambiente do experimento}

O experimento para o PPH foi realizado para três algoritmos de ordenação Merge Sort, Quick Sort e Selection Sort, foram utilizadas diversas instâncias de tamanhos variados: 10,100,1.000, 10.000, 100.000, e 1.000.000. Para cada tamanho de instância foram gerados dez arquivos diferentes por meio do 
gerador de instâncias. Essas foram executadas para os três tipos de algoritmo de ordenação, com tempo de execução de no mínimo dez segundos. Foi necessário deixar o sistema rodar as instâncias por esse tempo, pois o relógio do processador não possui precisão para poder medir com rigor a diferença de tempos. Pois se não fosse feito isso as instâncias 10, 100 e 1000 por serem muito pequenas não apresentariam resultados confiáveis.

Justifica-se o uso de instâncias diferentes de tamanhos iguais a fim de que a análise do tempo computacional seja realizada com entradas distintas, possibilitando uma melhor estimativa do custo do uso de assertivas em sistema em uso.

Os testes foram realizados em uma máquina de configurações: processador Intel Core i3 de 2,53GHz, 3GB de memória RAM. O sistema operacional utilizado foi Windows 8 e a IDE de desenvolvimento foi o Eclipse.

\subsubsection{Resultados obtidos para o PPH:}

\subsubsection{Resultados obtidos para o PPH com Merge Sort.}

Como pode ser observado na Tabela 18 por meio dos resultados obtidos, demonstram que o percentual de aumento do custo computacional total em utilizar assertivas para o problema do PPH com o algoritmo de ordenação Merge Sort foi de $5,8 \%$ em relação ao mesmo programa sem a utilização de assertivas executáveis.

Tabela 18 - Resultados obtidos para o Merge Sort

\begin{tabular}{|c|c|c|c|c|}
\hline \multirow{2}{*}{$\begin{array}{l}\text { Tamanho da } \\
\text { Entrada }\end{array}$} & Sem instrumentação & $\begin{array}{c}\text { Com } \\
\text { instrumentação }\end{array}$ & \multirow{2}{*}{ Diferença } & \multirow{2}{*}{ Aumento } \\
\hline & $\begin{array}{l}\text { Média de tempo } \\
\text { execução }\end{array}$ & $\begin{array}{l}\text { Média de tempo } \\
\text { execução }\end{array}$ & & \\
\hline 10 & 0,004 & 0,004 & 0 & $4,3 \%$ \\
\hline 100 & 0,056 & 0,060 & 0 & $8,9 \%$ \\
\hline 1.000 & 0,765 & 0,785 & 0,02 & $2,6 \%$ \\
\hline 10.000 & 9,822 & 10,336 & 0,51 & $5,2 \%$ \\
\hline 100.000 & 136,244 & 141,683 & 5,44 & $3,9 \%$ \\
\hline 1.000 .000 & 2034,780 & 2235,160 & 200,38 & $9,8 \%$ \\
\hline Total: 6 & Total: 146,89 & Total: 152,87 & Média: 1,20 & Média: 5,8\% \\
\hline
\end{tabular}




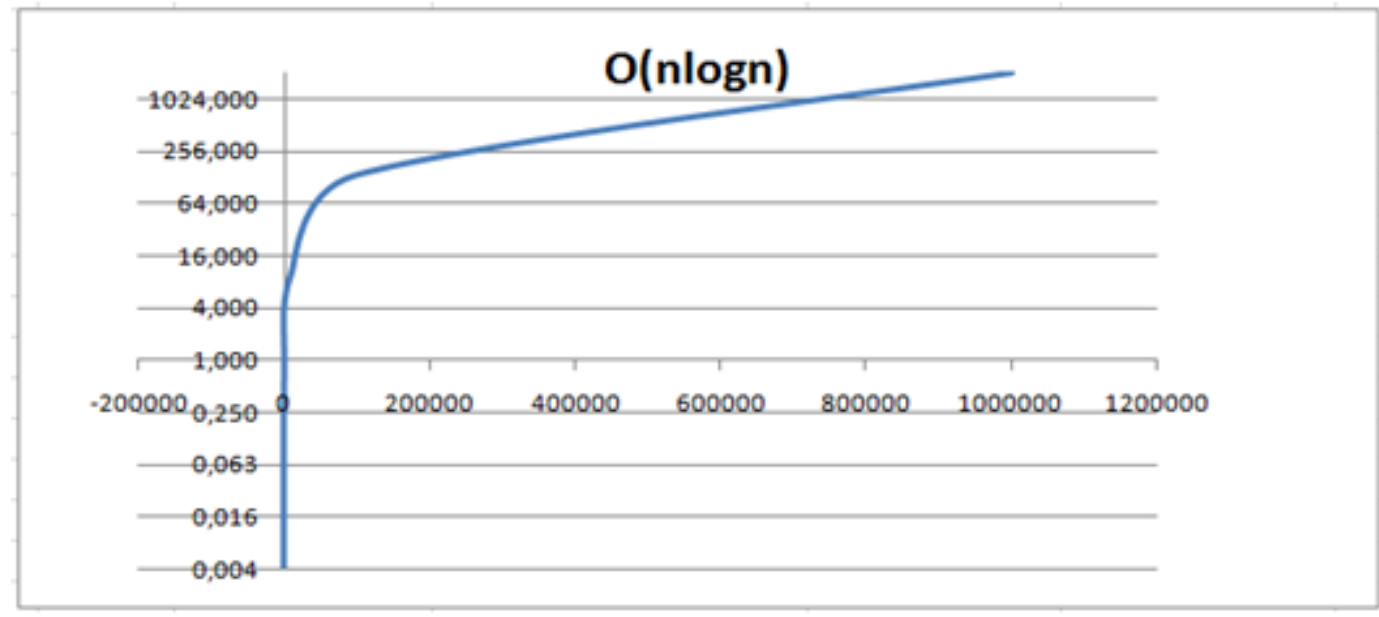

Figura 45 - Gráfico do resultado do Merge Sort sem instrumentação

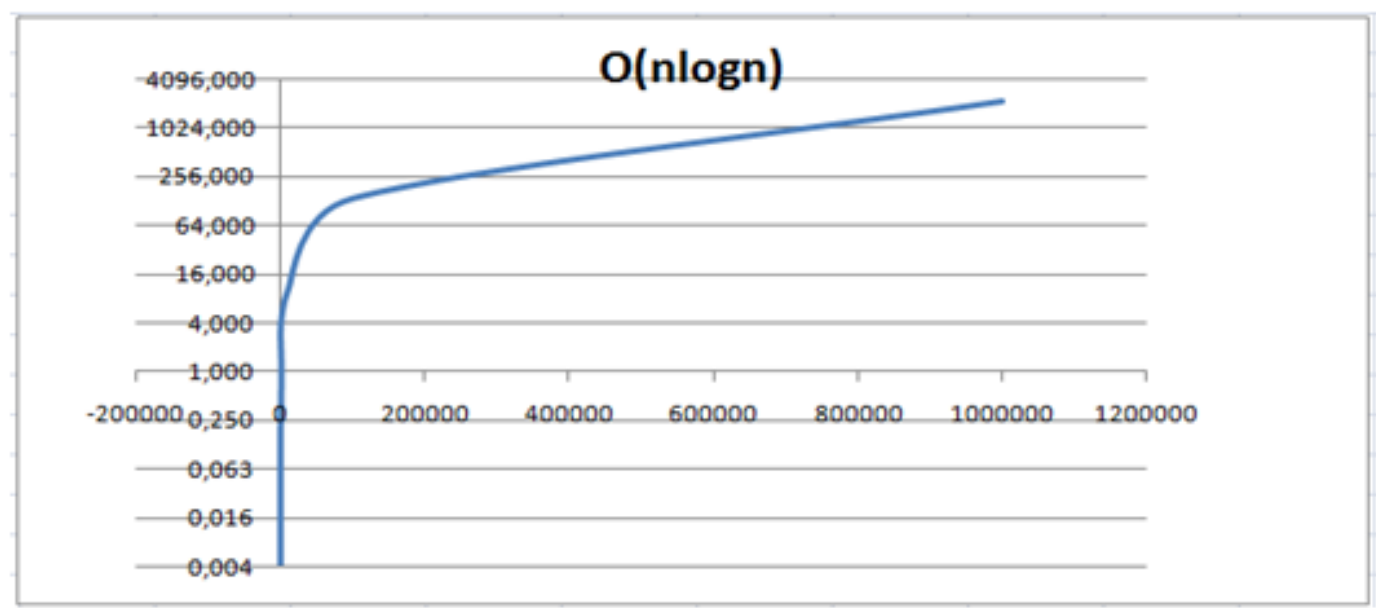

Figura 46 - Gráfico do resultado do Merge Sort com instrumentação

\subsubsection{Resultados obtidos para o PPH com Quick Sort.}

Para o PPH com o algoritmo Quick Sort o percentual de aumento do custo computacional no uso de assertivas executáveis foi de $4,8 \%$, como pode ser observado na Tabela 19. 
Tabela 19 - Resultados obtidos para o Quick Sort

\begin{tabular}{|c|c|c|c|c|}
\hline \multicolumn{5}{|c|}{ Quick Sort } \\
\hline \multirow{2}{*}{$\begin{array}{l}\text { Tamanho } \\
\text { da Entrada }\end{array}$} & Sem instrumentação & Com instrumentação & \multirow[b]{2}{*}{ Diferença } & \multirow[b]{2}{*}{ Aumento } \\
\hline & $\begin{array}{l}\text { Média de tempo } \\
\text { execução }\end{array}$ & $\begin{array}{l}\text { Média de tempo } \\
\text { execução }\end{array}$ & & \\
\hline 10 & 0,003 & 0,003 & 0,00 & $7,7 \%$ \\
\hline 100 & 0,034 & 0,034 & 0,00 & $0,1 \%$ \\
\hline 1.000 & 0,393 & 0,406 & 0,01 & $3,5 \%$ \\
\hline 10.000 & 4,700 & 5,158 & 0,46 & $9,7 \%$ \\
\hline 100.000 & 60,1280014 & 65,860469 & 5,73 & $9,5 \%$ \\
\hline 1.000 .000 & 1076,526709 & 1164,233289 & 87,71 & $8,1 \%$ \\
\hline Total: 6 & Total: 64,25 & Total: 72,32 & Média: 1,61 & Média: 4,8\% \\
\hline
\end{tabular}

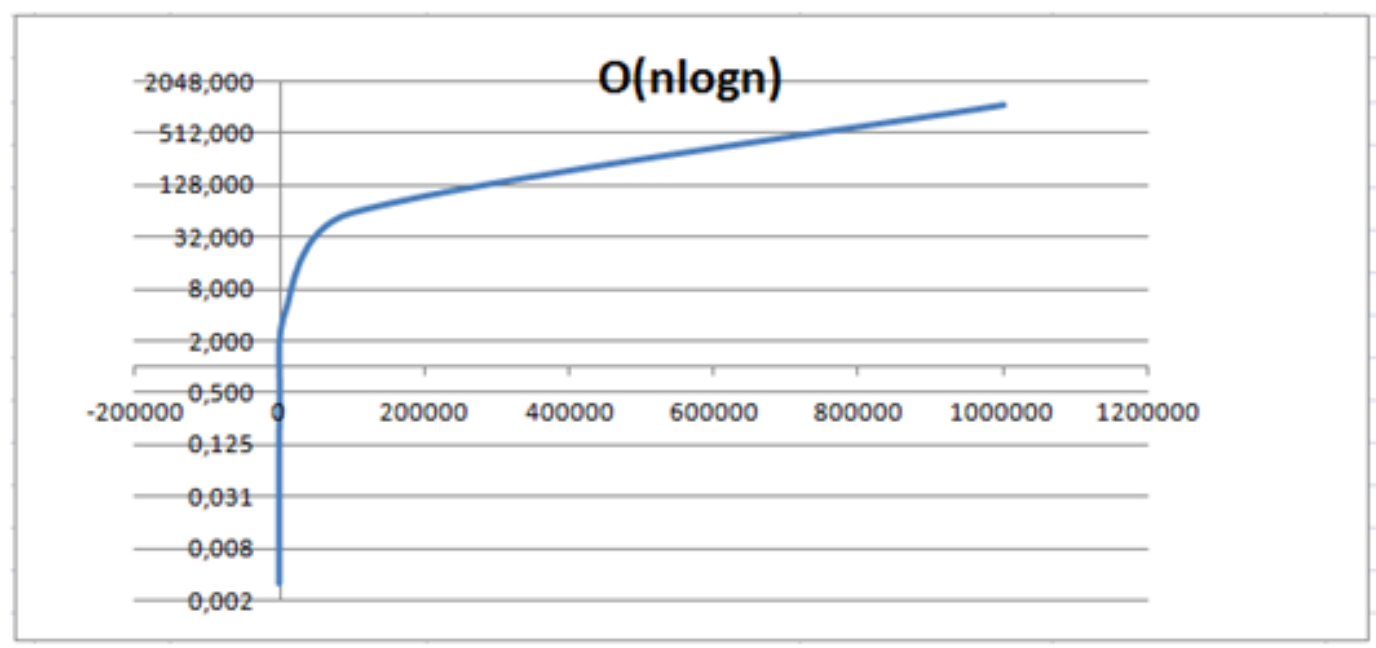

Figura 47 - Gráfico dos resultados do Quick Sort sem instrumentação

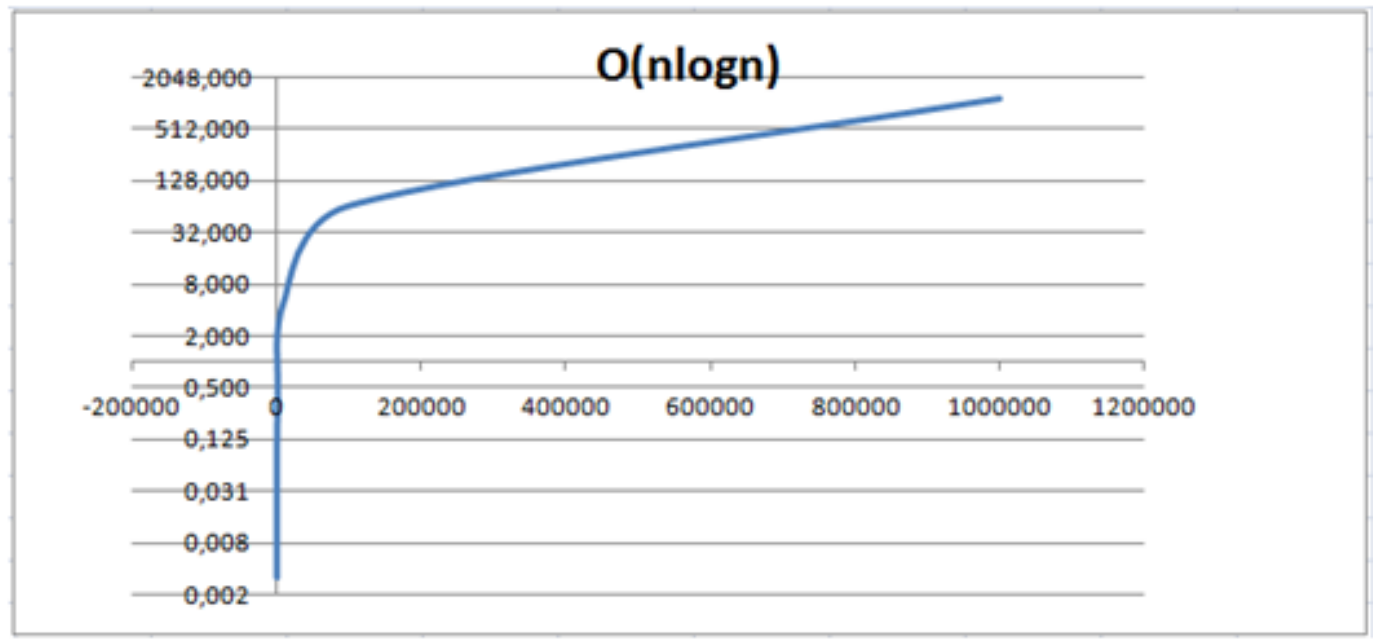

Figura 48 - Gráfico dos resultados do Quick Sort com instrumentação 


\subsubsection{Resultados obtidos para PPH com Selection Sort.}

Para o algoritmo Selection Sort que tem uma complexidade no pior caso na ordem de $N^{2}$ o crescimento do custo no uso de assertivas executáveis ainda se manteve na média dos demais algoritmos de ordenação o qual foi do percentual de 4,9\%, como pode ser observado na Tabela 20.

Tabela 20 - Resultados obtidos para o Selection Sort

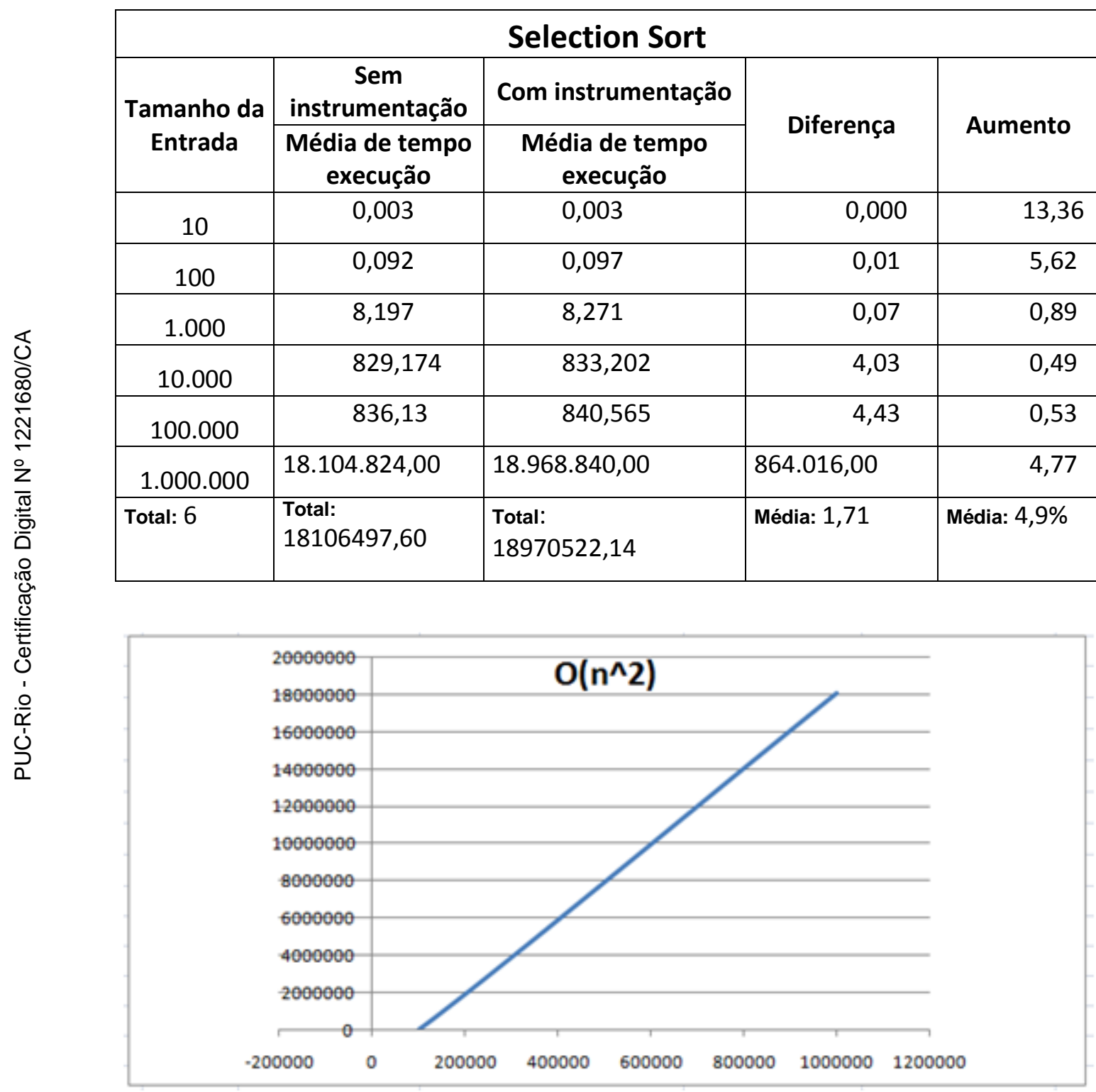

Figura 49 - Gráfico dos resultados do Selection Sort sem instrumentação 


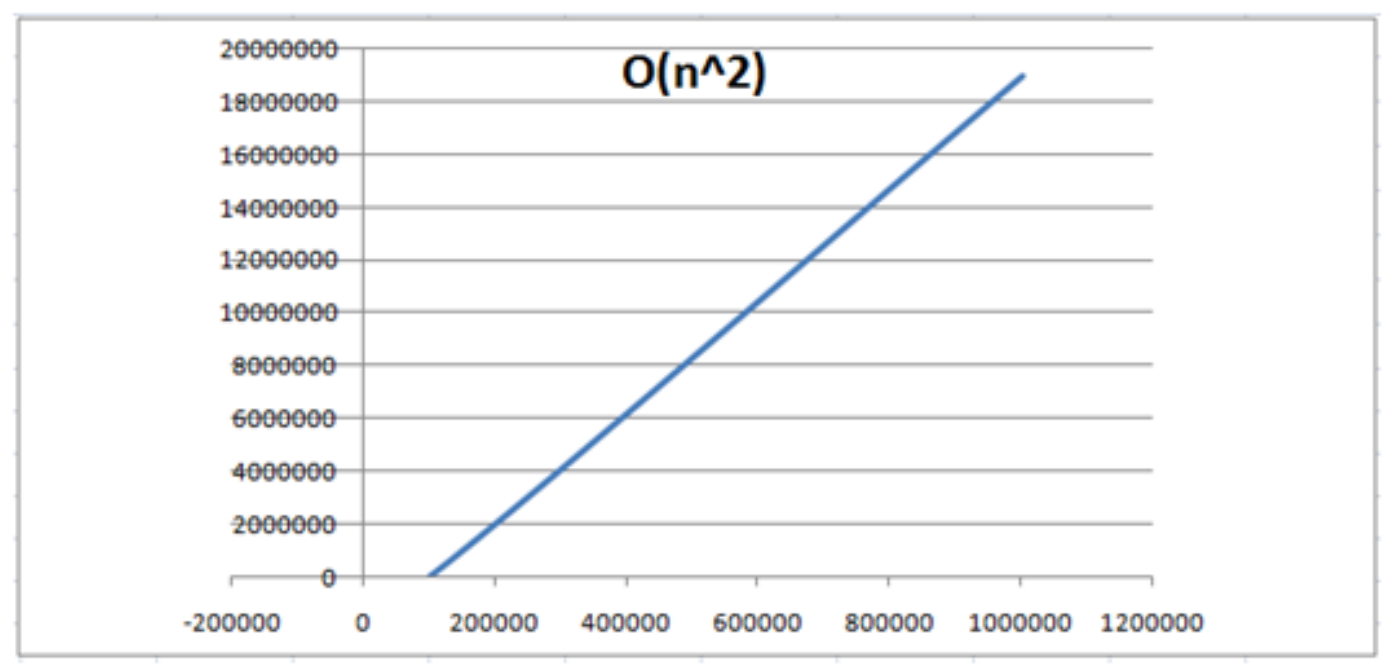

Figura 50 - Gráfico dos resultados do Selecion Sort com instrumentação

\subsubsection{Média de tempo de execução obtida para PPH.}

Por fim pode ser observada na Tabela 21 a média do custo computacional no uso de assertivas executáveis para o PPH utilizando os três algoritmos de ordenação descritos anteriormente. Segundo os dados obtidos a assertivas executáveis teve um percentual de aumento 5,7\%. Como pode ser observado nos gráficos demonstrados anteriormente a complexidade de nenhum algoritmo foi alterada.

Tabela 21 - Média dos resultados obtidos para o PPH

\begin{tabular}{|l|l|}
\hline Algoritmo & Percentual de aumento no uso de assertivas executáveis \\
\hline Merge Sort & $5,8 \%$ \\
\hline Quick Sort & $4,8 \%$ \\
\hline Selection Sort & $4,9 \%$ \\
\hline & Média: $5,7 \%$ \\
\hline
\end{tabular}

\subsubsection{Resultados obtidos para o PAGM:}

No experimento do Problema da Árvore Geradora Mínima (AGM) o conjunto de assertivas foi invocado três vezes no código para cada interação. Sendo primeiramente ao inicializar árvore $A V L$, seguinte quando é colocado o 
primeiro conjunto de arestas na árvore e por fim quando é adicionado um novo conjunto de arestas que sejam melhores que as tenham sido adicionadas.

Segue a tabela com a indicação dos tempos obtidos com o experimento, no programa sem a instrumentação e com a instrumentação por meio de assertivas executáveis. Ainda é disponibilizada a diferença do tempo computacional entre esses dois casos e o percentual de aumento. Com a finalidade de ser encontrar o tempo computacional exato utilizado na execução dos programas, cada instância foi executada dez vezes e uma média do tempo de execução dessas instâncias foi utilizada para a comparação nos dois casos. Ainda foi deixado o programa rodar por dez segundos e foi retirada uma média do tempo em cada iteração dentro desses dez segundos. 


\subsubsection{Resultados obtidos para AGM utilizando a árvore AVL}

Tabela 22 - Resultados obtidos para o PAGM com AVL

\begin{tabular}{|c|c|c|c|c|}
\hline \multicolumn{5}{|c|}{ Algoritmo: Prim com AVL Tree } \\
\hline \multirow[b]{2}{*}{ Instâncias } & Sem instrumentação & Com instrumentação & \multirow[b]{2}{*}{ Diferença } & \multirow[b]{2}{*}{ Aumento } \\
\hline & $\begin{array}{c}\begin{array}{c}\text { Média de tempo } \\
\text { execução }\end{array} \\
\end{array}$ & $\begin{array}{c}\begin{array}{c}\text { Média de tempo } \\
\text { execução }\end{array} \\
\end{array}$ & & \\
\hline alue2087.stp & 6,76 & 6,85 & 0,09 & $1,29 \%$ \\
\hline alue2105.stp & 6,77 & 6,77 & 0,00 & $0,04 \%$ \\
\hline alue3146.stp & 31,15 & 31,20 & 0,04 & $0,14 \%$ \\
\hline alue5067.stp & 25,64 & 25,69 & 0,04 & $0,18 \%$ \\
\hline alue5345.stp & 49,54 & 49,76 & 0,22 & $0,45 \%$ \\
\hline alue5623.stp & 42,14 & 42,46 & 0,33 & $0,77 \%$ \\
\hline alue5901.stp & 136,11 & 136,85 & 0,74 & $0,54 \%$ \\
\hline alue6179.stp & 22,80 & 22,81 & 0,01 & $0,03 \%$ \\
\hline alue6457.stp & 30,68 & 30,97 & 0,29 & $0,95 \%$ \\
\hline alue6735.stp & 35,32 & 35,48 & 0,16 & $0,46 \%$ \\
\hline alue6951.stp & 17,67 & 17,76 & 0,09 & $0,51 \%$ \\
\hline alue7066.stp & 62,03 & 62,49 & 0,46 & $0,73 \%$ \\
\hline alue7229.stp & 4,71 & 4,98 & 0,28 & $5,93 \%$ \\
\hline alut0787.stp & 10,05 & 10,07 & 0,02 & $0,23 \%$ \\
\hline alut0805.stp & 6,47 & 6,61 & 0,13 & $2,04 \%$ \\
\hline alut1181.stp & 33,98 & 34,21 & 0,23 & $0,68 \%$ \\
\hline alut2010.stp & 89,00 & 91,95 & 2,95 & $3,32 \%$ \\
\hline alut2288.stp & 131,08 & 132,44 & 1,36 & $1,04 \%$ \\
\hline alut2566.stp & 55,88 & 56,09 & 0,21 & $0,38 \%$ \\
\hline alut2764.stp & 2,22 & 2,23 & 0,02 & $0,75 \%$ \\
\hline dmxa0296.stp & 0,96 & 0,98 & 0,02 & $2,41 \%$ \\
\hline dmxa0368.stp & 18,36 & 18,51 & 0,15 & $0,84 \%$ \\
\hline dmxa0454.stp & 16,33 & 16,47 & 0,14 & $0,86 \%$ \\
\hline dmxa0628.stp & 0,69 & 0,70 & 0,01 & $1,62 \%$ \\
\hline dmxa0734.stp & 3,78 & 3,83 & 0,05 & $1,29 \%$ \\
\hline dmxa0848.stp & 2,57 & 2,60 & 0,03 & $1,18 \%$ \\
\hline dmxa0903.stp & 3,35 & 3,39 & 0,05 & $1,34 \%$ \\
\hline dmxa1010.stp & 31,47 & 32,06 & 0,59 & $1,89 \%$ \\
\hline dmxa1109.stp & 1,57 & 1,60 & 0,03 & $1,76 \%$ \\
\hline dmxa1200.stp & 4,87 & 4,89 & 0,02 & $0,39 \%$ \\
\hline dmxa1304.stp & 1,39 & 1,40 & 0,01 & $0,66 \%$ \\
\hline dmxa1516.stp & 4,29 & 4,29 & 0,00 & $0,07 \%$ \\
\hline dmxa1721.stp & 7,51 & 7,56 & 0,05 & $0,65 \%$ \\
\hline dmxa1801.stp & 19,64 & 19,64 & 0,00 & $0,00 \%$ \\
\hline Total: $\mathbf{3 3}$ & Total: 916,78 & Total: 925,62 & Média: 0,26 & Média: $1,04 \%$ \\
\hline Tempo tot & I de execução: & $1.842,41$ & & \\
\hline
\end{tabular}




\subsubsection{Resultados obtidos para AGM utilizando a Leftist Heap}

Tabela 23 - Resultados obtidos para o PAGM com Leftis Heap

\begin{tabular}{|c|c|c|c|c|}
\hline \multicolumn{5}{|c|}{ Algoritmo: Prim com leftist Heap } \\
\hline \multirow{2}{*}{ Instâncias } & Sem instrumentação & Com instrumentação & \multirow[t]{2}{*}{ Diferença } & \multirow{2}{*}{ Aumento } \\
\hline & $\begin{array}{c}\text { Média de tempo } \\
\text { execução }\end{array}$ & $\begin{array}{c}\text { Média de tempo } \\
\text { execução }\end{array}$ & & \\
\hline alue2087.stp & 7,16 & 7,17 & 0,01 & $0,16 \%$ \\
\hline alue2105.stp & 6,50 & 6,56 & 0,05 & $0,79 \%$ \\
\hline alue3146.stp & 56,86 & 58,40 & 1,54 & $2,71 \%$ \\
\hline alue5067.stp & 53,56 & 54,24 & 0,68 & $1,27 \%$ \\
\hline alue5345.stp & 110,57 & 110,83 & 0,27 & $0,24 \%$ \\
\hline alue5623.stp & 83,32 & 83,58 & 0,26 & $0,31 \%$ \\
\hline alue5901.stp & 572,07 & 572,36 & 0,29 & $0,05 \%$ \\
\hline alue6179.stp & 47,92 & 47,92 & 0,00 & $0,01 \%$ \\
\hline alue6457.stp & 48,59 & 64,65 & 16,06 & $33,04 \%$ \\
\hline alue6735.stp & 63,87 & 73,65 & 9,78 & $15,31 \%$ \\
\hline alue6951.stp & 34,34 & 35,45 & 1,11 & $3,24 \%$ \\
\hline alue7066.stp & 176,07 & 176,21 & 0,14 & $0,08 \%$ \\
\hline alue7229.stp & 3,97 & 3,98 & 0,00 & $0,13 \%$ \\
\hline alut0787.stp & 6,87 & 6,89 & 0,01 & $0,18 \%$ \\
\hline alut0805.stp & 4,51 & 4,53 & 0,02 & $0,46 \%$ \\
\hline alut1181.stp & 44,08 & 44,37 & 0,29 & $0,66 \%$ \\
\hline alut2010.stp & 165,51 & 167,63 & 2,12 & $1,28 \%$ \\
\hline alut2288.stp & 370,12 & 371,08 & 0,96 & $0,26 \%$ \\
\hline alut2566.stp & 115,95 & 116,27 & 0,31 & $0,27 \%$ \\
\hline alut2764.stp & 0,73 & 0,74 & 0,01 & $1,19 \%$ \\
\hline dmxa0296.stp & 0,34 & 0,34 & 0,00 & $0,73 \%$ \\
\hline dmxa0368.stp & 19,31 & 19,37 & 0,06 & $0,29 \%$ \\
\hline dmxa0454.stp & 16,06 & 16,07 & 0,01 & $0,08 \%$ \\
\hline dmxa0628.stp & 0,17 & 0,17 & 0,00 & $0,71 \%$ \\
\hline dmxa0734.stp & 2,02 & 2,03 & 0,00 & $0,10 \%$ \\
\hline dmxa0848.stp & 1,27 & 1,28 & 0,00 & $0,16 \%$ \\
\hline dmxa0903.stp & 2,01 & 2,01 & 0,00 & $0,00 \%$ \\
\hline dmxa1010.stp & 74,34 & 74,61 & 0,27 & $0,36 \%$ \\
\hline dmxa1109.stp & 0,62 & 0,63 & 0,00 & $0,74 \%$ \\
\hline dmxa1200.stp & 2,92 & 2,95 & 0,03 & $0,92 \%$ \\
\hline dmxa1304.stp & 0,46 & 0,46 & 0,00 & $0,29 \%$ \\
\hline dmxa1516.stp & 2,55 & 2,56 & 2,36 & $0,22 \%$ \\
\hline dmxa1721.stp & 4,90 & 4,91 & 0,01 & $0,20 \%$ \\
\hline dmxa1801.stp & 25,90 & 25,94 & 0,04 & $0,16 \%$ \\
\hline Total: $\mathbf{3 3}$ & Total: 2125,49 & Total: $\mathbf{2 1 5 9 , 8 4}$ & Média: 1,08 & Média: $1,96 \%$ \\
\hline \multicolumn{2}{|c|}{ Tempo total de execução: } & $4.285,33$ & & \\
\hline
\end{tabular}




\subsubsection{Resultados obtidos para AGM utilizando a Fibonacci}

Tabela 24 - Resultados obtidos para o PAGM com Fibonnaci Heap

\begin{tabular}{|c|c|c|c|c|}
\hline \multicolumn{5}{|c|}{ Algoritmo: Prim com Fibonacci Heap } \\
\hline \multirow[t]{2}{*}{ Instâncias } & \multirow{2}{*}{$\begin{array}{c}\text { Sem instrumentação } \\
\begin{array}{c}\text { Média de tempo } \\
\text { execução }\end{array}\end{array}$} & \multirow{2}{*}{$\begin{array}{c}\text { Com instrumentação } \\
\begin{array}{c}\text { Média de tempo } \\
\text { execução }\end{array}\end{array}$} & \multirow[t]{2}{*}{ Diferença } & \multirow[t]{2}{*}{ Aumento } \\
\hline & & & & \\
\hline alue2087.stp & 4,42 & 4,43 & 0,01 & $0,30 \%$ \\
\hline alue2105.stp & 4,33 & 4,37 & 0,05 & $1,11 \%$ \\
\hline alue3146.stp & 14,82 & 14,84 & 0,02 & $0,11 \%$ \\
\hline alue5067.stp & 13,93 & 14,04 & 0,11 & $0,81 \%$ \\
\hline alue5345.stp & 21,14 & 21,17 & 0,03 & $0,16 \%$ \\
\hline alue5623.stp & 18,33 & 18,52 & 0,19 & $1,05 \%$ \\
\hline alue5901.stp & 50,73 & 51,66 & 0,93 & $1,84 \%$ \\
\hline alue6179.stp & 13,06 & 13,14 & 0,07 & $0,57 \%$ \\
\hline alue6457.stp & 15,86 & 15,94 & 0,08 & $0,51 \%$ \\
\hline alue6735.stp & 16,71 & 16,80 & 0,09 & $0,56 \%$ \\
\hline alue6951.stp & 10,66 & 10,68 & 0,02 & $0,20 \%$ \\
\hline alue7229.stp & 3,25 & 3,29 & 0,04 & $1,34 \%$ \\
\hline alut0787.stp & 4,48 & 4,52 & 0,05 & $1,00 \%$ \\
\hline alut0805.stp & 3,54 & 3,57 & 0,02 & $0,65 \%$ \\
\hline alut1181.stp & 12,61 & 12,62 & 0,01 & $0,10 \%$ \\
\hline alut2010.stp & 26,65 & 26,71 & 0,07 & $0,25 \%$ \\
\hline alut2288.stp & 41,19 & 41,44 & 0,25 & $0,60 \%$ \\
\hline alut2566.stp & 21,94 & 22,24 & 0,30 & $1,36 \%$ \\
\hline alut2764.stp & 1,37 & 1,38 & 0,01 & $0,77 \%$ \\
\hline dmxa0296.stp & 0,82 & 0,87 & 0,05 & $6,22 \%$ \\
\hline dmxa0368.stp & 8,09 & 8,14 & 0,05 & $0,59 \%$ \\
\hline dmxa0454.stp & 7,10 & 7,20 & 0,10 & $1,41 \%$ \\
\hline dmxa0628.stp & 0,56 & 0,57 & 0,01 & $1,33 \%$ \\
\hline dmxa0734.stp & 2,42 & 2,43 & 0,01 & $0,39 \%$ \\
\hline dmxa0848.stp & 1,81 & 1,83 & 0,02 & $1,00 \%$ \\
\hline dmxa0903.stp & 2,32 & 2,35 & 0,03 & $1,26 \%$ \\
\hline dmxa1010.stp & 16,54 & 16,63 & 0,09 & $0,53 \%$ \\
\hline dmxa1109.stp & 1,17 & 1,18 & 0,01 & $0,74 \%$ \\
\hline dmxa1200.stp & 2,90 & 2,91 & 0,01 & $0,51 \%$ \\
\hline dmxa1304.stp & 1,03 & 1,03 & 0,00 & $0,45 \%$ \\
\hline dmxa1516.stp & 2,67 & 2,69 & 0,01 & $0,52 \%$ \\
\hline dmxa1721.stp & 3,74 & 3,79 & 0,04 & $1,20 \%$ \\
\hline dmxa1801.stp & 9,08 & 9,12 & 0,04 & $0,44 \%$ \\
\hline Total: $\mathbf{3 3}$ & Total: 359,27 & Total: 362,12 & Média: 0,09 & Média: $0,91 \%$ \\
\hline \multicolumn{2}{|c|}{ Tempo total de execução: } & 721,39 & & \\
\hline
\end{tabular}


Tabela 25 - Média dos resultados obtidos para o PAGM

\begin{tabular}{|l|l|}
\hline Algoritmo & Percentual de aumento no uso de assertivas executáveis \\
\hline Prim com AVL Tree & $1,0 \%$ \\
\hline Prim com lefttist Heap & $1,9 \%$ \\
\hline Prim com Fibonacci Heap & $4,9 \%$ \\
\hline & Média: $2,6 \%$ \\
\hline
\end{tabular}

\subsubsection{Resultados obtidos para AGM utilizando a árvore AVL.}

Nesta parte do experimento o conjunto de assertivas foi utilizado para verificar a integridade da árvore AVL cada vez que se tentava adicionar a uma nova aresta a Árvore Geradora Mínima. Assim o custo computacional foi bem maior comparado aos resultados obtidos anteriormente, como pode ser observado na Tabela 26 o percentual de aumento foi de $83,72 \%$. 
Tabela 26 - Resultados obtidos para o PAGM com AVL com instrumentação extra

\begin{tabular}{|c|c|c|c|c|}
\hline \multicolumn{5}{|c|}{ Algoritmo: Prim com AVLTree } \\
\hline \multirow[b]{2}{*}{ Instâncias } & Sem instrumentação & Com instrumentação & \multirow[b]{2}{*}{ Diferença } & \multirow[b]{2}{*}{ Aumento } \\
\hline & $\begin{array}{l}\text { Média de tempo } \\
\text { execução }\end{array}$ & $\begin{array}{l}\text { Média de tempo } \\
\text { execução }\end{array}$ & & \\
\hline alue2087.stp & 6,76 & 10,46 & 3,70 & $54,72 \%$ \\
\hline alue2105.stp & 6,77 & 9,77 & 3,00 & $44,29 \%$ \\
\hline alue3146.stp & 31,15 & 62,61 & 31,46 & $100,97 \%$ \\
\hline alue5067.stp & 25,64 & 44,87 & 19,22 & $74,97 \%$ \\
\hline alue5345.stp & 49,54 & 109,55 & 60,02 & $121,16 \%$ \\
\hline alue5623.stp & 42,14 & 92,58 & 50,44 & $119,72 \%$ \\
\hline alue5901.stp & 136,11 & 338,55 & 202,44 & $148,73 \%$ \\
\hline alue6179.stp & 22,80 & 36,76 & 13,95 & $61,20 \%$ \\
\hline alue6457.stp & 30,68 & 57,04 & 26,36 & $85,93 \%$ \\
\hline alue6735.stp & 35,32 & 67,17 & 31,85 & $90,17 \%$ \\
\hline alue6951.stp & 17,67 & 27,86 & 10,19 & $57,64 \%$ \\
\hline alue7066.stp & 62,03 & 130,82 & 68,78 & $110,88 \%$ \\
\hline alue7229.stp & 4,71 & 6,81 & 2,11 & $44,74 \%$ \\
\hline alut0787.stp & 10,05 & 19,82 & 9,78 & $97,33 \%$ \\
\hline alut0805.stp & 6,47 & 10,77 & 4,30 & $66,35 \%$ \\
\hline alut1181.stp & 33,98 & 76,85 & 42,88 & $126,20 \%$ \\
\hline alut2010.stp & 89,00 & 235,90 & 146,90 & $165,06 \%$ \\
\hline alut2288.stp & 131,08 & 325,11 & 194,03 & $148,03 \%$ \\
\hline alut2566.stp & 55,88 & 129,33 & 73,46 & $131,46 \%$ \\
\hline alut2764.stp & 2,22 & 3,77 & 1,55 & $69,86 \%$ \\
\hline dmxa0296.stp & 0,96 & 1,24 & 0,28 & $29,69 \%$ \\
\hline dmxa0368.stp & 18,36 & 37,39 & 19,03 & $103,68 \%$ \\
\hline dmxa0454.stp & 16,33 & 32,21 & 15,88 & $97,24 \%$ \\
\hline dmxa0628.stp & 0,69 & 0,96 & 0,28 & $40,43 \%$ \\
\hline dmxa0734.stp & 3,78 & 6,06 & 2,28 & $60,23 \%$ \\
\hline dmxa0848.stp & 2,57 & 3,83 & 1,25 & $48,76 \%$ \\
\hline dmxa0903.stp & 3,35 & 5,05 & 1,70 & $50,88 \%$ \\
\hline dmxa1010.stp & 31,47 & 59,06 & 27,59 & $87,69 \%$ \\
\hline dmxa1109.stp & 1,57 & 2,23 & 0,66 & $42,22 \%$ \\
\hline dmxa1200.stp & 4,87 & 8,17 & 3,30 & $67,66 \%$ \\
\hline dmxa1304.stp & 1,39 & 2,03 & 0,64 & $45,69 \%$ \\
\hline dmxa1516.stp & 4,29 & 7,03 & 2,74 & $63,86 \%$ \\
\hline dmxa1721.stp & 7,51 & 14,49 & 6,98 & $93,02 \%$ \\
\hline dmxa1801.stp & 19,64 & 38,64 & 18,99 & $96,67 \%$ \\
\hline $\begin{array}{c}\text { Total de } \\
\text { instâncias: }\end{array}$ & Total: & Total: & $\begin{array}{l}\text { Média da } \\
\text { diferença }\end{array}$ & $\begin{array}{l}\text { Média do } \\
\text { percentual de } \\
\text { aumento }\end{array}$ \\
\hline 33 & 916,78 & 2014,77 & 32,29 & $83,72 \%$ \\
\hline Tempo tot & I de execução: & $2.931,55$ & & \\
\hline
\end{tabular}




\section{7 \\ Considerações finais}

O conhecimento sobre o domínio de um problema tende a ser maior quando a solução em software para o mesmo é implementado muitas vezes, consequentemente levando as ultimas versões do sistema a terem um ganho de qualidade. Isso remete ao método de tentativas e erros, pois por meio das observações das falhas geradas, quando detectadas, um novo conhecimento vai sendo criado. Logo as causas geradoras dessas falhas podem ser eliminadas para as novas implementações.

Porém na tentativa do software ser correto por construção isso não se aplica. Pois se espera que o software tenha uma qualidade elevada logo na sua primeira versão. Assim se faz necessário usar técnicas para que o software possa aproximar-se de ser correto por construção.

Um dos benefícios que se adquire utilizando os métodos formais é o conhecimento apurado sobre os requisitos do sistema. Isso ocorre porque os desenvolvedores são forçados a encontrar, entender e exercitar os detalhes das regras de negócio do domínio do sistema a ser implementado. Assim esse esforço adicional para melhor entender os requisitos, reflete em sistemas mais corretos e menos passíveis de conter defeitos.

Os Métodos Formais Leves na forma de assertivas executáveis também trazem o benefício do entendimento dos detalhes dos requisitos. Porém com custos menores comparados com os métodos formais. Para a confecção das assertivas executáveis esse entendimento apurado se faz necessário, obrigando aos desenvolvedores a se preocuparem com partes críticas do código fonte, segundo o domínio do sistema, procurar fragmentos de códigos onde são passíveis de apresentar estados computacionais errôneos causando ao sistema inconsistências gerando defeitos.

No experimento realizado o custo do entendimento das especificações dos programas, os quais foram estruturas de dados, foi nulo por causa das suas propriedades serem bem definidas e provadas na literatura. Foram utilizadas implementações distintas para a árvore AVL na linguagem Java em uma implementação para linguagem PHP e pôde ser observado que o custo em traduzir as propriedades da AVL para assertivas foi muito pequeno em todas as 
implementações propostas. Mesmo com as mudanças de implementações as assertivas, uma vez criadas para a primeira versão, puderam ser traduzidas facilmente para as demais, sendo que as versões de implementação foram distintas. Em ambos os casos as assertivas executáveis puderam detectar as anomalias do programa original, geradas por meio dos testes de análise mutante.

O segundo momento do experimento foi realizado para observação de quanto o custo computacional foi acrescido com o emprego das assertivas executáveis utilizadas em tempo de uso. O percentual de aumento em relação ao programa original foi de 5,7\% para o sistema do Problema da Programação Hiperbólica e 2,6\% para o sistema Problema da Árvore Geradora Mínima. Portanto as assertivas executáveis podem ser consideradas viáveis para permanecerem acionadas nos sistemas em uso.

Ainda foi demonstrado no modelo de instrumentação com assertivas executáveis que elas podem ser ligadas ou desligadas nos sistemas em uso. Também pode haver uma equalização entre agilidade do programa que se deseja, levando-se em conta a velocidade do programa original, com o grau de verificação que permanecem acionadas nos fragmentos de código instrumentados. Portanto, para uma dada operação do sistema quanto mais as verificações forem invocadas no código, maior será o tempo computacional gasto. Como pôde ser observado no experimento para PAGM com a Árvore AVL que teve um percentual de aumento $1,04 \%$ quando o conjunto de assertivas foi invocado em três partes do código, mas não verificada para cada tentativa de incluir uma nova aresta. Porém o percentual de aumento se elevou para $83,72 \%$ quando o conjunto de assertiva foi chamado a cada tentativa de incluir uma nova aresta.

Portanto por meio dos experimentos: (i) análise mutante nas estruturas de dados e (ii) medidas do tempo computacional com o PPH e PAGM as assertivas foram eficazes e economicamente viáveis como forma de instrumentação e observação de falhas.

Ainda os questionamentos propostos nos objetivos específicos desse trabalho puderam ser respondidos com base no experimento realizado. As assertivas puderam encontrar falhas dos mutantes antes dos oráculos associados aos casos de teste. Como foram demonstrados todos os mutantes criados ficaram neutralizados pela intervenção das assertivas executáveis criadas. Elas foram $100 \%$ eficazes na detecção das anomalias que os mutantes apresentaram em relação o programa original. Também as falhas inseridas 
sistematicamente foram detectadas pelas assertivas executáveis em tempo de execução.

Por fim, a hipótese formulada na introdução do trabalho a qual preconiza que o uso dos Métodos Formais Leves, por meio do emprego sistemático de assertivas executáveis pôde ser um mecanismo eficaz e economicamente viável para assegurar a confiabilidade do software. Além de torná-lo autoverificante por viabilizar a observação de defeitos e possibilitar uma forma de reduzir falhas em tempo de uso produtivo. Por meio dos dados quantitativos obtidos essa hipótese pôde ser tomada como verdade.

\section{1 .}

\section{Contribuições}

A maior contribuição do trabalho é demonstrar de forma quantitativa por meio do experimento realizado que o uso de assertivas executáveis é economicamente viável para a utilização em produção, reforçando o conhecimento adquirido com a revisão realizada que já tinha chegado a essa conclusão.

Ainda como contribuições podem ser destacadas nos seguintes itens:

1. Modelo de instrumentação de assertivas: foi demonstrado na prática um mecanismo para instrumentar programas com assertivas executáveis;

2. Modelo para a utilização de teste análise mutante: foi demonstrado um modelo de utilização de assertivas e teste mutante por meio de forma prática como utilizar essas técnicas;

3. Métrica para avaliação de software: foram propostas métricas para avaliar a eficácia das assertivas executáveis;

4. MuPHP: protótipo de ferramenta para testes análise mutantes para a linguagem PHP;

5. Revisão da bibliografia: foi pesquisada em vários artigos a aplicação prática dos Métodos Formais Leves.

\section{2 .}

\section{Limitações e trabalhos futuros}

A redação de assertivas reduz o número de defeitos, mas não os elimina. Além disso, o conjunto de assertivas muitas vezes é incompleto, e pode até ser incorreto, permitindo a ocorrência de falsos negativos. 
Ainda se faz necessário o esforço adicional para o entendimento de detalhes dos requisitos, pois se as assertivas não contemplarem os pontos críticos do sistema, falhas não serão observadas por elas. Assim no experimento realizado neste trabalho o custo em tomar conhecimento das partes críticas foi nulo, porque as propriedades das estruturas de dados dos são bem definidas e provadas na literatura relacionada. Portanto não foi levado em consideração esse fator que é primordial que a criação do conhecimento dos requisitos do sistema. Em outro experimento que se tenha que levantar os requisitos para confecção das assertivas, elas podem ficar incompletas e não terem a eficácia de $100 \%$ que foi observado no experimento deste trabalho.

Além disso, as confecções das assertivas e da suíte de teste foram feitas por apenas um programador. Assim para se ter uma confiabilidade maior no resultado do experimento seria importante que essas atividades fossem feitas por programadores distintos.

$\mathrm{Na}$ segunda parte do experimento foi aferido o tempo computacional. Fazse necessário um estudo mais detalhado para identificar as possíveis causas do custo adicional no tempo computacional, a fim de que se possa encontrar um melhor balanceamento entre velocidade do programa original com uso do conjunto de assertivas executáveis.

Ainda existe a questão da escolha de estruturas de dados utilizadas no experimento como amostragem de uma população de sistemas. Seria necessário se fazer uma medição de quão boa é essa amostragem.

Não foi objetivo comparar a eficácia das assertivas com a suíte de testes, mas em dado momento do trabalho foi feita essa comparação. Porém essa comparação para que seja mais justa, seria importante pegar assertivas e testes criados por vários programadores e em diferentes tipos de programas.

O protótipo desenvolvido foi implementado segundo as especificações do MuJava seguindo seus operadores de mutação. Mas as falhas estão em muito relacionadas à linguagem em que o programa está escrito. Assim seria necessário criar operadores de mutação para a linguagem PHP. 
8

\section{Referências Bibliográficas}

AKHTAR, N. and MISSEN, M. M. S. (2014). "Practical application of a light-weight formal implementation for specifying a multi-agent robotic system" International Journal of Computer Science Issues, Vol. 11, Issue 1, No 2, January 2014.

ANDERSSON, A; "Balanced Search Trees Made Simple", Workshop on Algorithms and Data Structures, pages 60-71. Springer Verlag; 1993.

ARAÚJO, O.L.R; "Test-Driven Maintenance: uma abordagem para manutenção de sistemas legados". Dissertação de Mestrado - PUC-Rio Departamento de Informática; 2011.

ARAÚJO,T.P; CERQUEIRA,R; STAA, A.V; “Annotating Logs With Metainformation to Support Failure Diagnosis". Monografias em Ciência da Computação - PUC-Rio - Departamento de Informática, 2014.

BARTETZKO, DETLEF, et al. "Jass-Java with assertions." Electronic Notes in Theoretical Computer Science 55.2: 103-117, 2001.

BOYATT, R. C., and J. E. SINCLAIR. "A lightweight formal methods" perspective on investigating aspects of interactive systems", Pre-Proc. 2nd Int. Workshop Formal Methods Interact. Syst. 2007.

BERRY, D.M.; Academic Legitimacy of the Software Engineering Discipline; Technical Report 92-TR-34, Software Engineering Institute, Carnegie Mellon Academic, University; 1992.

BROWN, A, and D. A. PATTERSON. "To err is human." Proceedings of the First Workshop on evaluating and architecting system dependability (EASY'01). 2001. 
BLACKBURN, M.R., BUSSER, $R$ and A. NAUMAN. "Removing Requirement defects and Automating test." STAREAST, May (2001).

CALINESCU, R, and KIKUCHI, S. "Formal methods@ runtime". Springer Berlin Heidelberg, 2011.

CHEON,Y; LEAVENS, G,T; "A Runtime Assertion Checker for the Java Modeling Language JML", 2002.

CORMEN T, H; LEISERSON C, E; RIVEST, R,L; Stein, C; “Algoritmos Teoria e Prática”, Elsevier; 2002.

DELAMARO, M. E., MALDONADO, J. C., and JINO, M. (2007). "Introdução ao teste de software" Rio de Janeiro, RJ, BR: Editora Campus, 2007. $408 p$.

DEMILLO, R.; LIPTON, R.; SAYWARD, F. "Hints on Test Data Selection: Help for the Practicing Programmer”. Computer, 11(4):34-41, Apr. 1978.

Duncan, A., and Hölzle, U. (1998). "Adding contracts to Java with Handshake". Technical Report TRCS98-32, Department of Computer Science, University of California, Santa Barbara, CA.

EASTERBROOK, S., et al. "Experiences using lightweight formal methods for requirements modeling." Software Engineering, IEEE Transactions on $24.1 ; 1998$.

FEATHER, M. S. "Rapid application of lightweight formal methods for consistency analyses." Software Engineering, IEEE Transactions on 24.11 (1998): 949-959.

HIERONS, R. M., et al. "Using formal specifications to support testing." ACM Computing Surveys (CSUR) 41.2; 2009

JACKSON, D; “Alloy Tutorial”; acessado em 13/01/2014 http://alloy.mit.edu/alloy/, 2012. 
KARAORMAN,M; HÖLZLE,U; BRUNO,J. "jContractor: A reflective Java library to support design by contract." Meta-Level Architectures and Reflection. Springer Berlin Heidelberg, 1999.

Plösch, Reinhold. "Evaluation of assertion support for the java programming language." Journal of Object Technology 1.3 (2002): 5-17.

KNEUPER, R.; "Limits of formal methods." Formal Aspects of Computing 9.4 (1997): 379-394.

KRAMER,R; "iContract-the Java TM design by contract TM tool." Technology of Object-Oriented Languages, 1998. TOOLS 26. Proceedings. IEEE, 1998.

Larsen, P.G., Fitzgerald, J.S., Riddle, S. (2006). "Learning by Doing: Practical Courses in Lightweight Formal Methods using VDM++". Technical Report CS-TR:992, School of Computing Science, Newcastle University.

MA, Y.-S., Offutt, A. J. and Kwon, Y.-R. MuJava: "An Automated Class Mutation System. 2, June 2005, Software Testing, Verification \& Reliability", Vol. 15, pp. $97-133$.

MA, Y.-S, Y.R KWON, and J. OFFUTT. "Inter-class mutation operators for Java." Software Reliability Engineering, 2002. ISSRE 2003. Proceedings. 13th International Symposium on. IEEE, 2002.

Ma, Y.S, and Jeff OFFUTT. "Description of class mutation mutation operators for java", 2005.

MAGALHÃES, J., STAA, A.v, and de LUCENA, C. J. P. (2009). "Evaluating the recovery oriented approach through the systematic development of real complex applications". Software: Practice and Experience", 39(3), 315-330.

MALDONADO J. C; A. M VINCENZI; R; DELAMARO M. E.; "JaBUTi Java Bytecode Understanding and Testing", 2003. 
MEYER, B. "Eiffel: A language and environment for software engineering." Journal of Systems and Software 8.3 (1988): 199-246.

MOORE, I. "Jester-a JUnit test tester." Proc. of 2nd XP (2001): 84-87.

Paige, Richard F., and Jonathan S. Ostroff. "Specification-driven design with Eiffel and agents for teaching lightweight formal methods". Springer Berlin Heidelberg, 2004

PARASOFT; "Using Design by Contract to Automate Java Software and Component Testing", acessado em 13/02/2015 http://char.tuiasi.ro/doace/www.parasoft.com/products/jtest/papers/tech_dbc.htm 2002.

PEZZĖ, M; YOUNG M. "Teste e análise de software: processos, princípios e técnicas". Bookman, 2008.

SHAO, D, S KHURSHID, and D E. PERRY. "An incremental approach to scope-bounded checking using a lightweight formal method". FM 2009: Formal Methods. Springer Berlin Heidelberg, 2009. 757-772.

SIMÕES, S.C.F; “Automatização De Testes De Mutação Em Java”, 2014.

SLEATOR, D, D.; TARJAN, R, E; "Self-Adjusting Binary Search Trees" Journal of the ACM; 1985.

SMITH, B. H., and WILLIAMS, L. (2007, September). "An empirical evaluation of the MuJava mutation operators". In Testing: Academic and Industrial Conference Practice and Research Techniques-MUTATION, 2007. TAICPART-MUTATION 2007 (pp. 193-202). IEEE.

STAA, A.v. (2000) "Programação Modular, Desenvolvendo programas complexos de forma organizada e segura". Rio de Janeiro. Editora Campus/Elsevier. 
STAA, A.v; "Qualidade se Atinge com Profissionais de Qualidade", VIII Simpósio Brasileiro de Qualidade de Software, 2009. Acessado em 25 de maio de 2014 no endereço:

http://www.lbd.dcc.ufmg.br/bdbcomp/servlet/Trabalho?id=8818.

STAA, A.V; "Controle da Qualidade Baseada em Técnicas Formais", nota de aula PUC-Rio, 2013. Acessado em 25 de maio de 2014 no endereço: http://www.inf.pucrio.br/ inf2134/docs/INF2134_Modulo08_TecnicasFormais.pdf.

STAA, A.V; "Engenharia de Software Fidedigno Qualidade de Software", nota de aula PUC-Rio, 2014. Acessado em 20 de março de 2015 no endereço: http://www.inf.pucrio.br/ inf2134/docs/INF2134_Modulo03_IntroducaoControleQualidade.pdf

STAA, A.V; "Engenharia de Software Fidedigno", Monografias em Ciência da Computação- PUC-Rio - Departamento de Informática; 2006.

THOMAS, D.; "The Deplorable State of Class Libraries"; Journal of Object Technology; Zürich, CH: ETH Zürich; 2002; pags 21-27

VUILLEMIN, Jean. "A data structure for manipulating priority queues." Communications of the ACM 21.4 (1978): 309-315.

WEBER, T.S. "Um roteiro para exploração dos conceitos básicos de tolerância a falhas." Relatório técnico, Instituto de Informática UFRGS (2002).

WEISS, M,A. (2012) "Data Structures and Algorithm Analysis in Java". 3rd ed. ISBN-13: 978-0-13-257627-7.

WIKIPÉDIA; Métodos formais, 2013, acessado em 03 de agosto de 2014 http://pt.wikipedia.org/wiki/M\%C3\%A9todos_formais.

WOODCOCK, Jim, et al. "Formal methods: Practice and experience." ACM Computing Surveys (CSUR) 41.4 (2009): 19. 
YANG, G; KHURSHID,S; KIM, M;. "Specification-based test repair using a lightweight formal method." FM 2012: Formal Methods. Springer Berlin Heidelberg, 2012. 455-470.

YI, Q., YANG, Z., LIU, J., ZHAO, C., and WANG, C. (2015). "A synergistic analysis method for explaining failed regression tests". In International Conference on Software Engineering. 
Apêndice 1 Classificação dada aos artigos pesquisados

\begin{tabular}{|c|c|c|c|}
\hline Título & $\begin{array}{l}\text { Ano } \\
\text { Pub. }\end{array}$ & $\begin{array}{l}\text { Exemplos } \\
\text { práticos }\end{array}$ & $\begin{array}{l}\text { Relação } \\
\text { com } \\
\text { tema }\end{array}$ \\
\hline $\begin{array}{l}\text { Specification-Based Test Repair Using a } \\
\text { Lightweight Formal Method }\end{array}$ & 2012 & ok & 5 \\
\hline $\begin{array}{l}\text { An Incremental Approach to Scope-Bounded } \\
\text { Checking Using a Lightweight Formal Method }\end{array}$ & 2009 & ok & 5 \\
\hline $\begin{array}{l}\text { Learning by Doing: Practical Course } s \text { in } \\
\text { Lightweight Formal Methods using VDM++ }\end{array}$ & 2006 & ok & 5 \\
\hline $\begin{array}{l}\text { Specification-Driven Design with Eiffel and } \\
\text { Agents for Teaching Lightweight Formal } \\
\text { Methods }\end{array}$ & 2004 & ok & 5 \\
\hline $\begin{array}{l}\text { Practical application of "lightweight" Z in DEVS } \\
\text { framework }\end{array}$ & 2003 & - & 5 \\
\hline $\begin{array}{l}\text { Automatic analysis of consistency between } \\
\text { requirements and designs }\end{array}$ & 2001 & ok & 5 \\
\hline $\begin{array}{l}\text { Rapid Application of Lightweight Formal } \\
\text { Methods for Consistency Analyses }\end{array}$ & 1998 & ok & 5 \\
\hline $\begin{array}{l}\text { Tekes Ubicom program LIME project } \\
\text { Lightwelght formal Methods for distributed } \\
\text { component-based Embedded systems (2010) }\end{array}$ & 2010 & ok & 5 \\
\hline Formal Methods: Practice and Experience & 2009 & ok & 5 \\
\hline $\begin{array}{l}\text { Transformation techniques can make students } \\
\text { excited about formal methods }\end{array}$ & 2008 & ok & 5 \\
\hline $\begin{array}{l}\text { Rapid System Prototyping Creating and } \\
\text { Validating Embedded Assertion Statecharts }\end{array}$ & 2007 & ok & 5 \\
\hline $\begin{array}{l}\text { Triumphs and Challenges for the Industrial } \\
\text { Application of Model- Oriented Formal } \\
\text { Methods }\end{array}$ & 2007 & ok & 5 \\
\hline $\begin{array}{l}\text { Lightweight Formal Methods for Scenario- } \\
\text { Based Software Engineering }\end{array}$ & 2005 & ok & 5 \\
\hline $\begin{array}{l}\text { Ontology Based Requirements Analysis: } \\
\text { Lightweight Semantic Processing Approach }\end{array}$ & 2005 & ok & 5 \\
\hline $\begin{array}{l}\text { UML2ALLOY: A TOOL FOR LIGHTWEIGHT } \\
\text { MODELLING OF DISCRETE EVENT }\end{array}$ & 2005 & ok & 5 \\
\hline
\end{tabular}




\begin{tabular}{|c|c|c|c|}
\hline SYSTEMS & & & \\
\hline $\begin{array}{l}\text { A Lightweight LTL Runtime Verification Tool } \\
\text { for Java }\end{array}$ & 2004 & ok & 5 \\
\hline $\begin{array}{l}\text { Formal methods for smart cards: an } \\
\text { experience Report }\end{array}$ & 2004 & ok & 5 \\
\hline $\begin{array}{l}\text { Lightweight coarse-grained coordination: a } \\
\text { scalable system-level approach }\end{array}$ & 2004 & ok & 5 \\
\hline $\begin{array}{l}\text { Lightweightcoarse-grainedcoor dination: } \\
\text { ascalablesystem-levelapproach }\end{array}$ & 2004 & ok & 5 \\
\hline $\begin{array}{l}\text { General Test Result Checking with Log File } \\
\text { Analysis }\end{array}$ & 2003 & ok & 5 \\
\hline $\begin{array}{l}\text { Language Support for Lightweight } \\
\text { Transactions }\end{array}$ & 2003 & ok & 5 \\
\hline $\begin{array}{l}\text { Lurch: a Lightweight Alternative to Model } \\
\text { Checking }\end{array}$ & 2003 & ok & 5 \\
\hline $\begin{array}{l}\text { Managerial Issues for the Consideration and } \\
\text { Use of Formal Methods }\end{array}$ & 2003 & ok & 5 \\
\hline $\begin{array}{l}\text { RBAC Schema Verifications Using Lightweight } \\
\text { Formal Model and Constraint Analysis }\end{array}$ & 2003 & ok & 5 \\
\hline $\begin{array}{l}\text { Lightweight validation of natural language } \\
\text { requirements }\end{array}$ & 2002 & ok & 5 \\
\hline $\begin{array}{l}\text { AProposal for a Lightweight Rigorous UML- } \\
\text { Based Development Method for Reliable } \\
\text { Systems }\end{array}$ & 2001 & ok & 5 \\
\hline $\begin{array}{l}\text { Exploring the Design of an Intentional Naming } \\
\text { Scheme with an Automatic Constraint } \\
\text { Analyzer }\end{array}$ & 2000 & ok & 5 \\
\hline Support for Teaching Formal Methods & 2000 & ok & 5 \\
\hline $\begin{array}{l}\text { Questions and Answers about ten Formal } \\
\text { Methods }\end{array}$ & 1999 & ok & 5 \\
\hline A lightweight Approach to Formal Methods & 1998 & ok & 5 \\
\hline $\begin{array}{l}\text { Experience of using a lightweight formal } \\
\text { method for Requirements Modeling }\end{array}$ & 1998 & ok & 5 \\
\hline $\begin{array}{l}\text { Formal Methods for Verification and Validation } \\
\text { of Partial Specifications: A Case Study }\end{array}$ & 1998 & ok & 5 \\
\hline Lightweight formal method for Computer & 1998 & ok & 5 \\
\hline
\end{tabular}




\begin{tabular}{|c|c|c|c|}
\hline Algebra Systems & & & \\
\hline On the Need for practical Formal Methods & 1998 & - & 5 \\
\hline $\begin{array}{l}\text { Pragmatic Formal Design: A Case Study in } \\
\text { Integrating Formal Methods into the } \mathrm{HCl} \\
\text { Development Cycle }\end{array}$ & 1998 & ok & 5 \\
\hline $\begin{array}{l}\text { Formal Modeling and Validation Apllied to a } \\
\text { Commercial Coherent Bus: A case Study }\end{array}$ & 1997 & ok & 5 \\
\hline $\begin{array}{l}\text { The use of Industrial- Strength Formal } \\
\text { Methods }\end{array}$ & 1997 & - & 5 \\
\hline Lightweight causal and atomic group multicast & 1991 & ok & 5 \\
\hline $\begin{array}{l}\text { Balancing Insight and Effort: The Industrial } \\
\text { Uptake of Formal Methods }\end{array}$ & 2007 & - & 5 \\
\hline $\begin{array}{l}\text { Trustable Formal Specification for Software } \\
\text { Certification }\end{array}$ & 2010 & - & 4 \\
\hline Lightweight Self-Protecting JavaScript & 2009 & ok & 4 \\
\hline Automated Reasoning in Kleene Algebra & 2007 & ok & 4 \\
\hline $\begin{array}{l}\text { EXPLODE: a Lightweight, General System for } \\
\text { Finding Serious Storage System Errors }\end{array}$ & 2006 & ok & 4 \\
\hline $\begin{array}{l}\text { Experience of using a lightweight formal } \\
\text { specification method for a commercial } \\
\text { embedded system product line }\end{array}$ & 2005 & ok & 4 \\
\hline Ten Commandments Revisited & 2005 & - & 4 \\
\hline $\begin{array}{l}\text { A Formal Monitoring-based Framework for } \\
\text { Software Development and Analysis }\end{array}$ & 2004 & ok & 4 \\
\hline $\begin{array}{l}\text { How the Design of JML Accommodates Both } \\
\text { Runtime Assertion Checking and Formal } \\
\text { Verification }\end{array}$ & 2004 & ok & 4 \\
\hline $\begin{array}{l}\text { Java-MaC: A Run-Time Assurance Approach } \\
\text { for Java Programs }\end{array}$ & 2004 & ok & 4 \\
\hline $\begin{array}{l}\text { Model Comparison: A Key Challenge for } \\
\text { Transformation Testing and }\end{array}$ & 2004 & ok & 4 \\
\hline $\begin{array}{l}\text { Lightweight Reasoning about Program } \\
\text { Correctness }\end{array}$ & 2002 & - & 4 \\
\hline Intrusion Tolerant Software Architectures & 2001 & ok & 4 \\
\hline Lightweight Analysis of Object Interactions & 2001 & ok & 4 \\
\hline
\end{tabular}




\begin{tabular}{|c|c|c|c|}
\hline $\begin{array}{l}\text { Modular semantics for a UML statechart } \\
\text { diagrams kernel and its extension to } \\
\text { multicharts and branching }\end{array}$ & 2001 & ok & 4 \\
\hline Specification of the Javacard API in JML & 2000 & ok & 4 \\
\hline $\begin{array}{l}\text { NASA Langley's research and technology- } \\
\text { transfer program in formal methods }\end{array}$ & 1998 & - & 4 \\
\hline A ligtweight Approach to Formal Methods & 1997 & ok & 4 \\
\hline Software engineering and formal methods & 2008 & - & 3 \\
\hline $\begin{array}{l}\text { Formal Methods for Specifying, Validating, } \\
\text { and Verifying Requirements }\end{array}$ & 2007 & ok & 3 \\
\hline $\begin{array}{l}\text { A Lightweight Formal Framework for Service- } \\
\text { Oriented Applications Design }\end{array}$ & 2005 & - & 3 \\
\hline $\begin{array}{l}\text { Application of Lightweight Formal Methods to } \\
\text { Software Security }\end{array}$ & 2005 & - & 3 \\
\hline $\begin{array}{l}\text { Remote Integration and Coordination of } \\
\text { Verification Tools in JETI }\end{array}$ & 2005 & ok & 3 \\
\hline $\begin{array}{l}\text { Practical Application of Formal Methods in } \\
\text { Modeling and Simulation }\end{array}$ & 2003 & & 3 \\
\hline $\begin{array}{l}\text { JML: notations and tools supporting detailed } \\
\text { design in Java }\end{array}$ & 2000 & - & 3 \\
\hline $\begin{array}{l}\text { Formal Development of an Embedded Verifier } \\
\text { for Java Card Byte }\end{array}$ & 1999 & ok & 3 \\
\hline $\begin{array}{l}\text { Lightweight formal method (1996) - A } \\
\text { Specifier's Introduction to Formal Methods }\end{array}$ & 1990 & - & 3 \\
\hline Formal Methods @ Runtime & 2010 & - & 2 \\
\hline $\begin{array}{l}\text { MoDeST - A Modelling and Description } \\
\text { Language for Stochastic Timed Systems }\end{array}$ & 2006 & - & 2 \\
\hline $\begin{array}{l}\text { Lightweight Object Specification with } \\
\text { Typestates }\end{array}$ & 2005 & - & 2 \\
\hline $\begin{array}{l}\text { Dear Sir, Yours faithfully: an Everyday Story of } \\
\text { Formality }\end{array}$ & 2004 & - & 2 \\
\hline $\begin{array}{l}\text { Formal Techniques for Java-like } \\
\text { Programs(FTfJP) }\end{array}$ & 2004 & - & 2 \\
\hline $\begin{array}{l}\text { Modeling and Validating Distributed } \\
\text { Embedded Real-Time Systems with VDM++ }\end{array}$ & 2004 & - & 2 \\
\hline A Lightweight Formal Analysis of a Multicast & 2003 & ok & 2 \\
\hline
\end{tabular}




\begin{tabular}{|c|c|c|c|}
\hline Key Management Scheme & & & \\
\hline $\begin{array}{l}\text { Deriving Operational Software Specifications } \\
\text { from System Goals }\end{array}$ & 2002 & - & 2 \\
\hline $\begin{array}{l}\text { Experiences Using Lightweight Formal } \\
\text { Methods for Requirements Modeling }\end{array}$ & 2002 & - & 2 \\
\hline $\begin{array}{l}\text { Semantic Web for Extending and Linking } \\
\text { Formalisms }\end{array}$ & 2002 & ok & 2 \\
\hline $\begin{array}{l}\text { Validating Voice Communication } \\
\text { Requirements Using Lightweight Formal } \\
\text { Methods (2000) }\end{array}$ & 2000 & ok & 2 \\
\hline $\begin{array}{l}\text { A pragmatic approach to formalizing object- } \\
\text { oriented modeling and development }\end{array}$ & 1997 & ok & 2 \\
\hline $\begin{array}{l}\text { Transforming OntoUML into Alloy: towards } \\
\text { conceptual model validation using a } \\
\text { lightweight formal method }\end{array}$ & 2009 & ok & 1 \\
\hline $\begin{array}{l}\text { Applying a Formal Requirements Method to } \\
\text { three NASA Systems: Lessons Learned }\end{array}$ & 2007 & - & 1 \\
\hline $\begin{array}{l}\text { A "Lightweight Formal Methods" Perspective } \\
\text { on Investigating Aspects of Interactive } \\
\text { Systems (conjunto de artigos) }\end{array}$ & 2007 & ok & 1 \\
\hline Formal Methods Light & 2006 & - & 1 \\
\hline $\begin{array}{l}\text { Automating commutativity analysis at the } \\
\text { design level }\end{array}$ & 2004 & ok & 1 \\
\hline $\begin{array}{l}\text { Formal Specification and Static Checking of } \\
\text { Gemplus' Electronic Purse Using ESC/Java }\end{array}$ & 2004 & - & 1 \\
\hline $\begin{array}{l}\text { Goal-Oriented Requirements Engineering: } \\
\text { From System Objectives to Uml Models to } \\
\text { precise Software Specifications }\end{array}$ & 2003 & - & 1 \\
\hline $\begin{array}{l}\text { The application of Dependence Analysis to } \\
\text { Software Architecture Descriptions }\end{array}$ & 2003 & ok & 1 \\
\hline $\begin{array}{l}\text { A General Framework for Formalizing UML } \\
\text { with Formal Languages }\end{array}$ & 2001 & ok & 1 \\
\hline $\begin{array}{l}\text { Analyzing Uml Active Classes and Associated } \\
\text { State machines - A Lightweight Formal } \\
\text { Approach }\end{array}$ & 2000 & - & 1 \\
\hline
\end{tabular}




\begin{tabular}{|c|c|c|c|}
\hline $\begin{array}{l}\text { Requirements validation of a voice } \\
\text { communication system used in air traffic } \\
\text { control. An industrial application of light-weight } \\
\text { formal methods }\end{array}$ & 2000 & - & 1 \\
\hline Formal methods for extensions to CAS & 1999 & ok & 1 \\
\hline $\begin{array}{l}\text { Real-Time Reactive System Development -A } \\
\text { Formal Approach Based on UML and PVS }\end{array}$ & 1998 & ok & 1 \\
\hline $\begin{array}{l}\text { The LIME Interface Speciation Language and } \\
\text { Runtime Monitoring Tool }\end{array}$ & 2009 & ok & 0 \\
\hline $\begin{array}{l}\text { Security Requirements for the Rest of Us: A } \\
\text { Survey }\end{array}$ & 2008 & - & 0 \\
\hline $\begin{array}{l}\text { Motivating language learners: a classroom- } \\
\text { oriented investigation of teachers' motivational } \\
\text { practices and students' motivation }\end{array}$ & 2007 & - & 0 \\
\hline $\begin{array}{l}\text { Validating UML and OCL Models in USE by } \\
\text { Automatic Snapshot Generation }\end{array}$ & 2005 & - & 0 \\
\hline $\begin{array}{l}\text { Eliciting security requirements with misuse } \\
\text { cases }\end{array}$ & 2004 & & 0 \\
\hline Towards an FCA based tool for visualizing & 2003 & & 0 \\
\hline $\begin{array}{l}\text { Chase: a Static Checker for JML's Assignable } \\
\text { Clause }\end{array}$ & 2002 & - & 0 \\
\hline $\begin{array}{l}\text { equality in computer in Computer Algebra and } \\
\text { Beyond Agile Specifications }\end{array}$ & 2002 & - & 0 \\
\hline $\begin{array}{l}\text { Automata-based verification of temporal } \\
\text { properties on running programs }\end{array}$ & 2001 & - & 0 \\
\hline Automating First-Order Relational Logic & 2000 & - & 0 \\
\hline Broad Spectrum Studies of log File Analysis & 2000 & - & 0 \\
\hline Desugaring JML Method Specifications & 2000 & - & 0 \\
\hline $\begin{array}{l}\text { Viewpoints: a framework for integrating } \\
\text { multiple perspectives system development }\end{array}$ & 1992 & ok & 0 \\
\hline
\end{tabular}

